\title{
ECONOMICS
}

\section{REDUCING REGIONAL DISPARITIES IN CHINA: AN EVALUATION OF ALTERNATIVE POLICIES}

\author{
by
}

\section{Anping Chen, Jinan University}

And

Nicolaas Groenewold Business School

The University of Western Australia 
Reducing Regional Disparities in China: An Evaluation of Alternative Policies *

\author{
Anping Chen, \\ School of Economics, \\ Jinan University, \\ Guangzhou, 510632, \\ Guangdong Province, \\ China \\ e-mail: anping.chen@yahoo.com.cn \\ and \\ Nicolaas Groenewold, \\ Department of Economics, \\ University of Western Australia, \\ Crawley, WA 6009 \\ Australia \\ e-mail: nic.groenewold@uwa.edu.au
}

\begin{abstract}
* We are grateful to the Department of International Co-operation at Jinan University and to the Business School at the University of Western Australia for grants which supported the visit of Groenewold to Guangzhou in April and October, 2008, to the Australian Department of Education, Employment and Workplace Relations and to the Business School at UWA for support for Chen to visit UWA under the Endeavour Award scheme in 2009. We received useful comments at a seminar in the College of Public Administration at Zhejiang University in October 2008, at the CES conference at the University of Macau in March 2009, at the ACESA conference at RMIT in July 2009 and from an anonymous referee.
\end{abstract}




\title{
Reducing Regional Disparities in China: An Evaluation of Alternative Policies
}

\begin{abstract}
Regional disparities in output per capita and income in China are large and persistent. They have been the subject of considerable concern to policy-makers at the highest level for decades, yet little is known about the effectiveness of various alternative policies which may be used to combat them. In this paper we address this issue by analysing the effectiveness of a range of policies by both regional and central governments. We use a small model with various features of the Chinese economy: two regions (the interior and the coast), two industries (agriculture and manufacturing), inter-regional capital mobility, internal migration subject to the hukou system of household registration and some features of the Chinese tax and expenditure system. The model is calibrated to Chinese data and simulated to analyse the effects of a number of policies on a range of variables but focussing on per capita output disparities and welfare. We find that a policy reducing internal migration costs is effective in reducing the per capita output gap but does so at a substantial cost to the coast. Policies which improve agricultural productivity in the interior region are most likely to both reduce the gap and make both regions better off. Changes in government consumption expenditure, central government fiscal redistributions and tax cuts, on the other hand, are less effective and have their long-run effectiveness reduced by migration.
\end{abstract}

Key words: regional disparities, China, numerical modelling, hukou

JEL classifications: O15, O18, R11, R13, R23 


\section{Introduction}

The phenomenal growth of China's economy over the past three decades or so is well known. Less well known, perhaps, are the significant differences in the spatial distribution of growth which have occurred in a number of dimensions. Two of the most important arise from the urban-rural distinction and the regional disaggregation of the country. In this paper we focus on the regional dimension with the regions based on aggregations of the provinces. This does not reflect our judgement that urban-rural disparities are less important but that differences between regions are also substantial, interesting and a traditional policy focus.

The regional differences are substantial by international standards. At the provincial level, the post-1978 average annual growth rate has varied from a low of $8.4 \%$ for Qinghai province in the north-west of China to rates over $13 \%$ for the south coastal provinces of Zhejiang, Jiangsu, Fujian and Guangdong. Of greater concern are the resulting differences in levels: in 2007 Qinghai had a per capita GDP of 14,257 yuan compared to that of Zhejiang of 37,411, Jiangsu of 33,928, Fujian of 25,908 and Guangdong of 33,151.

The policy-importance of regional disparities is also beyond dispute. Thus, for example, one of the key issues discussed during the recent 17 th Chinese Communist Party National Congress was the gap between rich and poor regions which was seen as a major potential source of political instability. Moreover, the central government has promulgated a number of special policies to address regional income gaps; examples are the Great Western Experiment (announced in 1999 during the Ninth Five-Year Plan), the

\footnotetext{
${ }^{1}$ Data for per capita GDP are from State Statistical Bureau, China Statistical Year Book 2008. For a more extensive recent discussion of regional disparities in China, see Groenewold, Chen and Lee (2008).
} 
Resurgence of North-Eastern Old Industry Base and the Stimulation of the Central Region (both during the Tenth Five-Year Plan). In addition, in the Eleventh Five-Year Plan there has been a major push to redress the growing regional disparities. ${ }^{2}$

Regional disparities have also been of interest to researchers and there has been considerable empirical research on the nature and causes of differences in regional output and growth. Little of the empirical literature has, however, focussed specifically on possible policy responses; instead, policy implications of the results have typically been drawn out in an incidental way, if at all. Our paper aims to contribute to the filling of this gap by assessing the efficacy of a range of policy actions which might be used to reduce inter-regional disparities. We do this within a small theoretical general equilibrium model which captures some important features of the Chinese economy. We distinguish only two regions, we allow inter-regional migration but with a cost to reflect the Chinese household registration or hukou system and we capture some of the features of the Chinese taxation and expenditure system. We solve the model in linearised., numerical form, calibrating the linearised model using recent data for China.

While the theoretical analysis of Chinese regional issues is rather limited there are related papers. Our approach is most closely related to three recent papers, one by $\mathrm{Hu}$ (2002), one by Hertel and Zhai (2006) and the third by Whalley and Zhang (2007). Like our model, Hu also distinguishes two regions but, in contrast to our approach, Hu uses the urban-rural distinction to define the regions. Hu's model also incorporates the hukou restrictions but in an ad hoc way in contrast to our cost-based approach. Finally, our models differ in many details - Hu's model includes agglomeration and international

\footnotetext{
${ }^{2}$ For a more extensive discussion of post-war Chinese regional Policy and of the regional implications of the various Five-Year Plans, see Groenewold, Chen and Lee (2008).
} 
trade as a main part of the explanation whereas we include a number of tax-expenditure features necessary for the analysis of our policy shocks.

The model by Whalley and Zhang (2007) is arguably simpler than ours. In its basic form, they have two regions and two equations per region - a production function and an employment condition in which the real wage is set equal to the marginal product of labour. Their analysis of the effect of removing hukou then proceeds by calibrating the parameters of these two equations using actual data for output and the wage and solving the model numerically using these parameter values but for a wage equal across regions to reflect the effects of the free migration which is assumed to follow the removal of the hukou restrictions. While their basic model has similarities to ours, it omits several of the features which we have and, like $\mathrm{Hu}$, they do not incorporate the policy variables essential for our analysis.

Finally, the paper by Hertel and Zhai (2006) also analyses the effects on income disparities of a change in the hukou regime. Like the Hu's paper and unlike ours, it focuses on the urban-rural distinction. Unlike the two previous papers discussed as well as ours, it is a large CGE model as well as being dynamic. It is therefore less transparent than our model and, besides, does not distinguish between central and regional governments so that it would be quite unsuitable for the analysis of regional government responses to inter-regional disparities.

We investigate the effects on disparities and welfare of seven policy measures: an increase in regional government consumption expenditure, an increase in regional government spending on infrastructure, a cut in the regional tax rate, an improvement in agricultural technology, an easing of the hukou restrictions, a rise in central government 
expenditure in the poor region and a fiscal transfer by the central government from the rich to the poor region.

We derive many interesting conclusions. We find that policies which rely on increasing government consumption in the interior region (whether by the regional or central governments) have a perverse effect - they actually increase the per capita output gap between the two regions. Some policies have conflicting effects on output and welfare. Thus a tax cut in the interior region reduces the disparity in per capita output between the two regions but has the opposite effect on welfare. We find that boosting the productive capacity of the interior region (either by infrastructure investment or improving TFP) is the most effective policy in reducing the output gap as well as improving welfare in both regions. Finally, a relaxation of the hukou restrictions reduces the gap between the regions in both dimensions of per capita output and welfare but does so at the cost of reducing both welfare and per capita output in the coast. It is likely therefore to be resisted by the governments of the coastal provinces.

The remainder of the paper is structured as follows. We develop the model in section 2 and explain the simulations to be undertaken in section 3 . The results of these simulations are reported and discussed in section 4 . Conclusions are drawn in section 5.

\section{The Model}

To keep the regional structure of the model as simple as possible, we assume that there are two regions conventionally called the coastal and interior (or inland) regions. This two-region distinction has been widely used both in policy discussion and research; is the basis of much popular discussion of regional inequality in China and was the 
standard classification used by the Chinese central government until the sixth Five-Year Plan (1981-85) after which the interior region was further disaggregated into central and western regions. Despite the official extension to three regions after 1985, the two-region scheme has continued to be widely used in empirical work on China; recent papers using this classification are Fleisher and Chen (1997), Demurger (2001), Hu (2002) and Whalley and Zhang (2007). The definition of each region can be found in Appendix 2.

The coastal region is relatively wealthy compared to the interior. Moreover, primary industry which has been central to the Chinese economy is still a major source of employment in the inland provinces while its importance has been supplanted by secondary and tertiary industries in the coast ${ }^{3}$. We capture this structure starkly by assuming a poor interior region (denoted by $I$ ) which produces primary goods (which we call agricultural goods and denote by $A$ ) and a wealthy coastal region (denoted by $C$ ) which produces non-primary goods (which we call manufacturing goods and denote by $M)$.

Each region has households, firms and regional governments. There is also a central government. Households supply labour and capital to firms which produce output. Households receive wage, capital income and profits which they use to purchase some of each region's output; in addition they receive a government-provided consumption good which is private in the rival sense. Capital is inter-regionally mobile in both the short and long run. Labour can only migrate between regions in the long run although there are migration restrictions.

We distinguish between central and regional governments. Both levels of

\footnotetext{
${ }^{3}$ On average over the period 2004 to 2007 , primary industry accounted for $51 \%$ of employment in the interior region while it accounted for only $35 \%$ in the coastal provinces. The differences in output, however, are less pronounced with corresponding shares of $16 \%$ and $8 \%$.
} 
government provide households with a consumption good which is homogeneous from the households' perspective. The regional governments are also assumed to provide infrastructure which is an input into the production process. ${ }^{4}$

On the taxation side, a perusal of recent literature on the Chinese public finance suggests that the main tax which is also the fastest growing is the value-added tax (VAT), the proceeds of which are shared between the central and sub-national governments. ${ }^{5}$ There are also significant taxes which are raised at the sub-national level and which are not shared with the central government. We focus on two of the larger ones - the business tax and the agricultural tax. ${ }^{6}$ Zhang (2006) reports an effective agricultural tax rate in the inland being 1.72 yuan per 100 yuan of value of output while the corresponding figure for the coast was 1.06; on the other hand, business tax revenue per capita was about one third higher in the coast than the interior $(50 \%$ higher if we include enterprise revenue) but agricultural tax revenue was about one third lower in the coast. Thus, to keep the tax structure representative but as simple as possible and to allow us to investigate a range of fiscal shocks, we assume three taxes in the model: (i) the VAT, the rates for which (possibly regionally-differentiated) are set by the central government and is shared between the central government and the regions; (ii) a business tax levied by the coastal government on the value of manufacturing output; and (iii) an

\footnotetext{
${ }^{4}$ The notion of "infrastructure" may be quite broad here and may include not only the usual transport and communication infrastructure but also such things as expenditure on education and perhaps health which improve the quality of labour in the production process.

${ }^{5}$ See, e.g., Jin and Zou (2005), Shen, Jin and Zou (2006), Zhang and Zou (1998) and Zhang (2006). Note that the VAT was not introduced until the reform of the tax-sharing arrangements in 1994.

${ }^{6}$ It should be noted that the tax on agriculture was abolished in 2006. We nevertheless include it in our model since for much of the postwar period it has been an important source of revenue for the interior provincial governments. But it would be possible to replace it with an alternative that falls more heavily on the interior provinces and is an important source of revenue for them.
} 
agricultural tax levied on the value of agricultural output by the interior government. ${ }^{7}$

We assume that households own both the labour and the capital. Each household supplies one unit of labour to firms in their own region They allocate capital to the region in which the capital rental rate is the highest. They migrate to the region which provides the higher utility subject to hukou costs. Manufacturing firms choose employment, capital and output to maximise profits, taking the real wage and the capital rental rate as parameters and, in the interior, agricultural firms also choose capital to maximise profits and employ all labour and pay a wage equal to the average product of labour (net of capital costs). Governments are assumed to behave exogenously (other than satisfying their budget constraints).

We consider the behaviour of households, firms and governments in turn. ${ }^{8}$

\subsection{Households}

We assume a representative household in each region with a Cobb-Douglas utility function which is homogeneous of degree 1:

$$
V_{i}=\beta_{i} C_{A i}^{\gamma_{A i}} C_{M i}^{\gamma_{M i}} G H_{i}^{\delta_{i}}, \quad i=I, C
$$

where $V_{i}$ is the utility of the representative household, $C_{A i}$ is real private consumption of agricultural output per household, $C_{M i}$ is real private consumption of the manufactured good per household, $G H_{i}$ is real government-provided consumption per household in region $i . \beta_{i}, \gamma_{j i}$ and $\delta_{i}$ are constants with $\beta_{i}>0,0<\gamma_{j i}<1,0<\delta_{i}<1, \gamma_{A i}+\gamma_{M i}+\delta_{i}=1$, for $j=A, M$, and $i=I, C$.

The central government collects a VAT at rate $T_{V \cdot}{ }^{9}$ In our model, the VAT is

\footnotetext{
${ }^{7}$ The main individual taxes omitted according to the data in Zhang (2006) are the personal income tax and the revenue received from enterprises. As we argued, we might think of the enterprise revenue as a business tax captured by our manufacturing tax and the income tax as a VAT since they are equivalent in our model.

${ }^{8} \mathrm{~A}$ list of variables is given in Appendix 1 at the end of the paper.
} 
equivalent to a tax on final consumption and to an income tax. We model income as net of the VAT and account for the tax when we define income below. We measure income in terms of $\mathrm{M}$ so that the constraints can be written as:

$$
\text { P. } C_{A i}+C_{M i}=J_{i}
$$

where $P$ is the price of the agricultural good in terms of the manufactured good, and $J_{i}$ is real household income (net of VAT) in region $i$. Utility maximisation subject to the household budget constraint gives the demand functions:

$$
\begin{gathered}
C_{A i}=\frac{\gamma_{A i}}{\gamma_{A i}+\gamma_{M i}} \frac{J_{i}}{P}, \quad i=I, C, \\
C_{M i}=\frac{\gamma_{M i}}{\gamma_{A i}+\gamma_{M i}} J_{i}, \quad i=I, C .
\end{gathered}
$$

Households own a unit of labour each, they own the capital in the economy as a whole in equal shares and they own the firms in their region in equal shares. They therefore receive wage income and profit distributions from firms in the region, and capital income from firms in both regions. ${ }^{10}$ We have the following relationship between income, the sources of income (wages, capital rental income and profits) and the VAT rate:

$$
\begin{aligned}
& \left(1+T_{v}\right) J_{I}=P\left(\Pi H_{I}+W_{I}\right)+\left(P R_{A} K_{A}+R_{M} K_{M}\right) / N, \\
& \left(1+T_{v}\right) J_{C}=\Pi H_{C}+W_{C}+\left(P R_{A} K_{A}+R_{M} K_{M}\right) / N
\end{aligned}
$$

where $\Pi H_{i}$ is real profit distribution per household, region $i, W_{i}$ is the real wage, region $i$, $R_{j}$ is the capital rental rate, sector $j, K_{j}$ is the capital stock, sector $j$ and $N$ is population.

$$
\text { As indicated earlier, inter-regional migration is possible in the long run but }
$$

\footnotetext{
${ }^{9}$ We assume that the VAT rate is the same in both regions, an assumption which could easily be relaxed.

${ }^{10}$ Note that we could also assume that firms are owned by all households rather than just the households in the region in which the firm is located but this would add another avenue of influence between the regions which would confound the effects of labour and capital migration which we want to focus on.
} 
subject to migration restrictions. ${ }^{11}$ Moreover, we assume that migration occurs only from the poor to the rich region; see Woodland and Yashida (2006) for an approach similar to ours but applied to immigration from poor to rich countries.

In the models with free migration it is customary to assume that migration occurs until utility is equalised across regions. ${ }^{12}$ But under the hukou system, people will be worse off in the interior since they will have to incur costs to obtain hukou for the coastal region. We model the migration equilibrium condition as:

$$
V_{C}=\left[\frac{N_{C} / A_{C}}{N_{I} / A_{I}}\right]^{\mu} V_{I}, \mu>0
$$

where $N_{i} / A_{i}$ is the population density, with $N_{i}$ being population and $A_{i}$ being area in region $i$, and $\mu$ can be thought of as the hukou parameter - the larger is $\mu$ the greater will be the difference in utilities across the two regions (since the coastal population density exceeds that in the interior). ${ }^{13}$ The intuition is that the higher the population density the more resistant will the coastal region be to further migration from the interior provinces. We experiment with the alternative of wage equalisation across regions in our robustness tests reported in Appendix 3.

The "migration condition" for the capital market is that the capital rental rates are equal across sectors:

$$
R_{A}=R_{M}
$$

\subsection{Firms}

We assume that there are a given number of firms in each region, denoted $F_{j}$

\footnotetext{
${ }^{11}$ See Cheng and Selden (1994) for a general description and history of the hukou system. There have been various analyses of the effects of the hukou system; see Whalley and Zhang (2007), Hertel and Zhai (2006), Liu (2005) and Poncet (2006).

${ }^{12}$ See, e.g. Boadway and Flatters (1982).

${ }^{13}$ We will assume that household size is fixed and equal to 1 so that $N_{i}$ will be used to denote both population and the number of households in region $i$.
} 
$(j=A, M)$. Firms use four factors: labour, capital, land and infrastructure. Production technology is constant-returns-to-scale Cobb-Douglas:

$$
\begin{aligned}
& Y_{j}=B_{j}\left(L A N D_{j}\right)^{\left(1-\alpha_{j L}-\alpha_{j M}-\alpha_{j G}\right)}\left(L_{j} / F_{j}\right)^{\alpha_{j L}}\left(K_{j} / F_{j}\right)^{\alpha_{j K}}\left(G R F_{j}\right)^{\alpha_{j G}}, j=A, M \\
& 0<\alpha_{j L}, \alpha_{j K}, \alpha_{j G},\left(1-\alpha_{j L}-\alpha_{j K}-\alpha_{j G}\right)<1
\end{aligned}
$$

where $B_{j}$ is the total factor productivity (TFP), $L_{j}$ is the total labour and $G R F_{j}$ is regional government expenditure on infrastructure, all in sector $j$. We can simplify and write:

$$
D_{j}=B_{j}\left(L A N D_{j}\right)^{\left(1-\alpha_{j L}-\alpha_{j K}-\alpha_{j G}\right)}
$$

so that the production function becomes:

$$
\begin{aligned}
& Y_{j}=D_{j}\left(G R F_{j}\right)^{\alpha_{j G}}\left(L_{j} / F_{j}\right)^{\alpha_{j L}}\left(K_{j} / F_{j}\right)^{\alpha_{j K}}, \\
& 0<\alpha_{j L}, \alpha_{j K}, \alpha_{j G},\left(1-\alpha_{j L}-\alpha_{j K}-\alpha_{j G}\right)<1, \quad j=A, M
\end{aligned}
$$

Consider now firms' behaviour. Profits are defined as:

$$
\Pi F_{j}=\left(1-T_{j}\right) Y_{j}-W_{j}\left(L_{j} / F_{j}\right)-R_{j}\left(K_{j} / F_{j}\right) \quad j=A, M
$$

where $T_{A}$ is the tax on agricultural output levied by the government of the interior region and $T_{M}$ is the tax levied by the coastal region's government on manufacturing output. We assume that each firm takes the wage, the capital rental rate, the tax rate and the quantity of infrastructure as given and chooses the level of employment and capital. Following a long tradition in the economic development literature ( see, e.g., Lewis, 1954 and Rey, 1998), we make different behavioural assumptions for the two sectors - manufacturing firms are assumed to choose employment and capital to maximise profits but in the inland region firm choose only capital to maximise profits and all workers are assumed to find employment in agriculture with farm output (after capital costs) being shared equally among all workers. In agriculture, therefore, the wage is equal to the average product net 
of capital costs.

The profit-maximising condition for manufacturing firms implies:

$$
\begin{aligned}
& \left(1-T_{M}\right) \alpha_{M K} D_{M}\left(L_{M} / F_{M}\right)^{\alpha_{M L}}\left(K_{M} / F_{M}\right)^{\alpha_{M K}-1}\left(G R F_{M}\right)^{\alpha_{M G}}=R_{M} \\
& \left(1-T_{M}\right) \alpha_{M L} D_{M}\left(G R F_{M}\right)^{\alpha_{M G}}\left(L_{M} / F_{M}\right)^{\alpha_{M L}-1}\left(K_{M} / F_{M}\right)^{\alpha_{M K}}=W_{M}
\end{aligned}
$$

In agriculture capital is paid its marginal product but labour is paid its average product:

$$
\begin{aligned}
& \left(1-T_{A}\right) \alpha_{A K} D_{A}\left(L_{A} / F_{A}\right)^{\alpha_{A L}}\left(K_{A} / F_{A}\right)^{\alpha_{A K}-1}\left(G R F_{A}\right)^{\alpha_{A G}}=R_{A} \\
& {\left[\left(1-T_{A}\right) Y_{A}-R_{A}\left(K_{A} / F_{A}\right)\right] /\left(L_{A} / F_{A}\right)=W_{A}}
\end{aligned}
$$

On the labour supply side, each household in each region is assumed to provide one unit of labour inelastically to the firms in its own region so that labour force, labour supply, employment and the number of households are all equal.

\subsection{Governments}

There are three sources of government revenue. The central government levies a VAT at possibly different rates in the two regions and shares the revenue with the regional governments in which the revenue is raised. In addition, the coastal government imposes a business tax on manufacturing and the inland government an agricultural tax on farm output. Each government (central, coastal and interior) receives tax revenue in the form of output and costlessly transforms this output into a homogeneous government good. The central government provides this to households as a consumption good in both regions, in per capita amounts which are equal within each region but may differ across regions. Each regional government provides some output to households as a consumption good within its own region as well as providing some to firms as infrastructure. 
There are no financial assets in the model so that neither households, nor firms nor governments can lend or borrow. Governments therefore must balance their budgets. The central government raises VAT of $N_{I} T_{V} J_{I}$ in region $I$ and $N_{C} T_{V} J_{C}$ in region $C$ of which it retains a proportion $\theta$ which is transformed costlessly into the government consumption good. ${ }^{14}$ We choose units of the two goods so that one unit of each good can be transformed into one unit of the government consumption good. In that case they can be added together and set equal to the amounts of the government consumption goods supplied: $N_{I} G C_{I}$ in region $I$ and $N_{C} G C_{C}$ in region $C$ where $G C_{i}$ is the amount of the government good supplied by the central government per household in region $i$. The central government's budget constraint can then be written as:

$$
N_{I} G C_{I}+N_{C} G C_{C}=\theta T_{V}\left(N_{I} J_{I}+N_{C} J_{C}\right)
$$

The regional governments receive a share $(1-\theta)$ of the VAT revenue raised in their region. In addition, the interior government raises a tax at the rate $T_{A}$ on the value of agricultural output producing revenue of $F_{A} T_{A} Y_{A}$. and the coastal government taxes manufacturing with revenue of $F_{M} T_{M} Y_{M}$. Each regional government transforms this revenue costlessly into the homogeneous government good which it provides to all households in the region in equal amounts, $G R H_{i}$, and into the infrastructure which it provides to firms in the region, $G R F_{j}$. The regional government constraints are:

(10a) $N_{I} G R H_{I}+G R F_{A}=F_{A} T_{A} Y_{A}+(1-\theta) T_{V} N_{I} J_{I}$, and

(10b) $N_{C} G R H_{C}+G R F_{M}=F_{M} T_{M} Y_{M}+(1-\theta) T_{V} N_{C} J_{C}$

\subsection{Closure}

There remains a number of definitions and market-clearing conditions which close the model. First, the relationship between $G H_{i}$ and its components is given by:

\footnotetext{
${ }^{14}$ Again, we assume that the proportion $\theta$ is the same in each region but this could easily be generalised.
} 


$$
G H_{i}=G R H_{i}+G C_{i}, \quad i=I, C
$$

The labour market in each region clears so that, in each region, employment, population and the number of households are the same:

(12a) $\quad L_{A}=N_{I}$

(12b) $\quad L_{M}=N_{C}$

The wage in manufacturing is the same as the wage in the coastal region and the agricultural wage is the same as the wage in the interior region:

(13a) $\quad W_{I}=W_{A}$

(13b) $\quad W_{C}=W_{M}$

There is a given national population, $N$ :

$$
N_{I}+N_{C}=N
$$

There is a given national capital stock, $\mathrm{K}$ :

$$
K_{A}+K_{M}=K
$$

Firms are assumed to distribute all their profits to households in their own region in equal per capita amounts:

(16a) $\quad F_{A} \Pi F_{A}=N_{I} \Pi H_{I}$,

(16b) $\quad F_{M} \Pi F_{M}=N_{C} \Pi H_{C}$

Goods markets are assumed to clear in each region:

$$
F_{A} Y_{A}=N_{I} C_{A I}+N_{C} C_{A C}+T_{A} F_{A} Y_{A}+T_{V} J_{I} N_{I} / P
$$

(17b) $\quad F_{M} Y_{M}=N_{I} C_{M I}+N_{C} C_{M C}+T_{M} F_{M} Y_{M}+T_{V} J_{C} N_{C}$

Given that there are no financial assets in the model, there must be balanced trade:

$$
N_{C} P C_{A C}=N_{I} C_{M I}
$$

To summarise, the model consists of the 34 equations, (1) to (18) in 46 
variables: $V_{i}, C_{j i}, G H_{i}, P, J_{i}, \Pi H_{i}, W_{i}, F_{j}, D_{j}, Y_{j}, L_{j}, K_{j}, R_{j}, N_{i}, \Pi F_{j}, T_{V}, T_{j}, W_{j}, G R H_{i}, G R F_{j}$, $G C_{i}, \theta, N, K, \mu$ of which 14 are exogenous: $F_{j}, D_{j}, T_{j}$, one of $\left(G R H_{I}, G R F_{A}\right)$, one of $\left(G R H_{C}, G R F_{M}\right)$, one of $\left(G C_{I}, G C_{C}\right), \theta, T_{V}, N, K$ and $\mu$. Hence there are 32 endogenous variables: $V_{i}, C_{j i}, G H_{i}, P, J_{i}, \Pi H_{i}, W_{i}, Y_{j}, L_{j}, K_{j}, R_{j}, N_{i}, \Pi F_{j}, W_{j}$, one of $\left(G R H_{I}, G R F_{A}\right)$, one of $\left(G R H_{C}, G R F_{M}\right)$ and one of $\left(G C_{I}, G C_{C}\right) .{ }^{15}$ Two equations are redundant since (3), (7), (12), (13), (16), (18) and the household budget constraint can be used to derive (17) so that there are 32 endogenous variables and independent equations.

\subsection{Short-run and long-run versions of the model}

In the simulations to be reported below we distinguish between short-run and long-run versions of the model. The distinction is very simple: we define the short run as the stretch of time before inter-regional migration begins to respond to the changes in $V_{I}$ and $V_{C}$. In terms of the model, this simply involves suspending equations (4) and (14) and making $N_{I}$ and $N_{C}$ exogenous in the simulation. The long run is used to refer to the simulation results using the model as set out above.

We linearised the model in proportional changes using log-differentiation and then calibrated it using data for China for the period 2000 to 2006 . The linearised model and the details of the calibration are given in Appendix 2.

\section{The simulations}

$\mathrm{W}$ assume that the (poor) interior and central governments are both interested in reducing disparities between the two regions and consider possible policies by each.

\footnotetext{
${ }^{15}$ Note that which of $\left(G R H_{I}, G R F_{A}\right)$, for example, is chosen to be exogenous may affect the simulation results. In some cases the choice will be determined by the simulation; where this is not so, we choose $G R F_{A}, G R F_{M}$ and $G C_{C}$ to be the exogenous variable. In Appendix 3 we report experiments with alternatives, including maximising regional governments.
} 
Policy actions by the interior government are:

(i) An increase in interior government-provided consumption.

(ii) An increase in public expenditure on infrastructure by the interior government.

(iii) A cut in the tax on agricultural output.

(iv) Measures which increase productivity in the agriculture sector, such as releasing more land for agriculture or improving agricultural TFP. ${ }^{16}$

Policies which the central government might undertake to reduce disparities are:

(v) A cut in hukou cost, making migration from the interior to the coast cheaper. ${ }^{17}$

(vi) An increase in expenditure in the interior region by the central government.

(vii) A fiscal transfer from the coastal to the interior region by the central government's adjusting the tax-sharing arrangements.

To simulate these policies, we set each of $\operatorname{grh}_{I}, \operatorname{grf}_{A}, t_{A}, d_{A}, \mu^{*}$ and $g c_{I}$ equal to 1 in turn for policies 1 to 6 respectively where the lower case symbols are the log differentials of their upper case counterparts and $\mu^{*}$ is the proportional change in $\mu$. For policy 7 , we assume a reduction in $\theta_{I}$ and a matching increase in $\theta_{C}$.

\section{Simulation results}

We limit our discussion in two ways. First, we focus just a few key variables: regional output, per capita output and utility, as well as inter-regional migration and capital movements, with the full results being reported in Appendix 4. Second, we

\footnotetext{
${ }^{16}$ It might be argued that there is little additional land available for release to agriculture in China. However, the shock here may also be thought of as the implementation of policy which halts or slows down the alienation of farm land for non-agricultural purposes.

${ }^{17}$ We note that originally the hukou system was instituted and administered by the central government but that since reforms began in the late 1970s it has increasingly been the wealthier coastal provinces which have maintained the force of the hukou restrictions Coastal provinces are, therefore, hardly likely to allow relaxation of the migration restrictions and it must be assumed that only the central government is likely to implement such reform.
} 
present a detailed discussion only of the "base case", i.e., the results using the original parameter values and closure assumptions. Simulations using alternatives to these are briefly discussed in Appendix 3 with detailed tables of results appearing in Appendix 4.

A summary of the results of the seven simulations is presented in Table 1. We focus on whether policies have been successful in reducing the disparity between coastal and interior per capita output and also ask whether residents of each region are better-off.

\section{[Table 1 near here]}

\subsection{Policy 1: An increase in interior government consumption expenditure}

Table 1 shows that policy 1 is ineffective in reducing the per capita output gap both in the short run and long run. In fact, in both the short and long runs, policy actually reduces output and per capita output in the interior region while leaving coastal output slightly higher in both the short and long run with the result that the gap between the two regions worsens. Welfare in both regions is also reduced in both short and long runs with the welfare loss in the coastal region being slightly greater than that in the interior so that, strictly-speaking, the welfare gap is narrowed slightly.

The mechanism underlying these counter-productive results is that the increase in government consumption expenditure requires a decrease in government infrastructure expenditure to balance the interior government's budget. This reduces agricultural productivity, output and output per capita, both of which are reinforced by capital movement from the interior to the coast driven by the fall in the marginal product of capital in the interior. The result is a fall in consumption of the agricultural good in both regions (this happens in the coastal region through a relative price change) and a consequent fall in welfare in both regions. The welfare fall in the interior is smaller, 
however, because of the offsetting effect of the increase in government-provided consumption good. This welfare effect induces a small internal migration flow from the coast to the interior which exacerbates the effect on per capita output in the long run.

All in all, then, in both short and long runs, not only does the per capita output disparity between the two regions increase, but residents in both regions are worse-off.

\subsection{Policy 2: An increase in infrastructure provision in the interior region}

By contrast, Table 1 shows that policy 2 is effective in improving output and output per capita in the interior region, while reducing both in the coast. The disparities between them is therefore reduced. Welfare increases in both regions in both short and long runs, although more in the coast so that the welfare gap widens. The mechanism is essentially the opposite of that for policy 1.

\subsection{Policy 3: A cut in the agricultural tax}

Table 1 shows that policy 3 increases output in the interior region in the short run since the reduction in the agricultural tax improves the marginal product of capital in the interior region and so induces capital movement from the coastal to the interior. The reduction in government consumption expenditure needed to balance its budget leaves more agricultural output available for private consumption which results in a small relative price change in favour of manufactured goods. On balance, this makes interior households worse-off and coastal households better-off. In the long run, the utility differential induces migration to the coast from the interior, which reverse the short-run effects of capital movement on output so that both population and output in the coastal region increase and the output gap between the two regions increases although, given decreasing marginal product of labour, the gap in output per capita moves in the opposite 
direction.

Thus, on balance, even though the interior government is successful in increasing output per capita relative to that in the coastal region, its citizens are actually worse-off.

\subsection{Policy 4: An improvement in agricultural productivity}

From Table 1 we also see that policy 4 is clearly effective in reducing the gap in regional output per capita both in the short run and long run since it greatly increases the output in the interior region while decreasing manufacturing output. This reflects both the direct effect of the increase in productivity on output and the capital movement from the coastal to the interior region induced by the increase in the marginal product of capital in the interior. The immediate effects of the increase in agricultural output is to increase consumption of the agricultural good in both regions. Moreover, the interior government's tax base increases, thus allowing it to provide more consumption goods to its citizens. The overall effect of this is to improve welfare in both regions although by more in the interior, providing an incentive for internal migration from the coast to the interior which offsets the initial beneficial effects on output per capita and welfare, but only slightly.

In summary, the policy reduces the disparity between the two regions' per capita output and welfare increases in both regions but by more in the interior so that the welfare effects in this case are consistent with the per capita output effects.

\subsection{Policy 5: A relaxation of hukou restrictions}

Table 1 shows that policy 5 has no effect in the short run which is not surprising since it operates initially through the internal migration channel which is closed in the short run. However, over time the reduction of hukou cost induces substantial migration 
over time from the interior to the coastal region. The reduction of population in the interior region reduces output in this region both directly and via the capital movement from the interior to the coast induced by the fall in the marginal product of capital in the interior. Given decreasing marginal productivity of labour, output per capita increases in the onterior. On the other hand, the migration of population to the coast increases output but reduces output per capita in this region. Therefore, policy 5 unambiguously narrows inter-regional disparities in output per capita.

The outflow of migration is also helpful for improving utility in the interior region in the long run since the fall in population in the interior region increases the profits per household and the government-provided consumption good in the interior region also rises (both because of the rise in per capita tax base and an increase in the tax revenue from the VAT). On the contrary, the inflow of migration into the coastal regions is harmful for welfare in this region.

The papers by Hertel and Zhai (2006) and Whalley and Zhang (2007) also address the issue of the effects on disparities of a relaxation of the migration restrictions. They both find, as we do, that the relaxation results in a narrowing of the rural-urban gap (in the case of Hertel and Zhai) and the inter-regional gap (in the case of Whalley and Zhang), this despite very different models - Hertel and Zhai use a large CGE model and Whalley and Zhang, in their simplest version, have a two-equation model for each of two regions.

In summary, therefore, policy 5 is effective in reducing gaps between the two regions in output per capita and utility. Note, though, that the coastal region becomes worse-off, providing strong incentives for the provinces in this region to maintain the 
status quo.

4.6 Policy 6: Increasing the central government's expenditure in the interior region

Table 1 shows that policy 6 is a shift of central government consumption from the coast to the interior and has short-run effects only on welfare, increasing interior welfare and reducing welfare in the coast. Thus, policy 6 reduces the welfare gap between regions in the short run but does nothing to change the per capita output gap.

Over time, as inter-regional migration is permitted, people move from the coastal to the interior region in response to the welfare gap. This improves the marginal product of capital in the interior, thus inducing capital movement from the coast which reinfoirces the output expansion in the interior region. This means that output in the interior region increases while that in the coastal region decreases but, since the absolute magnitude of population changes are larger than those of output changes, output per capita in the interior region decrease and that in the coastal increases. Thus policy 6 enlarges, rather than narrows regional per capita output disparities across regions in the long run. The internal migration response also significantly reduces the short-run welfare effects so that, while the central government reallocation of output from one region to the other has substantial short-run welfare effects, these are largely reversed as a result of the migration and capital flows which occur in response to them.

\subsection{Policy 7: A fiscal transfer from the coastal to the interior region}

Recall that this policy involves a change in the VAT-sharing arrangements in favour of the interior but with the overall VAT rate unchanged and so redistributes resources from the coast to the interior via regional government budgets. Table 1 shows that, in the short run, policy 7 has effects only on regional governments' expenditure on 
the consumption good which, in turn, affects welfare in each region. There is an increase in utility in the recipient region (the interior) and a welfare decrease in the donor region (the coast), so reducing inter-regional disparities in welfare in the short run but having no effect on the per capita output gap.

Over time, the migration from the coastal to the interior region induced by the change in the welfare gap increases the interior labour force and employment and reduces them in the coastal region. The migration from the coast to the interior also induces capital movement in the same direction since the inflow of employment into the interior region improves the marginal product of capital in this region. As a result, agricultural output increases while manufacturing output falls but output per capita moves in the opposite direction so that the gap in output per capita worsens while the welfare gap improves.

\section{Conclusions}

This paper began from the observation that regional disparities are large and persistent and that an important policy objective for some time has been to narrow them. Nevertheless, little analysis of the effectiveness of alternative policy instruments has been carried out.

This paper has made a contribution to filling this gap by developing a small theoretical model which captures some of the salient features of the Chinese economy. It has two regions, one a poor inland region dependent on agriculture and the other a more prosperous coastal region producing manufactured goods. There is migration between the two regions but only in a restricted way and unrestricted capital mobility. Finally, we 
capture some of the rudiments of the tax-expenditure characteristics of the Chinese economy.

The model was solved in linear numerical form with the numerical values of the parameters being based on recent Chinese data. We simulated the effects of a variety of policies which may be thought to reduce the gap between the coast and the interior including tax cuts and expenditure increases by both the central and interior governments and policies to boost agricultural productivity as well as a relaxation of migration restrictions.

We found that several of the policies have the opposite effect to that intended once the reality of the government budget constraint and other model restrictions are taken into account. Moreover, improving the per capita output gap did not necessarily move the welfare gap in the same direction so that it was possible that the policy objective in terms of reducing output disparities is achieved but people in the poor region are actually worse-off. It was found that policies which improve agricultural productivity either by increases in TFP or by investing in agricultural infrastructure have the strongest effect on output and per capita output. Finally, a reduction in the hukou restrictions has the expected effect on the per capita output gap as well as reducing the welfare gap but only at considerable cost to the coastal region which can, therefore, be expected to continue to resist such moves. 
Table 1 Summary of Simulation Results: Base Case

\begin{tabular}{|c|c|c|c|c|c|c|c|c|c|c|c|c|c|c|}
\hline \multirow[t]{2}{*}{ Variables } & \multicolumn{2}{|c|}{$\begin{array}{l}\text { Policy 1: } \\
\operatorname{grh}_{1}=1\end{array}$} & \multicolumn{2}{|c|}{$\begin{array}{l}\text { Policy 2: } \\
\text { grf }_{\mathrm{A}}=1\end{array}$} & \multicolumn{2}{|c|}{$\begin{array}{c}\text { Policy } 3: \\
t_{A}=-1\end{array}$} & \multicolumn{2}{|c|}{$\begin{array}{c}\text { Policy 4: } \\
d_{A}=1\end{array}$} & \multicolumn{2}{|c|}{$\begin{array}{c}\text { Policy 5: } \\
\mu^{*}=-1\end{array}$} & \multicolumn{2}{|c|}{$\begin{array}{l}\text { Policy 6: } \\
\mathrm{gc}_{\mathrm{I}}=1\end{array}$} & \multicolumn{2}{|c|}{$\begin{array}{c}\text { Policy 7: } \\
\theta^{*}=-1, \theta^{*}=0.8013\end{array}$} \\
\hline & SR & LR & SR & LR & SR & LR & SR & LR & SR & LR & SR & LR & SR & LR \\
\hline $\mathrm{v}_{\mathrm{I}}$ & -0.0804 & -0.0876 & 0.0674 & 0.0729 & -0.0356 & -0.0215 & 0.4407 & 0.4103 & 0.0000 & 0.3782 & 0.1366 & 0.0807 & 0.1300 & 0.0721 \\
\hline $\mathrm{v}_{\mathrm{C}}$ & -0.1062 & -0.1014 & 0.0891 & 0.0844 & 0.0202 & 0.0082 & 0.3199 & 0.3458 & 0.0000 & -0.3220 & -0.1049 & -0.0565 & -0.0998 & -0.0504 \\
\hline $\mathrm{k}_{\mathrm{A}}$ & -0.2120 & -0.2110 & 0.1778 & 0.1757 & 0.0402 & 0.0348 & 0.6385 & 0.6504 & 0.0000 & -0.1472 & 0.0000 & 0.0252 & 0.0000 & 0.0225 \\
\hline $\mathrm{k}_{\mathrm{M}}$ & 0.1641 & 0.1634 & -0.1377 & -0.1360 & -0.0312 & -0.0269 & -0.4944 & -0.5036 & 0.0000 & 0.1140 & 0.0000 & -0.0195 & 0.0000 & -0.0175 \\
\hline $\mathrm{y}_{\mathrm{A}}$ & -0.3577 & -0.3587 & 0.3001 & 0.2986 & 0.0049 & 0.0011 & 1.0776 & 1.0859 & 0.0000 & -0.1027 & 0.0000 & 0.0176 & 0.0000 & 0.0157 \\
\hline $\mathrm{y}_{\mathrm{M}}$ & 0.0184 & 0.0158 & -0.0154 & -0.0131 & -0.0035 & 0.0024 & -0.0553 & -0.0681 & 0.0000 & 0.1584 & 0.0000 & -0.0272 & 0.0000 & -0.0243 \\
\hline $1_{\mathrm{A}}$ & 0.0000 & 0.0059 & 0.0000 & -0.0049 & 0.0000 & -0.0126 & 0.0000 & 0.0273 & 0.0000 & -0.3393 & 0.0000 & 0.0582 & 0.0000 & 0.0520 \\
\hline $1_{\mathrm{M}}$ & 0.0000 & -0.0080 & 0.0000 & 0.0066 & 0.0000 & 0.0171 & 0.0000 & -0.0371 & 0.0000 & 0.4605 & 0.0000 & -0.0790 & 0.0000 & -0.0705 \\
\hline $\mathrm{y}_{\mathrm{A}}-\mathrm{l}_{\mathrm{A}}$ & -0.3577 & -0.3645 & 0.3001 & 0.3035 & 0.0049 & 0.0137 & 1.0776 & 1.0585 & 0.0000 & 0.2366 & 0.0000 & -0.0406 & 0.0000 & -0.0362 \\
\hline $\mathrm{y}_{\mathrm{M}}-\mathrm{l}_{\mathrm{M}}$ & 0.0184 & 0.0237 & -0.0154 & -0.0198 & -0.0035 & -0.0147 & -0.0553 & -0.0310 & 0.0000 & -0.3020 & 0.0000 & 0.0518 & 0.0000 & 0.0463 \\
\hline
\end{tabular}

Notes: since $y_{j}$ and $l_{j}$ are $\log$ differences of output and population in sector $j, y_{j}-l_{j}$ means the log difference of output per capita in sector $j$. The symbols in the

first column as the proportional changes of their upper-case counterparts (thus, for example, $v_{I}$ is the proportional change in $V_{I}$ ), $\mu^{*}$ and $\theta^{*}$ are the proportional changes in $\mu$ and $\theta$. 
References:

Boadway, R. and Flatters, F. (1982), 'Efficiency and Equalisation Payments in a Federal System of Government: A Synthesis and Extension of Recent Results', Canadian Journal of Economics, 15, 613-633.

Cheng, T. and Selden, M. (1994), “The Origins and Consequences of China's Hukou System", The China Quarterly, No. 139, 644-668.

Demurger, S. (2001), "Infrastructure Development and Economic Growth: An Explanation for Regional Disparities in China?", Journal of Comparative Economics, 29, 95-117.

Fan, S. (1991), "Effects of Technological Change and Institutional Reform on Production Growth in Chinese Agriculture", American Journal of Agricultural Economics, 73, 266-275.

Fleisher, B. M and J. Chen (1997), "The Coast-Noncoast Income Gap, Productivity and Regional Economic Policy in China", Journal of Comparative Economics, $25,220-236$

Groenewold, N., A Chen and G. Lee (2008), Linkages between China's Regions: Measurement and Policy, Edward Elgar, Cheltenham, UK.

Hertel, T. and Zhai, F. (2006), "Labour Market Distortions, Rural-Urban Inequality and the Opening of China's Economy", Economic Modelling, 23, 76-109.

Hu, D.(2002), 'Trade, rural-urban migration, and regional income disparity in developing countries: a spatial general equilibrium model inspired by the case of China', Regional Science and Urban Economics, 32, 311-338.

Jin, J. and H. Zou (2005), “ Fiscal Decentralization, Revenue and Expenditure Assignments and Growth in China", Journal of Asian Economics, 16, 1047 1064. 
Lewis, W. A. (1954), "Economic Development with Unlimited Supplies of Labour”, The Manchester School, 22, 139-191.

Liu, Z. (2005), "Institution and Inequality: The Hukou System in China”, Journal of Comparative Economics, 33, 133-157.

Poncet, S. (2006), "Provincial Migration Dynamics in China: Borders, Costs and Economic Motivations", Regional Science and Urban Economics, 36, 385398.

Rey, D. (1998), Development Economics, Princeton University Press, Princeton, NJ.

Shen, C., Jin, J. and Zou, H. (2006), "Fiscal Decentralization in China: History, Impacts, Challenges and Next Steps", World Bank Discussion Paper.

State Statistical Bureau (various issues), China Statistical Yearbook, Statistical Publishing House of China, Beijing.

Whalley, J. and Zhang, S. (2007), “A Numerical Simulation Analysis of (Hukou) Labour Mobility Restrictions in China", Journal of Development Economics, $83,392-410$.

Woodland, A.D. and Yoshida, C.(2006), "Risk Preference, Immigration Policy and Illegal Immigration”, Journal of Development Economics, 81, 500- 513.

Zhang, T. and Zou, H. (1998), "Fiscal Decentralization, Public Spending and Economic Growth in China", Journal of Public Economics, 67, 221-240.

Zhang, X. (2006), "Fiscal Decentralization and Political Centralization in China: Implications for Growth and Inequality", Journal of Comparative Economics, $34,713-726$. 
Appendix 1: Definition of variables

$V_{i}=$ utility of the representative household, region $\mathrm{i}$,

$C_{A i}=$ real private consumption of agricultural output per household, region $\mathrm{i}$,

$C_{M i}=$ real private consumption of manufactured good per household, region i,

$G_{H i}=$ real government-provided consumption per household, region i.

$P=$ price of agricultural good in terms of manufactured good

$J_{i}=$ real household income (net of VAT), region i

$\Pi H_{i}=$ real profit distribution per household, region $\mathrm{i}$

$W_{i}=$ real wage income per household, region $\mathrm{i}$

$F_{j}=$ the number of firms, sector $\mathrm{j}$

$D_{j}=$ productivity parameter, sector $\mathrm{j}$

$K_{\mathrm{j}}=$ capital, sector $\mathrm{j}$

$R_{\mathrm{j}}=$ marginal product, sector $\mathrm{j}$

$Y_{j}=$ real output, sector $\mathrm{j}$

$L_{j}=$ employment, sector $\mathrm{j}$

$N_{i}=$ population, region $\mathrm{i}$

$\Pi F_{j}=$ firm profit, sector $\mathrm{j}$

$T_{v}=$ value added tax rate

$T_{j}=$ output tax rate, sector $\mathrm{j}$

$W_{j}=$ real wage income, sector $\mathrm{j}$

$G R H_{i}=$ real regional government-provided consumption good per household, region i

$G R F_{i}=$ real regional government-provided public good, region $\mathrm{i}$

$G C_{i}=$ real central government-provided consumption good per household in region i

$\theta=$ share of valued tax to the central government

$N=$ national population 
$\mu=$ hukou parameter

$\mathrm{K}=$ the aggregate capital stock 
Appendix 2. The linearised and calibrated model

\section{A2.1 The linearised model}

The model of section 2 is linearised in terms of proportional differences by taking logarithms and differentials of each equation. The linearised form of equations (1) to (19) (excluding equations (17) which are redundant) of the model are as follows, with the linearised form having the same number as the original equation but being distinguished by a prime.

The linearised utility function is:

(1') $v_{i}=\gamma_{A i} c_{A i}+\gamma_{M i} c_{M i}+\delta_{i} g h_{i}$

$i=I, C$

where lower-case letters represent the proportional changes (log differential) of their upper-case counterparts.

The linearised consumption demand functions are:
(2a') $c_{A i}=j_{i}-p$
$i=I, C$
(2b') $c_{M i}=j_{i}$
$i=I, C$

The linearised definitions of real household income are:

$$
\begin{aligned}
& \text { (3a') } \sigma_{t v} t_{v}+j_{I}+n=\sigma_{\pi h w j I}(p+n)+\sigma_{\pi h w j I}\left(\sigma_{\pi h j} \pi h_{I}+\sigma_{w j I} w_{I}\right)+\sigma_{r A j I}\left(p+r_{A}+k_{A}\right) \\
& +\sigma_{r M j I}\left(r_{M}+k_{M}\right) \\
& \text { where } \sigma_{t v}=\frac{T_{v}}{1+T_{v}}, \sigma_{\pi h j I}=\frac{\Pi H_{I}}{\Pi H_{I}+W_{I}}, \sigma_{w j I}=\frac{W_{I}}{\Pi H_{I}+W_{I}} \text {, } \\
& \sigma_{\pi h w j l}=\frac{\mathrm{PN}\left(\Pi \mathrm{H}_{\mathrm{I}}+\mathrm{W}_{\mathrm{I}}\right)}{\mathrm{PN}\left(\Pi \mathrm{H}_{\mathrm{I}}+\mathrm{W}_{\mathrm{I}}\right)+\mathrm{PR}_{\mathrm{A}} \mathrm{K}_{\mathrm{A}}+\mathrm{R}_{\mathrm{M}} \mathrm{K}_{\mathrm{M}}} \\
& \sigma_{r A j I}=\frac{\mathrm{PR}_{\mathrm{A}} \mathrm{K}_{\mathrm{A}}}{\mathrm{PN}\left(\Pi \mathrm{H}_{\mathrm{I}}+\mathrm{W}_{\mathrm{I}}\right)+\mathrm{PR}_{\mathrm{A}} \mathrm{K}_{\mathrm{A}}+\mathrm{R}_{\mathrm{M}} \mathrm{K}_{\mathrm{M}}} \\
& \sigma_{r M j I}=\frac{\mathrm{R}_{\mathrm{M}} \mathrm{K}_{\mathrm{M}}}{\mathrm{PN}\left(\Pi_{\mathrm{I}}+\mathrm{W}_{\mathrm{I}}\right)+\mathrm{PR}_{\mathrm{A}} \mathrm{K}_{\mathrm{A}}+\mathrm{R}_{\mathrm{M}} \mathrm{K}_{\mathrm{M}}} \text { and } \\
& \text { (3b') } \sigma_{t v} t_{v}+j_{C}+n=\sigma_{\pi h w j C} n+\sigma_{\pi h w j C}\left(\sigma_{\pi h j C} \pi h_{C}+\sigma_{w j C} w_{C}\right)+\sigma_{r A j C}\left(p+r_{A}+k_{A}\right) \\
& +\sigma_{r M j C}\left(r_{M}+k_{M}\right)
\end{aligned}
$$


where $\sigma_{t v}=\frac{T_{v}}{1+T_{v}}, \sigma_{\pi h j C}=\frac{\Pi H_{C}}{\Pi H_{C}+W_{C}}, \sigma_{w j I}=\frac{W_{I}}{\Pi H_{I}+W_{I}}$,

$\sigma_{\pi h w j C}=\frac{\mathrm{N}\left(\Pi_{\mathrm{C}}+\mathrm{W}_{\mathrm{C}}\right)}{\mathrm{N}\left(\Pi_{\mathrm{C}}+\mathrm{W}_{\mathrm{C}}\right)+\mathrm{PR}_{\mathrm{A}} \mathrm{K}_{\mathrm{A}}+\mathrm{R}_{\mathrm{C}} \mathrm{K}_{\mathrm{C}}}$

$\sigma_{r A j C}=\frac{\mathrm{PR}_{\mathrm{A}} \mathrm{K}_{\mathrm{A}}}{\mathrm{N}\left(\Pi_{\mathrm{C}}+\mathrm{W}_{\mathrm{C}}\right)+\mathrm{PR}_{\mathrm{A}} \mathrm{K}_{\mathrm{A}}+\mathrm{R}_{\mathrm{M}} \mathrm{K}_{\mathrm{M}}}$

$\sigma_{r M j C}=\frac{\mathrm{R}_{\mathrm{M}} \mathrm{K}_{\mathrm{M}}}{\mathrm{N}\left(\Pi \mathrm{H}_{\mathrm{C}}+\mathrm{W}_{\mathrm{C}}\right)+\mathrm{PR}_{\mathrm{A}} \mathrm{K}_{\mathrm{A}}+\mathrm{R}_{\mathrm{M}} \mathrm{K}_{\mathrm{M}}}$

The linearised migration equilibrium condition corresponding to equation (4)

is:

(4') $v_{C}=v_{I}+\mu^{*} \mu \log \left(\frac{N_{C} / A_{C}}{N_{I} / A_{I}}\right)+\mu\left(n_{C}-n_{I}\right)$

where $\mu^{*}=d \mu / \mu$ and we have used the obvious assumption that area is constant.

The capital allocation equilibrium condition is:

$$
r_{A}=r_{M}
$$

The linearised production functions are:

$$
y_{j}=d_{j}+\alpha_{j G} g r f_{j}+\alpha_{j L}\left(l_{j}-f_{j}\right)+\alpha_{j k}\left(k_{j}-f_{j}\right) \quad j=A, M
$$

The linearised profit definitions are given by:

$$
\pi f_{j}=\sigma_{y \pi f j} y_{j}-\sigma_{t j} \sigma_{y \pi f j} t_{j}-\sigma_{w \pi f j}\left(w_{j}+l_{j}-f_{j}\right)-\sigma_{k \pi f j}\left(r_{j}+k_{j}-f_{j}\right) \quad j=A, M
$$

where $\sigma_{y \pi f j}=\frac{\left(1-T_{j}\right) Y_{j}}{\Pi F_{j}}, \sigma_{t j}=\frac{T_{j}}{1-T_{j}}, \sigma_{w \pi f j}=\frac{W_{j}\left(L_{j} / F_{j}\right)}{\Pi F_{j}}, \sigma_{k \pi f j}=\frac{R_{j}\left(K_{j} / F_{j}\right)}{\Pi F_{j}}$

The manufacturing sector's profit-maximisation condition in linear form is:

$$
r_{M}+\sigma_{t M} t_{M}-d_{M}-\alpha_{M G} g r f_{M}+\left(1-\alpha_{M K}\right)\left(k_{M}-f_{M}\right)-\alpha_{M L}\left(L_{M}-f_{M}\right)=0
$$

$$
w_{M}+\sigma_{t M} t_{M}-d_{M}-\alpha_{M G} g r f_{M}+\left(1-\alpha_{M L}\right)\left(l_{M}-f_{M}\right)-\alpha_{M K}\left(k_{M}-f_{M}\right)=0 .
$$

and that for agriculture is given by:

(8c') $r_{A}+\sigma_{t A} t_{A}-d_{A}-\alpha_{A G} g r f_{A}+\left(1-\alpha_{A K}\right)\left(k_{A}-f_{A}\right)-\alpha_{A L}\left(L_{A}-f_{A}\right)=0$

(8d') $\quad w_{A}+\sigma_{t A} t_{A}-y_{A}-\left(l_{A}-f_{A}\right)=0$ 
The central government's budget constraint is linearised as:

$$
\sigma_{g c l g c}\left(n_{I}+g c_{I}\right)+\sigma_{g c C g c}\left(n_{C}+g c_{C}\right)=\theta^{*}+t_{v}+\sigma_{j I j}\left(n_{I}+j_{I}\right)+\sigma_{j C j}\left(n_{C}+j_{C}\right)
$$

where $\sigma_{g c l g c}=\frac{N_{I} G C_{I}}{N_{I} G C_{I}+N_{C} G C_{C}}, \sigma_{g c C g c}=\frac{N_{C} G C_{C}}{N_{I} G C_{I}+N_{C} G C_{C}}, \sigma_{j I j}=\frac{N_{I} J_{I}}{N_{I} J_{I}+N_{C} J_{C}}$,

$\sigma_{j C j}=\frac{N_{C} J_{C}}{N_{I} J_{I}+N_{C} J_{C}}, \theta^{*}=d \theta / \theta$

The interior government's budget constraint in linear form is given by:

$\left(10 \mathrm{a}^{\prime}\right) \sigma_{g r h l g r}\left(n_{I}+g r h_{I}\right)+\sigma_{g r f A g r} g r f_{A}=\sigma_{t A g r}\left(f_{A}+t_{A}+y_{A}\right)+\sigma_{t v I g r}\left(-\sigma_{\theta} \theta^{*}+t_{V}+n_{I}+j_{I}\right)$

where $\sigma_{\text {grhgrI }}=\frac{N_{I} G R H_{I}}{N_{I} G R H_{I}+G R F_{A}}, \sigma_{\text {grfgrA }}=\frac{G R F_{A}}{N_{I} G R H_{I}+G R F_{A}}, \sigma_{\theta}=\frac{\theta}{1-\theta}$,

$\sigma_{\text {tAgrI }}=\frac{F_{A} T_{A} Y_{A}}{F_{A} T_{A} Y_{A}+(1-\theta) T_{V} N_{I} J_{I}}, \sigma_{\text {tvgrI }}=\frac{(1-\theta) T_{V} N_{I} J_{I}}{F_{A} T_{A} Y_{A}+(1-\theta) T_{V} N_{I} J_{I}}$

Similarly, for the coastal region's government budget constraint we have:

$\left(10 \mathrm{~b}^{\prime}\right) \sigma_{g r h C g r}\left(n_{C}+g r h_{C}\right)+\sigma_{g r m g r} g r f_{M}=\sigma_{t M g r}\left(f_{M}+t_{M}+y_{M}\right)+\sigma_{t v C g r}\left(-\sigma_{\theta} \theta^{*}+t_{V}+n_{C}+j_{C}\right)$

where $\sigma_{g r h g r C}=\frac{N_{C} G R H_{C}}{N_{C} G R H_{C}+G R F_{M}}, \sigma_{g r f g r M}=\frac{G R F_{M}}{N_{C} G R H_{C}+G R F_{M}}$,

$\sigma_{t M g r C}=\frac{F_{M} T_{M} Y_{M}}{F_{M} T_{M} Y_{M}+(1-\theta) T_{V} N_{C} J_{C}}, \sigma_{t v g r C}=\frac{(1-\theta) T_{V} N_{C} J_{C}}{F_{M} T_{M} Y_{M}+(1-\theta) T_{V} N_{C} J_{C}}$

The definition of $G H_{i}$ is linearised as:

(11') $g h_{i}=\sigma_{\text {grhigh }} g r h_{i}+\sigma_{g c i g h} g c_{i} \quad i=I, C$

where $\sigma_{g r h g h i}=\frac{G R H_{i}}{G H_{i}}, \sigma_{g c g h i}=\frac{G C_{i}}{G H_{i}}$

The equalities between interior and agricultural employment and between coastal and manufacturing employment imply:

(12a') $l_{A}=n_{I}$

(12b') $l_{M}=n_{C}$ 
Similarly for wages:

(13a') $w_{I}=w_{A}$

$\left(13 \mathrm{~b}^{\prime}\right) w_{C}=w_{M}$

The national employment constraint results in the following linearised condition:

$\sigma_{n I} n_{I}+\sigma_{n C} n_{C}=n$

where $\sigma_{n I}=N_{I} / N, \sigma_{n C}=N_{C} / N$.

The national capital constraint is linearised as:

$\sigma_{K A} k_{A}+\sigma_{K C} k_{C}=k$

where $\sigma_{k A}=K_{A} / K, \sigma_{k M}=K_{M} / K$

The profit distribution condition can be linearised to give:

(16a') $f_{A}+\pi f_{A}=n_{I}+\pi h_{I}$

(16b') $f_{M}+\pi f_{M}=n_{C}+\pi h_{C}$

Equations (17), the goods markets clearing conditions, are dropped from the model due to the redundancy result explained above. The final equation of the model is the balance or trade condition which, in linear form, is:

$$
n_{C}+p+c_{A C}=n_{I}+c_{M I}
$$

In the version of the model which assumes provincial governments are empire builders the following conditions are added to the linearised model:

(19a') $\sigma_{n g r h C} n_{C}+\sigma_{g r h C} g r h_{C}=0$

where $\sigma_{\text {ngrh } C}=\frac{N_{C} \frac{\partial G R H_{C}}{\partial G R F_{M}}}{N_{C} \frac{\partial G R H_{C}}{\partial G R F_{M}}+G R H_{C} \frac{\partial N_{C}}{\partial G R F_{M}}}, \quad \sigma_{g r h C}=\frac{G R H_{C} \frac{\partial N_{C}}{\partial G R F_{M}}}{N_{C} \frac{\partial G R H_{C}}{\partial G R F_{M}}+G R H_{C} \frac{\partial N_{C}}{\partial G R F_{M}}}$ 


$$
\sigma_{n g r h I} n_{I}+\sigma_{g r h l} g r h_{I}=0
$$

where $\sigma_{n g r h I}=\frac{N_{I} \frac{\partial G R H_{I}}{\partial G R F_{A}}}{N_{I} \frac{\partial G R H_{I}}{\partial G R F_{A}}+G R H_{I} \frac{\partial N_{I}}{\partial G R F_{A}}}, \quad \sigma_{g r h I}=\frac{G R H_{I} \frac{\partial L_{I}}{\partial G R F_{A}}}{L_{I} \frac{\partial G R H_{I}}{\partial G R F_{A}}+G R H_{I} \frac{\partial L_{I}}{\partial G R F_{A}}}$

\section{A2.2 Calibrating the linearised model}

Having linearised the model in terms of proportional changes, we can solve the model for any one of the (changes in the) endogenous variables in terms of (the changes in) the exogenous variables. However, given the number of endogenous variables, this is unlikely to lead to any interpretable results and we proceed to solve the model numerically using data for China's regions to calibrate the key parameters of the model, a matter we turn to now.

The linearised model contains a number of parameters which have to be evaluated before the model can be put to work to simulate the effects of various shocks. These parameters fall into two groups. The first are parameters which appear in model relationships; $\gamma_{j i}$ and $\delta_{i}$ appear in the utility function (1) and $\alpha_{j G}, \alpha_{j K}$ and $\alpha_{j L}$ appear in the production function (6). The remainder, on the other hand, are linearisation parameters which are all shares of some sort.

The model parameters can be evaluated with the help of model restrictions. Start with $\gamma_{j i}$ and $\delta_{i}$. Here we follow the approach conventionally adopted by GE modellers and calibrate the utility function to ensure that the initial solution is one of utility maximisation. ${ }^{18}$ Since the relative price of $C$ and $G$ is unity, utility maximisation and the constraint that $\gamma_{A i}+\gamma_{M i}+\delta_{i}=1$ implies that

\footnotetext{
${ }^{18}$ It should be noted that, while this parameterisation is conventional, it is not strictly implied by our model specification since the households maximise utility subject to a given level of GH.
} 


$$
\begin{aligned}
& \gamma_{A i}=\frac{C_{A i}}{C_{A i}+C_{M i}+G_{H i}}, \\
& \gamma_{M i}=\frac{C_{M i}}{C_{A i}+C_{M i}+G_{H i}}, \text { and } \\
& \delta_{i}=\frac{G_{H i}}{C_{A i}+C_{M i}+G_{H i}} .
\end{aligned}
$$

We can compute the values of these parameters using data for government and private consumption expenditure.

Turn now to manufacturing sector production parameters, $\alpha_{M K}, \alpha_{M G}$ and $\alpha_{M L}$. Using the firm's first-order condition for profit-maximisation, equation ( $7 \mathrm{a}$ and $7 \mathrm{~b}$ ), and the assumption that the firm can choose the government expenditure to maximize profit, we can write:

$$
\begin{aligned}
& \alpha_{M K}=\frac{K_{M} R_{M} / F_{M}}{Y_{M}\left(1-T_{M}\right)} \\
& \alpha_{M L}=\frac{W_{M} L_{M} / F_{M}}{Y_{M}\left(1-T_{M}\right)}, \text { and } \\
& \alpha_{M G}=\frac{G R F_{M}}{Y_{M}\left(1-T_{M}\right)}
\end{aligned}
$$

and use data for the wage bill, capital income, government infrastructure expenditure and manufacturing output net of tax to compute the parameters.

Since we assume that firms in the interior region (the agricultural sector) choose only capital to maximise profits and pay all workers the average product after capital costs rather than paying a wage equal to the marginal product, we can derive the capital parameters for agriculture as we did for manufacturing:

$$
\alpha_{A K}=\frac{K_{A} R_{A} / F_{A}}{Y_{A}\left(1-T_{A}\right)}
$$

but can not derive production parameter $\alpha_{A L}$ for agricultural sector in the same way. 
Instead, we rely on previous work which has estimated agricultural production functions of the Cobb-Douglas type from which we obtain parameter values. In particular, we use a value of 0.25 for the labour parameter $\left(\alpha_{A L}\right)$ and 0.35 for the land parameter, based on values reported in Fan (1991) and derived capital parameters and use the constant-returns-to-scale assumption to derive the value for the government expenditure parameter $\left(\alpha_{A G}\right)$.

Given that the calibration of all the model parameters involve using conditions not strictly implied by the model, we will assess the sensitivity of the results we obtain by experimenting with a range of alternative values. The results of these experiments are reported in our account of robustness-testing in Appendix 3.

The linearisation parameters can be evaluated directly from their definitions, given values for $P, \theta, \mu, I I H_{i}, W_{i}, T_{v}, T_{j}, Y_{j}, \Pi F_{j}, L_{j}, K_{j}, R_{j}, N_{i}, G C_{i}, J_{i}, G R H_{i}, G R F_{i}$, $G H_{i}, F_{j}$ and $N_{i}$. We normalise $P$ at unity and also set the immigration parameter, $\mu$, at unity (although report experiments with different values for $\mu$ in Appendix 3); $\theta$ is set at 0.75 to reflect the current division of VAT revenue between the central and regional governments. We then use these assumed values and the data for $C_{i}, G R H_{i}, G R F_{j}$, $G C_{i}, K_{j}, R_{j}, N_{i}, W_{i}$ together with the model definitions to calculate the value of all other variables. The use of the model definitions ensures that the parameter values used in the simulations are consistent with the model constraints.

We therefore need data for two regions, the interior and the coast, for the variables $C_{i}, G R H_{i}, G R F_{j}, G C_{i}, K_{j}, R_{j}, N_{i}, W_{i}$. The data we use are based on those for the Chinese provinces which we have allocated to the two regions as follows. The coastal region consists of Beijing, Tianjin, Hebei, Guangdong, Hainan, Shandong, Fujian, Zhejiang, Jiangsu, Shanghai, Liaoning and Guangxi with the remaining provinces being allocated to the interior region. The interior therefore consists of: 
Shanxi, Inner Mongolia, Jilin, Heilongjiang, Anhui, Jiangxi, Henan, Hubei, Hunan, Sichuan, Chongqing, Guizhou, Yunnan, Shaanxi, Gansu, Qinghai, Ningxia, Tibet, Xinjiang.

For each region we use data averaged over the seven-year period 2000-2006 to avoid cyclical influences on the share parameters. All the data come from China Statistics Year Book (SSB, various issues) except for data on area used to compute population density for the migration equilibrium condition, equation (4), which come from China Civil Affairs Statistical Yearbook 2005 (SSB, 2005). 


\section{Appendix 3: Robustness tests}

To assess the robustness of the base-case results to our parameter choices and closure assumptions, we computed the following alternative simulations.

\section{A3.1 Manufacturing production function parameters}

We experimented with three alternative sets of values for the parameters of the manufacturing production function. Recall that we calibrated them on the assumption that firms could choose the value of the regional government's infrastructure expenditure so as to maximise profits and we assumed that in the initial situations it was so chosen. But, in fact, they cannot choose the level of infrastructure expenditure so that this assumption may lead to misleading results. The simulations with the alternative values are reported in Appendix 4, Tables 2, 3 and $4 .{ }^{19}$ Comparing the results to those in Table 1 in the text and Table 1 in Appendix 4 shows that our conclusions are not affected by these variations and therefore robust to the original assumption.

\section{A3.2 Agricultural production function parameters}

Alternative sets of values for the agricultural production function were used. This was necessary since we relied on others' estimates of these parameters because we could not infer them from our model implications and the data base. The effects of varying these (reported in Appendix 4 Tables 5 and 6) are not so large as to change the conclusions regarding the effectiveness of any of the policies.

\section{A3.3 Hukou parameters}

We used two alternative values for the hukou parameter, $\mu$, since it could not be calibrated from our data base. The results are reported in Tables 7 and 8 of Appendix 4. The effects on the policies of using a different underlying initial value of

\footnotetext{
${ }^{19}$ For the purposes of comparison, note that the values for the production function parameters implied by the calibration exercise are: $\alpha_{M L}=0.32, \alpha_{M K}=0.11, \alpha_{M G}=0.09, \alpha_{A L}=0.25, \alpha_{A K}=0.12$ and $\alpha_{A G}=0.28$.
} 
this parameter are trivial and do not change any conclusions.

\section{A3.4 Regional government closure assumptions}

The closure assumption for the interior regional government was changed. In all the policies except for policies 1 and 2 we had a choice of two endogenous variables to ensure the regional government's budget remains balanced: $g r f_{A}$ and $g r h_{I}$. In all cases we chose the latter as endogenous and the former as exogenous. But we saw in comparing policies 1 and 2 that these two components of regional government expenditure have very different effects so that we would expect this closure assumption to be far from innocuous. We therefore re-ran all policies except 1 and 2 with $\operatorname{grf}_{A}$ as the endogenous variable. The results are reported in Appendix 4 Table 9.

It is clear that our expectation of different results was fully justified. Thus, if the agricultural tax cut is matched by a reduction in infrastructure spending, the effects are quite serious for both regions - region 1 now suffers a large fall in output and both regions experience big reductions in welfare. The effect of an increase in agricultural productivity is also significantly affected by this change in closure assumption since the extra tax base created for the interior region by the productivity increase is used to increase infrastructure expenditure which, in turn, further boosts agricultural output. The signs of effects of the reduction in the hukou costs are unaffected except for the effect on agricultural output which is now positive despite the departure of agricultural workers to the coast. The reason is that the fewer people in the interior now require less resources devoted to government consumption, with the freed-up output being devoted to infrastructure which improves agricultural output by more than the fall occasioned by the departure of workers to the coast. On the other hand, the results for policy 6 (an increase in central government expenditure in the interior region) are little affected by this closure assumption except that, again, 
population movement (inward this time) necessitates greater resources being devoted to keep government consumption expenditure in the interior constant (since it is now exogenous) and this is at the expense of government expenditure on infrastructure which reduces agricultural output slightly. However, those for Policy 7 are importantly influenced since the central government-effected transfer from the coast to the interior is used by the interior government to boost infrastructure expenditure which enhances agricultural productivity and so output of the agricultural good. The effect is to increase welfare considerably in both regions, to increase per capita output in the interior region and to narrow the per capita output gap.

\section{A3.5 Maximising regional governments.}

We make regional governments behave strategically by assuming that they are empire-builders. In modelling terms, this makes them endogenous just as households and firms are. There are various objectives which might be assigned to governments. Governments might be assumed to be benevolent so that they maximise the welfare of their citizens - the welfare of the representative household in our model. An alternative which we follow in this Appendix is to assume that regional governments are empire-builders in that they make their fiscal decisions so as to maximise total expenditure - the size of their empire. We find this an interesting and plausible alternative - many would argue that, in the case of the Chinese provincial-level governments, it is more plausible than the beneficent alternative.

Recall that each regional government is faced with a budget constraint so that its expenditure is limited by its revenue which depends, in turn, on the regional tax rate (which is set by the central government) and the tax base. The tax base may be influenced by the amount of expenditure allocated to infrastructure expenditure which positively affects firms' output and therefore the tax base. Thus, each regional 
government is assumed to make its expenditure-mix decisions so as to maximize its total expenditure, subject to the constraints imposed by its budget constraint and the structure of its economy, as depicted in the model set out above. In carrying out its maximization process each regional government takes the fiscal decisions of the other as given. In effect, therefore, the two governments are engaged in a non-cooperative strategic game with a Nash equilibrium as the outcome.

Formally, the coastal regional government's choice problem is to choose the value of $G R F_{M}$ to maximise $G R F_{M}+N_{C} G R H_{C}$ which will have a first-order condition of the form:

$$
1+N_{C} \frac{\partial G R H_{C}}{\partial G R F_{M}}+G R H_{C} \frac{\partial N_{C}}{\partial G R F_{M}}=0
$$

A similar condition holds for the interior region's government:

$$
1+N_{I} \frac{\partial G R H_{I}}{\partial G R F_{A}}+G R H_{I} \frac{\partial N_{I}}{\partial G R F_{A}}=0
$$

Once we add these equations to the model, we will make $G R F_{M}$ and $G R F_{A}$ endogenous so that we will have 34 independent equations and 34 endogenous variables. The results are reported in Appendix 4 Table 10. Again, this is relevant only to policies 3-7 since policies 1 and 2 involve regional government policies which require the expenditure levels to be exogenous. The impact here is similar to that in the previous variation since it also allows regional government expenditure on infrastructure to be endogenous rather than constant in the background. This would suggest that it is not the strategic behaviour of regional governments as such that makes the difference but the endogenisation of infrastructure expenditure which allows governments to influence regional output and hence the size of their budget.

\section{A3.6 Alternative migration equilibrium assumption}

Finally, we experimented with an alternative migration equilibrium condition 
which involves wage rather than utility comparisons between the two regions. the results of this experiment are reported in Appendix 4 Table 11. Clearly this will make a difference only in the long run. The results are noticeably different (but only for some policies) since the short-run effects on wages are usually quite different to those on utility. Thus, in response to policy 1 utility moves slightly in favour of the interior setting off a small migration flow from the coastal to the inland provinces in the original simulations but wages move significantly in the opposite direction so that a substantial migration from the interior to the coast follows. This has implications for output, per capita output and welfare as a comparison of the relevant columns in Tables 1 and 11 shows. On the other hand, the results for policies 2, 3, 4 and 5 are largely unaffected. 
Appendix 4 Table 1: Base Case Results

\begin{tabular}{|c|c|c|c|c|c|c|c|c|}
\hline \multirow[t]{2}{*}{ Variables } & \multicolumn{2}{|c|}{$\begin{array}{c}\text { Policy 1: } \\
\operatorname{grh}_{\mathrm{I}}=1\end{array}$} & \multicolumn{2}{|c|}{$\begin{array}{c}\text { Policy 2: } \\
\operatorname{grf}_{A}=1\end{array}$} & \multicolumn{2}{|c|}{$\begin{array}{c}\text { Policy 3: } \\
t_{A}=-1\end{array}$} & \multicolumn{2}{|c|}{$\begin{array}{c}\text { Policy 4: } \\
d_{A}=1\end{array}$} \\
\hline & SR & LR & SR & LR & SR & LR & SR & LR \\
\hline$v_{I}$ & -0.0804 & -0.0876 & 0.0674 & 0.0729 & -0.0356 & -0.0215 & 0.4407 & 0.4103 \\
\hline $\mathbf{v}_{\mathrm{C}}$ & -0.1062 & -0.1014 & 0.0891 & 0.0844 & 0.0202 & 0.0082 & 0.3199 & 0.3458 \\
\hline $\mathrm{ca}_{\mathrm{I}}$ & -0.3577 & -0.3626 & 0.3001 & 0.3019 & 0.0679 & 0.0726 & 1.0776 & 1.0674 \\
\hline $\mathbf{c m}_{\mathrm{I}}$ & 0.0184 & 0.0081 & -0.0154 & -0.0068 & -0.0035 & 0.0188 & -0.0553 & -0.1035 \\
\hline $\mathbf{c a} \mathbf{a}_{\mathrm{C}}$ & -0.3577 & -0.3488 & 0.3001 & 0.2904 & 0.0679 & 0.0429 & 1.0776 & 1.1319 \\
\hline $\mathbf{c m}_{\mathrm{C}}$ & 0.0184 & 0.0220 & -0.0154 & -0.0183 & -0.0035 & -0.0110 & -0.0553 & -0.0391 \\
\hline $\mathbf{g h}_{\mathbf{I}}$ & 0.2780 & 0.2733 & -0.2332 & -0.2275 & -0.3321 & -0.3174 & 0.2537 & 0.2219 \\
\hline $\mathbf{g h}_{\mathbf{C}}$ & 0.0157 & 0.0158 & -0.0132 & -0.0132 & -0.0030 & -0.0030 & -0.0473 & -0.0471 \\
\hline $\mathbf{j}_{\mathbf{I}}$ & 0.0184 & 0.0081 & -0.0154 & -0.0068 & -0.0035 & 0.0188 & -0.0553 & -0.1035 \\
\hline $\mathbf{j}_{\mathbf{C}}$ & 0.0184 & 0.0220 & -0.0154 & -0.0183 & -0.0035 & -0.0110 & -0.0553 & -0.0391 \\
\hline$\pi \mathbf{h}_{\mathbf{I}}$ & -0.3577 & -0.3746 & 0.3001 & 0.3119 & 0.0679 & 0.0982 & 1.0776 & 1.0118 \\
\hline$\pi \mathbf{h}_{\mathbf{C}}$ & 0.0184 & 0.0237 & -0.0154 & -0.0198 & -0.0035 & -0.0147 & -0.0553 & -0.0310 \\
\hline $\mathbf{w}_{\text {I }}$ & -0.3577 & -0.3528 & 0.3001 & 0.2937 & 0.0679 & 0.0515 & 1.0776 & 1.1132 \\
\hline $\mathbf{w}_{\mathbf{C}}$ & 0.0184 & 0.0237 & -0.0154 & -0.0198 & -0.0035 & -0.0147 & -0.0553 & -0.0310 \\
\hline $\mathbf{y}_{\mathbf{A}}$ & -0.3577 & -0.3587 & 0.3001 & 0.2986 & 0.0049 & 0.0011 & 1.0776 & 1.0859 \\
\hline $\mathbf{y}_{\mathbf{M}}$ & 0.0184 & 0.0158 & -0.0154 & -0.0131 & -0.0035 & 0.0024 & -0.0553 & -0.0681 \\
\hline $\mathbf{l}_{\mathbf{A}}$ & 0.0000 & 0.0059 & 0.0000 & -0.0049 & 0.0000 & -0.0126 & 0.0000 & 0.0273 \\
\hline $\mathbf{l}_{M}$ & 0.0000 & -0.0080 & 0.0000 & 0.0066 & 0.0000 & 0.0171 & 0.0000 & -0.0371 \\
\hline $\mathbf{k}_{\mathbf{A}}$ & -0.2120 & -0.2110 & 0.1778 & 0.1757 & 0.0402 & 0.0348 & 0.6385 & 0.6504 \\
\hline $\mathbf{k}_{\mathbf{M}}$ & 0.1641 & 0.1634 & -0.1377 & -0.1360 & -0.0312 & -0.0269 & -0.4944 & -0.5036 \\
\hline $\mathbf{r}_{\mathrm{A}}$ & -0.1458 & -0.1476 & 0.1223 & 0.1229 & 0.0277 & 0.0293 & 0.4391 & 0.4355 \\
\hline $\mathbf{r}_{M}$ & -0.1458 & -0.1476 & 0.1223 & 0.1229 & 0.0277 & 0.0293 & 0.4391 & 0.4355 \\
\hline$\pi \mathbf{f}_{\mathrm{A}}$ & -0.3577 & -0.3687 & 0.3001 & 0.3070 & 0.0679 & 0.0856 & 1.0776 & 1.0391 \\
\hline$\pi \mathbf{f}_{\mathrm{M}}$ & 0.0184 & 0.0158 & -0.0154 & -0.0131 & -0.0035 & 0.0024 & -0.0553 & -0.0681 \\
\hline $\mathbf{P}$ & 0.3761 & 0.3707 & -0.3155 & -0.3087 & -0.0714 & -0.0538 & -1.1329 & -1.1710 \\
\hline $\operatorname{grh}_{I}$ & 1.0000 & 1.0000 & -0.8389 & -0.8325 & -1.3104 & -1.2941 & 1.3656 & 1.3302 \\
\hline $\operatorname{grf}_{\mathbf{A}}$ & -1.1921 & -1.2012 & 1.0000 & 1.0000 & 0.0000 & 0.0000 & 0.0000 & 0.0000 \\
\hline $\operatorname{grh}_{C}$ & 0.0449 & 0.0453 & -0.0376 & -0.0377 & -0.0085 & -0.0087 & -0.1352 & -0.1348 \\
\hline $\operatorname{grf}_{M}$ & 0.0000 & 0.0000 & 0.0000 & 0.0000 & 0.0000 & 0.0000 & 0.0000 & 0.0000 \\
\hline $\mathrm{gc}_{\mathrm{I}}$ & 0.0383 & 0.0320 & -0.0321 & -0.0266 & -0.0073 & 0.0069 & -0.1154 & -0.1460 \\
\hline$g_{C}$ & 0.0000 & 0.0000 & 0.0000 & 0.0000 & 0.0000 & 0.0000 & 0.0000 & 0.0000 \\
\hline $\mathbf{f}_{\mathrm{A}}$ & 0.0000 & 0.0000 & 0.0000 & 0.0000 & 0.0000 & 0.0000 & 0.0000 & 0.0000 \\
\hline $\mathbf{f}_{M}$ & 0.0000 & 0.0000 & 0.0000 & 0.0000 & 0.0000 & 0.0000 & 0.0000 & 0.0000 \\
\hline$d_{A}$ & 0.0000 & 0.0000 & 0.0000 & 0.0000 & 0.0000 & 0.0000 & 1.0000 & 1.0000 \\
\hline $\mathbf{d}_{\mathbf{M}}$ & 0.0000 & 0.0000 & 0.0000 & 0.0000 & 0.0000 & 0.0000 & 0.0000 & 0.0000 \\
\hline $\mathbf{t}_{\mathrm{A}}$ & 0.0000 & 0.0000 & 0.0000 & 0.0000 & -1.0000 & -1.0000 & 0.0000 & 0.0000 \\
\hline $\mathbf{t}_{M}$ & 0.0000 & 0.0000 & 0.0000 & 0.0000 & 0.0000 & 0.0000 & 0.0000 & 0.0000 \\
\hline$\theta *{ }_{I}$ & 0.0000 & 0.0000 & 0.0000 & 0.0000 & 0.0000 & 0.0000 & 0.0000 & 0.0000 \\
\hline$\theta^{*}{ }_{C}$ & 0.0000 & 0.0000 & 0.0000 & 0.0000 & 0.0000 & 0.0000 & 0.0000 & 0.0000 \\
\hline $\mathbf{t}_{\mathbf{v}}$ & 0.0000 & 0.0000 & 0.0000 & 0.0000 & 0.0000 & 0.0000 & 0.0000 & 0.0000 \\
\hline n & 0.0000 & 0.0000 & 0.0000 & 0.0000 & 0.0000 & 0.0000 & 0.0000 & 0.0000 \\
\hline$\mu^{*}$ & 0.0000 & 0.0000 & 0.0000 & 0.0000 & 0.0000 & 0.0000 & 0.0000 & 0.0000 \\
\hline k & 0.0000 & 0.0000 & 0.0000 & 0.0000 & 0.0000 & 0.0000 & 0.0000 & 0.0000 \\
\hline
\end{tabular}


Appendix 4 Table 1(cont'd): Base Case Results

\begin{tabular}{|c|c|c|c|c|c|c|}
\hline \multirow[t]{2}{*}{ Variables } & \multicolumn{2}{|c|}{$\begin{array}{c}\text { Policy 5: } \\
\mu^{*=-1}\end{array}$} & \multicolumn{2}{|c|}{$\begin{array}{c}\text { Policy 6: } \\
\mathrm{gc}_{\mathrm{I}}=1\end{array}$} & \multicolumn{2}{|c|}{$\begin{array}{c}\text { Policy 7: } \\
\theta *{ }_{I}=-1, \theta^{*}{ }_{C}=0.8013\end{array}$} \\
\hline & SR & LR & SR & LR & SR & LR \\
\hline $\mathbf{V}_{\text {I }}$ & 0.0000 & 0.3782 & 0.1366 & 0.0807 & 0.1300 & 0.0721 \\
\hline $\mathbf{v}_{\mathbf{C}}$ & 0.0000 & -0.3220 & -0.1049 & -0.0565 & -0.0998 & -0.0504 \\
\hline $\mathbf{c a}_{\mathbf{I}}$ & 0.0000 & 0.1263 & 0.0000 & -0.0217 & 0.0000 & -0.0193 \\
\hline $\mathbf{c m}_{I}$ & 0.0000 & 0.5987 & 0.0000 & -0.1027 & 0.0000 & -0.0917 \\
\hline $\mathbf{c a}_{\mathrm{C}}$ & 0.0000 & -0.6735 & 0.0000 & 0.1155 & 0.0000 & 0.1032 \\
\hline $\mathbf{c m}_{\mathrm{C}}$ & 0.0000 & -0.2011 & 0.0000 & 0.0345 & 0.0000 & 0.0308 \\
\hline $\mathbf{g h}_{\mathbf{I}}$ & 0.0000 & 0.3949 & 0.7508 & 0.7320 & 0.7143 & 0.6538 \\
\hline $\mathbf{g h}_{\mathbf{C}}$ & 0.0000 & -0.0017 & -0.5986 & -0.6373 & -0.5695 & -0.5692 \\
\hline $\mathbf{j}_{\mathbf{I}}$ & 0.0000 & 0.5987 & 0.0000 & -0.1027 & 0.0000 & -0.0917 \\
\hline $\mathbf{j}_{\mathbf{C}}$ & 0.0000 & -0.2011 & 0.0000 & 0.0345 & 0.0000 & 0.0308 \\
\hline$\pi \mathbf{h}_{\mathbf{I}}$ & 0.0000 & 0.8168 & 0.0000 & -0.1401 & 0.0000 & -0.1251 \\
\hline $\boldsymbol{\pi} \mathbf{h}_{\mathrm{C}}$ & 0.0000 & -0.3020 & 0.0000 & 0.0518 & 0.0000 & 0.0463 \\
\hline $\mathbf{w}_{\text {I }}$ & 0.0000 & -0.4420 & 0.0000 & 0.0758 & 0.0000 & 0.0677 \\
\hline $\mathbf{w}_{\mathbf{C}}$ & 0.0000 & -0.3020 & 0.0000 & 0.0518 & 0.0000 & 0.0463 \\
\hline $\mathbf{y}_{\mathbf{A}}$ & 0.0000 & -0.1027 & 0.0000 & 0.0176 & 0.0000 & 0.0157 \\
\hline $\mathbf{y}_{\mathbf{M}}$ & 0.0000 & 0.1584 & 0.0000 & -0.0272 & 0.0000 & -0.0243 \\
\hline $\mathbf{l}_{\mathrm{A}}$ & 0.0000 & -0.3393 & 0.0000 & 0.0582 & 0.0000 & 0.0520 \\
\hline $\mathbf{l}_{M}$ & 0.0000 & 0.4605 & 0.0000 & -0.0790 & 0.0000 & -0.0705 \\
\hline $\mathbf{k}_{\mathbf{A}}$ & 0.0000 & -0.1472 & 0.0000 & 0.0252 & 0.0000 & 0.0225 \\
\hline $\mathbf{k}_{\mathbf{M}}$ & 0.0000 & 0.1140 & 0.0000 & -0.0195 & 0.0000 & -0.0175 \\
\hline $\mathbf{r}_{\mathbf{A}}$ & 0.0000 & 0.0445 & 0.0000 & -0.0076 & 0.0000 & -0.0068 \\
\hline $\mathbf{r}_{\mathbf{M}}$ & 0.0000 & 0.0445 & 0.0000 & -0.0076 & 0.0000 & -0.0068 \\
\hline $\boldsymbol{\pi} \mathbf{f}_{\mathrm{A}}$ & 0.0000 & 0.4775 & 0.0000 & -0.0819 & 0.0000 & -0.0731 \\
\hline$\pi \mathbf{f}_{M}$ & 0.0000 & 0.1584 & 0.0000 & -0.0272 & 0.0000 & -0.0243 \\
\hline $\mathbf{P}$ & 0.0000 & 0.4724 & 0.0000 & -0.0810 & 0.0000 & -0.0724 \\
\hline $\operatorname{grh}_{I}$ & 0.0000 & 0.4392 & 0.0000 & -0.0753 & 2.7164 & 2.6491 \\
\hline $\operatorname{grf}_{\mathbf{A}}$ & 0.0000 & 0.0000 & 0.0000 & 0.0000 & 0.0000 & 0.0000 \\
\hline $\operatorname{grh}_{\mathrm{C}}$ & 0.0000 & -0.0049 & 0.0000 & 0.0008 & -1.6285 & -1.6278 \\
\hline $\operatorname{grf}_{M}$ & 0.0000 & 0.0000 & 0.0000 & 0.0000 & 0.0000 & 0.0000 \\
\hline $\mathbf{g c}_{\mathrm{I}}$ & 0.0000 & 0.3802 & 1.0000 & 1.0000 & 0.0496 & -0.0087 \\
\hline $\mathbf{g c}_{\mathrm{C}}$ & 0.0000 & 0.0000 & -0.9205 & -0.9805 & 0.0000 & 0.0000 \\
\hline $\mathbf{f}_{\mathrm{A}}$ & 0.0000 & 0.0000 & 0.0000 & 0.0000 & 0.0000 & 0.0000 \\
\hline $\mathbf{f}_{M}$ & 0.0000 & 0.0000 & 0.0000 & 0.0000 & 0.0000 & 0.0000 \\
\hline $\mathbf{d}_{\mathbf{A}}$ & 0.0000 & 0.0000 & 0.0000 & 0.0000 & 0.0000 & 0.0000 \\
\hline $\mathbf{d}_{\mathbf{M}}$ & 0.0000 & 0.0000 & 0.0000 & 0.0000 & 0.0000 & 0.0000 \\
\hline $\mathbf{t}_{\mathrm{A}}$ & 0.0000 & 0.0000 & 0.0000 & 0.0000 & 0.0000 & 0.0000 \\
\hline $\mathbf{t}_{M}$ & 0.0000 & 0.0000 & 0.0000 & 0.0000 & 0.0000 & 0.0000 \\
\hline$\theta *_{I}$ & 0.0000 & 0.0000 & 0.0000 & 0.0000 & -1.0000 & -1.0000 \\
\hline$\theta^{*}{ }_{C}$ & 0.0000 & 0.0000 & 0.0000 & 0.0000 & 0.8031 & 0.8031 \\
\hline $\mathbf{t}_{\mathbf{V}}$ & 0.0000 & 0.0000 & 0.0000 & 0.0000 & 0.0000 & 0.0000 \\
\hline $\mathbf{n}$ & 0.0000 & 0.0000 & 0.0000 & 0.0000 & 0.0000 & 0.0000 \\
\hline$\mu^{*}$ & -1.0000 & -1.0000 & 0.0000 & 0.0000 & 0.0000 & 0.0000 \\
\hline $\mathbf{k}$ & 0.0000 & 0.0000 & 0.0000 & 0.0000 & 0.0000 & 0.0000 \\
\hline
\end{tabular}




\begin{tabular}{|c|c|c|c|c|c|c|c|c|}
\hline \multirow[t]{2}{*}{ Variables } & \multicolumn{2}{|c|}{$\begin{array}{c}\text { Policy 1: } \\
\operatorname{grh}_{\mathrm{I}}=1\end{array}$} & \multicolumn{2}{|c|}{$\begin{array}{c}\text { Policy 2: } \\
\operatorname{grf}_{\mathbf{A}}=1\end{array}$} & \multicolumn{2}{|c|}{$\begin{array}{c}\text { Policy 3: } \\
t_{A}=-1\end{array}$} & \multicolumn{2}{|c|}{$\begin{array}{c}\text { Policy 4: } \\
d_{A}=1\end{array}$} \\
\hline & SR & LR & SR & LR & SR & LR & SR & LR \\
\hline$v_{I}$ & -0.0806 & -0.0878 & 0.0676 & 0.0731 & -0.0355 & -0.0214 & 0.4414 & 0.4109 \\
\hline $\mathbf{v}_{\mathbf{C}}$ & -0.1064 & -0.1017 & 0.0892 & 0.0846 & 0.0202 & 0.0083 & 0.3205 & 0.3464 \\
\hline $\mathbf{c a}_{\text {I }}$ & -0.3578 & -0.3627 & 0.3001 & 0.3019 & 0.0679 & 0.0726 & 1.0775 & 1.0674 \\
\hline $\mathbf{c m}_{\mathrm{I}}$ & 0.0180 & 0.0078 & -0.0151 & -0.0065 & -0.0034 & 0.0189 & -0.0543 & -0.1027 \\
\hline $\mathbf{c a}_{\mathrm{C}}$ & -0.3578 & -0.3489 & 0.3001 & 0.2904 & 0.0679 & 0.0429 & 1.0775 & 1.1318 \\
\hline $\mathbf{c m}_{\mathrm{C}}$ & 0.0180 & 0.0216 & -0.0151 & -0.0180 & -0.0034 & -0.0108 & -0.0543 & -0.0382 \\
\hline $\mathbf{g h}_{\mathbf{I}}$ & 0.2775 & 0.2727 & -0.2327 & -0.2270 & -0.3320 & -0.3172 & 0.2554 & 0.2234 \\
\hline $\mathbf{g h}_{\mathbf{C}}$ & 0.0154 & 0.0156 & -0.0129 & -0.0129 & -0.0029 & -0.0029 & -0.0465 & -0.0464 \\
\hline $\mathbf{j}_{\mathbf{I}}$ & 0.0180 & 0.0078 & -0.0151 & -0.0065 & -0.0034 & 0.0189 & -0.0543 & -0.1027 \\
\hline $\mathbf{j}_{\mathbf{C}}$ & 0.0180 & 0.0216 & -0.0151 & -0.0180 & -0.0034 & -0.0108 & -0.0543 & -0.0382 \\
\hline$\pi \mathbf{h}_{\mathbf{I}}$ & -0.3578 & -0.3746 & 0.3001 & 0.3118 & 0.0679 & 0.0982 & 1.0775 & 1.0117 \\
\hline$\pi \mathbf{h}_{\mathbf{C}}$ & 0.0180 & 0.0234 & -0.0151 & -0.0195 & -0.0034 & -0.0146 & -0.0543 & -0.0301 \\
\hline $\mathbf{w}_{\mathrm{I}}$ & -0.3578 & -0.3529 & 0.3001 & 0.2937 & 0.0679 & 0.0515 & 1.0775 & 1.1132 \\
\hline $\mathbf{w}_{\mathbf{C}}$ & 0.0180 & 0.0234 & -0.0151 & -0.0195 & -0.0034 & -0.0146 & -0.0543 & -0.0301 \\
\hline $\mathbf{y}_{\mathbf{A}}$ & -0.3578 & -0.3587 & 0.3001 & 0.2986 & 0.0049 & 0.0011 & 1.0775 & 1.0858 \\
\hline $\mathbf{y}_{\mathbf{M}}$ & 0.0180 & 0.0154 & -0.0151 & -0.0128 & -0.0034 & 0.0025 & -0.0543 & -0.0672 \\
\hline $\mathbf{I}_{\mathrm{A}}$ & 0.0000 & 0.0059 & 0.0000 & -0.0049 & 0.0000 & -0.0126 & 0.0000 & 0.0274 \\
\hline $\mathbf{l}_{M}$ & 0.0000 & -0.0080 & 0.0000 & 0.0066 & 0.0000 & 0.0171 & 0.0000 & -0.0371 \\
\hline $\mathbf{k}_{\mathbf{A}}$ & -0.2118 & -0.2109 & 0.1776 & 0.1755 & 0.0402 & 0.0347 & 0.6379 & 0.6499 \\
\hline $\mathbf{k}_{\mathbf{M}}$ & 0.1640 & 0.1633 & -0.1375 & -0.1359 & -0.0311 & -0.0269 & -0.4939 & -0.5032 \\
\hline $\mathbf{r}_{\mathrm{A}}$ & -0.1460 & -0.1479 & 0.1224 & 0.1231 & 0.0277 & 0.0294 & 0.4396 & 0.4359 \\
\hline $\mathbf{r}_{M}$ & -0.1460 & -0.1479 & 0.1224 & 0.1231 & 0.0277 & 0.0294 & 0.4396 & 0.4359 \\
\hline $\boldsymbol{\pi \mathbf { f } _ { \mathrm { A } }}$ & -0.3578 & -0.3688 & 0.3001 & 0.3069 & 0.0679 & 0.0856 & 1.0775 & 1.0391 \\
\hline$\pi \mathbf{f}_{M}$ & 0.0180 & 0.0154 & -0.0151 & -0.0128 & -0.0034 & 0.0025 & -0.0543 & -0.0672 \\
\hline $\mathbf{P}$ & 0.3758 & 0.3705 & -0.3152 & -0.3084 & -0.0713 & -0.0537 & -1.1319 & -1.1701 \\
\hline $\operatorname{grh}_{I}$ & 1.0000 & 1.0000 & -0.8387 & -0.8323 & -1.3104 & -1.2940 & 1.3663 & 1.3308 \\
\hline $\operatorname{grf}_{\mathbf{A}}$ & -1.1924 & -1.2015 & 1.0000 & 1.0000 & 0.0000 & 0.0000 & 0.0000 & 0.0000 \\
\hline $\operatorname{grh}_{C}$ & 0.0441 & 0.0445 & -0.0370 & -0.0370 & -0.0084 & -0.0084 & -0.1328 & -0.1327 \\
\hline $\operatorname{grf}_{M}$ & 0.0000 & 0.0000 & 0.0000 & 0.0000 & 0.0000 & 0.0000 & 0.0000 & 0.0000 \\
\hline $\mathbf{g c}_{\mathbf{I}}$ & 0.0376 & 0.0313 & -0.0316 & -0.0260 & -0.0071 & 0.0071 & -0.1134 & -0.1443 \\
\hline $\mathbf{g c}_{\mathrm{C}}$ & 0.0000 & 0.0000 & 0.0000 & 0.0000 & 0.0000 & 0.0000 & 0.0000 & 0.0000 \\
\hline $\mathbf{f}_{\mathrm{A}}$ & 0.0000 & 0.0000 & 0.0000 & 0.0000 & 0.0000 & 0.0000 & 0.0000 & 0.0000 \\
\hline $\mathbf{f}_{M}$ & 0.0000 & 0.0000 & 0.0000 & 0.0000 & 0.0000 & 0.0000 & 0.0000 & 0.0000 \\
\hline $\mathbf{d}_{\mathbf{A}}$ & 0.0000 & 0.0000 & 0.0000 & 0.0000 & 0.0000 & 0.0000 & 1.0000 & 1.0000 \\
\hline$d_{M}$ & 0.0000 & 0.0000 & 0.0000 & 0.0000 & 0.0000 & 0.0000 & 0.0000 & 0.0000 \\
\hline$t_{A}$ & 0.0000 & 0.0000 & 0.0000 & 0.0000 & -1.0000 & -1.0000 & 0.0000 & 0.0000 \\
\hline $\mathbf{t}_{M}$ & 0.0000 & 0.0000 & 0.0000 & 0.0000 & 0.0000 & 0.0000 & 0.0000 & 0.0000 \\
\hline$\theta *{ }_{I}$ & 0.0000 & 0.0000 & 0.0000 & 0.0000 & 0.0000 & 0.0000 & 0.0000 & 0.0000 \\
\hline$\theta^{*}{ }_{C}$ & 0.0000 & 0.0000 & 0.0000 & 0.0000 & 0.0000 & 0.0000 & 0.0000 & 0.0000 \\
\hline $\mathbf{t}_{\mathrm{V}}$ & 0.0000 & 0.0000 & 0.0000 & 0.0000 & 0.0000 & 0.0000 & 0.0000 & 0.0000 \\
\hline n & 0.0000 & 0.0000 & 0.0000 & 0.0000 & 0.0000 & 0.0000 & 0.0000 & 0.0000 \\
\hline$\mu^{*}$ & 0.0000 & 0.0000 & 0.0000 & 0.0000 & 0.0000 & 0.0000 & 0.0000 & 0.0000 \\
\hline $\mathbf{k}$ & 0.0000 & 0.0000 & 0.0000 & 0.0000 & 0.0000 & 0.0000 & 0.0000 & 0.0000 \\
\hline
\end{tabular}




\begin{tabular}{|c|c|c|c|c|c|c|}
\hline \multirow[t]{2}{*}{ Variables } & \multicolumn{2}{|c|}{$\begin{array}{c}\text { Policy 5: } \\
\mu^{*}=-1\end{array}$} & \multicolumn{2}{|c|}{$\begin{array}{c}\text { Policy 6: } \\
\operatorname{gc}_{\mathrm{I}}=1\end{array}$} & \multicolumn{2}{|c|}{$\begin{array}{c}\text { Policy 7: } \\
\theta^{*}=-1, \theta^{*}{ }_{C}=0.8013\end{array}$} \\
\hline & SR & LR & SR & LR & SR & LR \\
\hline$v_{I}$ & 0.0000 & 0.3793 & 0.1366 & 0.0805 & 0.1297 & 0.0717 \\
\hline $\mathbf{v}_{\mathbf{C}}$ & 0.0000 & -0.3211 & -0.1049 & -0.0567 & -0.0995 & -0.0505 \\
\hline $\mathrm{ca}_{\mathrm{I}}$ & 0.0000 & 0.1261 & 0.0000 & -0.0216 & 0.0000 & -0.0193 \\
\hline $\mathbf{c m}_{I}$ & 0.0000 & 0.6001 & 0.0000 & -0.1030 & 0.0000 & -0.0917 \\
\hline $\mathrm{ca}_{\mathrm{C}}$ & 0.0000 & -0.6736 & 0.0000 & 0.1156 & 0.0000 & 0.1029 \\
\hline $\mathbf{c m}_{\mathrm{C}}$ & 0.0000 & -0.1996 & 0.0000 & 0.0342 & 0.0000 & 0.0305 \\
\hline $\mathbf{g h}_{\mathrm{I}}$ & 0.0000 & 0.3976 & 0.7508 & 0.7319 & 0.7127 & 0.6519 \\
\hline $\mathbf{g h}_{\mathrm{C}}$ & 0.0000 & -0.0004 & -0.5986 & -0.6379 & -0.5682 & -0.5681 \\
\hline $\mathbf{j}_{\mathbf{I}}$ & 0.0000 & 0.6001 & 0.0000 & -0.1030 & 0.0000 & -0.0917 \\
\hline $\mathbf{j}_{\mathbf{C}}$ & 0.0000 & -0.1996 & 0.0000 & 0.0342 & 0.0000 & 0.0305 \\
\hline$\pi \mathbf{h}_{\mathbf{I}}$ & 0.0000 & 0.8166 & 0.0000 & -0.1401 & 0.0000 & -0.1248 \\
\hline$\pi \mathbf{h}_{\mathbf{C}}$ & 0.0000 & -0.3005 & 0.0000 & 0.0516 & 0.0000 & 0.0459 \\
\hline $\mathbf{w}_{\mathbf{I}}$ & 0.0000 & -0.4421 & 0.0000 & 0.0759 & 0.0000 & 0.0676 \\
\hline $\mathbf{w}_{\mathbf{C}}$ & 0.0000 & -0.3005 & 0.0000 & 0.0516 & 0.0000 & 0.0459 \\
\hline $\mathbf{y}_{\mathbf{A}}$ & 0.0000 & -0.1028 & 0.0000 & 0.0176 & 0.0000 & 0.0157 \\
\hline $\mathbf{y}_{M}$ & 0.0000 & 0.1600 & 0.0000 & -0.0274 & 0.0000 & -0.0244 \\
\hline$l_{A}$ & 0.0000 & -0.3393 & 0.0000 & 0.0582 & 0.0000 & 0.0518 \\
\hline$I_{M}$ & 0.0000 & 0.4604 & 0.0000 & -0.0790 & 0.0000 & -0.0704 \\
\hline $\mathbf{k}_{\mathbf{A}}$ & 0.0000 & -0.1481 & 0.0000 & 0.0254 & 0.0000 & 0.0226 \\
\hline $\mathbf{k}_{\mathbf{M}}$ & 0.0000 & 0.1147 & 0.0000 & -0.0197 & 0.0000 & -0.0175 \\
\hline $\mathbf{r}_{\mathrm{A}}$ & 0.0000 & 0.0453 & 0.0000 & -0.0078 & 0.0000 & -0.0069 \\
\hline $\mathbf{r}_{M}$ & 0.0000 & 0.0453 & 0.0000 & -0.0078 & 0.0000 & -0.0069 \\
\hline$\pi \mathbf{f}_{\mathrm{A}}$ & 0.0000 & 0.4773 & 0.0000 & -0.0819 & 0.0000 & -0.0729 \\
\hline$\pi \mathrm{f}_{M}$ & 0.0000 & 0.1600 & 0.0000 & -0.0274 & 0.0000 & -0.0244 \\
\hline $\mathbf{P}$ & 0.0000 & 0.4740 & 0.0000 & -0.0813 & 0.0000 & -0.0724 \\
\hline $\operatorname{grh}_{I}$ & 0.0000 & 0.4404 & 0.0000 & -0.0756 & 2.7164 & 2.6491 \\
\hline $\operatorname{grf}_{A}$ & 0.0000 & 0.0000 & 0.0000 & 0.0000 & 0.0000 & 0.0000 \\
\hline $\operatorname{grh}_{\mathrm{C}}$ & 0.0000 & -0.0012 & 0.0000 & 0.0002 & -1.6249 & -1.6247 \\
\hline $\operatorname{grf}_{M}$ & 0.0000 & 0.0000 & 0.0000 & 0.0000 & 0.0000 & 0.0000 \\
\hline $\mathrm{gc}_{\mathrm{I}}$ & 0.0000 & 0.3834 & 1.0000 & 1.0000 & 0.0474 & -0.0112 \\
\hline $\mathrm{gc}_{\mathrm{C}}$ & 0.0000 & 0.0000 & -0.9205 & -0.9810 & 0.0000 & 0.0000 \\
\hline $\mathbf{f}_{\mathrm{A}}$ & 0.0000 & 0.0000 & 0.0000 & 0.0000 & 0.0000 & 0.0000 \\
\hline $\mathbf{f}_{M}$ & 0.0000 & 0.0000 & 0.0000 & 0.0000 & 0.0000 & 0.0000 \\
\hline$d_{A}$ & 0.0000 & 0.0000 & 0.0000 & 0.0000 & 0.0000 & 0.0000 \\
\hline$d_{M}$ & 0.0000 & 0.0000 & 0.0000 & 0.0000 & 0.0000 & 0.0000 \\
\hline$t_{A}$ & 0.0000 & 0.0000 & 0.0000 & 0.0000 & 0.0000 & 0.0000 \\
\hline$t_{M}$ & 0.0000 & 0.0000 & 0.0000 & 0.0000 & 0.0000 & 0.0000 \\
\hline$\theta *{ }_{I}$ & 0.0000 & 0.0000 & 0.0000 & 0.0000 & -1.0000 & -1.0000 \\
\hline$\theta *{ }_{C}$ & 0.0000 & 0.0000 & 0.0000 & 0.0000 & 0.8013 & 0.8013 \\
\hline $\mathbf{t}_{\mathrm{v}}$ & 0.0000 & 0.0000 & 0.0000 & 0.0000 & 0.0000 & 0.0000 \\
\hline $\mathrm{n}$ & 0.0000 & 0.0000 & 0.0000 & 0.0000 & 0.0000 & 0.0000 \\
\hline$\mu^{*}$ & -1.0000 & -1.0000 & 0.0000 & 0.0000 & 0.0000 & 0.0000 \\
\hline $\mathbf{k}$ & 0.0000 & 0.0000 & 0.0000 & 0.0000 & 0.0000 & 0.0000 \\
\hline
\end{tabular}




\begin{tabular}{|c|c|c|c|c|c|c|c|c|}
\hline \multirow[t]{2}{*}{ Variables } & \multicolumn{2}{|c|}{$\begin{array}{c}\text { Policy 1: } \\
\operatorname{grh}_{\mathrm{I}}=1\end{array}$} & \multicolumn{2}{|c|}{$\begin{array}{c}\text { Policy 2: } \\
\operatorname{grf}_{A}=1\end{array}$} & \multicolumn{2}{|c|}{$\begin{array}{c}\text { Policy 3: } \\
t_{A}=-1\end{array}$} & \multicolumn{2}{|c|}{$\begin{array}{c}\text { Policy 4: } \\
d_{A}=1\end{array}$} \\
\hline & SR & LR & SR & LR & SR & LR & SR & LR \\
\hline$v_{I}$ & -0.0606 & -0.0684 & 0.0519 & 0.0581 & -0.0391 & -0.0244 & 0.3848 & 0.3553 \\
\hline $\mathbf{v}_{\mathbf{C}}$ & -0.0884 & -0.0834 & 0.0757 & 0.0708 & 0.0171 & 0.0055 & 0.2719 & 0.2952 \\
\hline $\mathbf{c a}_{\mathbf{I}}$ & -0.3523 & -0.3576 & 0.3017 & 0.3036 & 0.0683 & 0.0729 & 1.0833 & 1.0739 \\
\hline $\mathbf{c m}_{I}$ & 0.0431 & 0.0319 & -0.0369 & -0.0271 & -0.0084 & 0.0148 & -0.1327 & -0.1791 \\
\hline $\mathbf{c a} \mathbf{a}_{\mathbf{C}}$ & -0.3523 & -0.3427 & 0.3017 & 0.2909 & 0.0683 & 0.0430 & 1.0833 & 1.1340 \\
\hline $\mathbf{c m}_{\mathrm{C}}$ & 0.0431 & 0.0469 & -0.0369 & -0.0398 & -0.0084 & -0.0152 & -0.1327 & -0.1190 \\
\hline $\mathbf{g h}_{\mathrm{I}}$ & 0.3168 & 0.3115 & -0.2713 & -0.2645 & -0.3407 & -0.3246 & 0.1170 & 0.0847 \\
\hline $\mathbf{g h}_{\mathbf{C}}$ & 0.0369 & 0.0369 & -0.0316 & -0.0313 & -0.0072 & -0.0066 & -0.1134 & -0.1145 \\
\hline $\mathbf{j}_{\mathbf{I}}$ & 0.0431 & 0.0319 & -0.0369 & -0.0271 & -0.0084 & 0.0148 & -0.1327 & -0.1791 \\
\hline $\mathbf{j}_{\mathbf{C}}$ & 0.0431 & 0.0469 & -0.0369 & -0.0398 & -0.0084 & -0.0152 & -0.1327 & -0.1190 \\
\hline$\pi \mathbf{h}_{\mathbf{I}}$ & -0.3523 & -0.3705 & 0.3017 & 0.3146 & 0.0683 & 0.0988 & 1.0833 & 1.0220 \\
\hline$\pi \mathbf{h}_{\mathbf{C}}$ & 0.0431 & 0.0488 & -0.0369 & -0.0414 & -0.0084 & -0.0189 & -0.1327 & -0.1114 \\
\hline $\mathbf{w}_{\text {I }}$ & -0.3523 & -0.3470 & 0.3017 & 0.2946 & 0.0683 & 0.0517 & 1.0833 & 1.1166 \\
\hline $\mathbf{w}_{\mathbf{C}}$ & 0.0431 & 0.0488 & -0.0369 & -0.0414 & -0.0084 & -0.0189 & -0.1327 & -0.1114 \\
\hline $\mathbf{y}_{\mathbf{A}}$ & -0.3523 & -0.3533 & 0.3017 & 0.3000 & 0.0053 & 0.0014 & 1.0833 & 1.0911 \\
\hline$y_{M}$ & 0.0431 & 0.0402 & -0.0369 & -0.0341 & -0.0084 & -0.0017 & -0.1327 & -0.1461 \\
\hline $\mathbf{l}_{\mathrm{A}}$ & 0.0000 & 0.0064 & 0.0000 & -0.0054 & 0.0000 & -0.0127 & 0.0000 & 0.0255 \\
\hline$I_{M}$ & 0.0000 & -0.0086 & 0.0000 & 0.0073 & 0.0000 & 0.0172 & 0.0000 & -0.0346 \\
\hline $\mathbf{k}_{\mathbf{A}}$ & -0.2229 & -0.2218 & 0.1908 & 0.1883 & 0.0432 & 0.0372 & 0.6853 & 0.6973 \\
\hline $\mathbf{k}_{\mathbf{M}}$ & 0.1726 & 0.1717 & -0.1478 & -0.1458 & -0.0334 & -0.0288 & -0.5306 & -0.5399 \\
\hline $\mathbf{r}_{\mathrm{A}}$ & -0.1294 & -0.1316 & 0.1108 & 0.1117 & 0.0251 & 0.0271 & 0.3980 & 0.3938 \\
\hline $\mathbf{r}_{M}$ & -0.1294 & -0.1316 & 0.1108 & 0.1117 & 0.0251 & 0.0271 & 0.3980 & 0.3938 \\
\hline$\pi f_{A}$ & -0.3523 & -0.3642 & 0.3017 & 0.3092 & 0.0683 & 0.0861 & 1.0833 & 1.0475 \\
\hline$\pi f_{M}$ & 0.0431 & 0.0402 & -0.0369 & -0.0341 & -0.0084 & -0.0017 & -0.1327 & -0.1461 \\
\hline $\mathbf{P}$ & 0.3954 & 0.3896 & -0.3386 & -0.3308 & -0.0766 & -0.0581 & -1.2159 & -1.2531 \\
\hline $\operatorname{grh}_{I}$ & 1.0000 & 1.0000 & -0.8563 & -0.8491 & -1.3144 & -1.2973 & 1.3030 & 1.2688 \\
\hline $\operatorname{grf}_{\mathbf{A}}$ & -1.1678 & -1.1778 & 1.0000 & 1.0000 & 0.0000 & 0.0000 & 0.0000 & 0.0000 \\
\hline $\operatorname{grh}_{C}$ & 0.1055 & 0.1056 & -0.0903 & -0.0896 & -0.0204 & -0.0188 & -0.3243 & -0.3276 \\
\hline $\operatorname{grf}_{M}$ & 0.0000 & 0.0000 & 0.0000 & 0.0000 & 0.0000 & 0.0000 & 0.0000 & 0.0000 \\
\hline$g c_{I}$ & 0.0900 & 0.0829 & -0.0771 & -0.0704 & -0.0174 & -0.0017 & -0.2768 & -0.3085 \\
\hline$g_{C}$ & 0.0000 & 0.0000 & 0.0000 & 0.0000 & 0.0000 & 0.0000 & 0.0000 & 0.0000 \\
\hline$f_{A}$ & 0.0000 & 0.0000 & 0.0000 & 0.0000 & 0.0000 & 0.0000 & 0.0000 & 0.0000 \\
\hline $\mathbf{f}_{M}$ & 0.0000 & 0.0000 & 0.0000 & 0.0000 & 0.0000 & 0.0000 & 0.0000 & 0.0000 \\
\hline$d_{A}$ & 0.0000 & 0.0000 & 0.0000 & 0.0000 & 0.0000 & 0.0000 & 1.0000 & 1.0000 \\
\hline$d_{M}$ & 0.0000 & 0.0000 & 0.0000 & 0.0000 & 0.0000 & 0.0000 & 0.0000 & 0.0000 \\
\hline$t_{A}$ & 0.0000 & 0.0000 & 0.0000 & 0.0000 & -1.0000 & -1.0000 & 0.0000 & 0.0000 \\
\hline$t_{M}$ & 0.0000 & 0.0000 & 0.0000 & 0.0000 & 0.0000 & 0.0000 & 0.0000 & 0.0000 \\
\hline$\theta *{ }_{I}$ & 0.0000 & 0.0000 & 0.0000 & 0.0000 & 0.0000 & 0.0000 & 0.0000 & 0.0000 \\
\hline$\theta^{*}{ }_{C}$ & 0.0000 & 0.0000 & 0.0000 & 0.0000 & 0.0000 & 0.0000 & 0.0000 & 0.0000 \\
\hline$t_{V}$ & 0.0000 & 0.0000 & 0.0000 & 0.0000 & 0.0000 & 0.0000 & 0.0000 & 0.0000 \\
\hline n & 0.0000 & 0.0000 & 0.0000 & 0.0000 & 0.0000 & 0.0000 & 0.0000 & 0.0000 \\
\hline$\mu^{*}$ & 0.0000 & 0.0000 & 0.0000 & 0.0000 & 0.0000 & 0.0000 & 0.0000 & 0.0000 \\
\hline k & 0.0000 & 0.0000 & 0.0000 & 0.0000 & 0.0000 & 0.0000 & 0.0000 & 0.0000 \\
\hline
\end{tabular}




\begin{tabular}{|c|c|c|c|c|c|c|}
\hline \multirow[t]{2}{*}{ Variables } & \multicolumn{2}{|c|}{$\begin{array}{c}\text { Policy 5: } \\
\mu^{*=-1}\end{array}$} & \multicolumn{2}{|c|}{$\begin{array}{c}\text { Policy 6: } \\
\operatorname{gc}_{\mathrm{I}}=1\end{array}$} & \multicolumn{2}{|c|}{$\begin{array}{c}\text { Policy 7: } \\
\theta^{*}=-1, \theta^{*}{ }_{C}=0.8013\end{array}$} \\
\hline & SR & LR & SR & LR & SR & LR \\
\hline$v_{I}$ & 0.0000 & 0.3919 & 0.1366 & 0.0789 & 0.1297 & 0.0698 \\
\hline $\mathbf{v}_{\mathbf{C}}$ & 0.0000 & -0.3094 & -0.1049 & -0.0591 & -0.0995 & -0.0523 \\
\hline ca $_{I}$ & 0.0000 & 0.1246 & 0.0000 & -0.0215 & 0.0000 & -0.0190 \\
\hline $\mathbf{c m}_{\mathrm{I}}$ & 0.0000 & 0.6176 & 0.0000 & -0.1066 & 0.0000 & -0.0944 \\
\hline $\mathbf{c a}_{\mathrm{C}}$ & 0.0000 & -0.6741 & 0.0000 & 0.1164 & 0.0000 & 0.1030 \\
\hline $\mathbf{c m}_{\mathrm{C}}$ & 0.0000 & -0.1811 & 0.0000 & 0.0313 & 0.0000 & 0.0277 \\
\hline $\mathbf{g h}_{\mathbf{I}}$ & 0.0000 & 0.4292 & 0.7508 & 0.7312 & 0.7127 & 0.6471 \\
\hline $\mathbf{g h}_{\mathbf{C}}$ & 0.0000 & 0.0151 & -0.5986 & -0.6447 & -0.5682 & -0.5705 \\
\hline $\mathbf{j}_{\mathbf{I}}$ & 0.0000 & 0.6176 & 0.0000 & -0.1066 & 0.0000 & -0.0944 \\
\hline $\mathbf{j}_{\mathbf{C}}$ & 0.0000 & -0.1811 & 0.0000 & 0.0313 & 0.0000 & 0.0277 \\
\hline$\pi \mathbf{h}_{\mathbf{I}}$ & 0.0000 & 0.8142 & 0.0000 & -0.1406 & 0.0000 & -0.1244 \\
\hline$\pi \mathbf{h}_{\mathbf{C}}$ & 0.0000 & -0.2819 & 0.0000 & 0.0487 & 0.0000 & 0.0431 \\
\hline $\mathbf{w}_{\mathrm{I}}$ & 0.0000 & -0.4429 & 0.0000 & 0.0765 & 0.0000 & 0.0677 \\
\hline $\mathbf{w}_{\mathbf{C}}$ & 0.0000 & -0.2819 & 0.0000 & 0.0487 & 0.0000 & 0.0431 \\
\hline $\mathbf{y}_{\mathbf{A}}$ & 0.0000 & -0.1040 & 0.0000 & 0.0180 & 0.0000 & 0.0159 \\
\hline $\mathbf{y}_{\mathbf{M}}$ & 0.0000 & 0.1779 & 0.0000 & -0.0307 & 0.0000 & -0.0272 \\
\hline $\mathbf{I}_{\mathrm{A}}$ & 0.0000 & -0.3389 & 0.0000 & 0.0585 & 0.0000 & 0.0518 \\
\hline $\mathbf{l}_{M}$ & 0.0000 & 0.4598 & 0.0000 & $\begin{array}{l}-0.0794 \\
\end{array}$ & 0.0000 & -0.0703 \\
\hline $\mathbf{k}_{\mathbf{A}}$ & 0.0000 & -0.1589 & 0.0000 & 0.0274 & 0.0000 & 0.0243 \\
\hline $\mathbf{k}_{\mathbf{M}}$ & 0.0000 & 0.1230 & 0.0000 & -0.0212 & 0.0000 & -0.0188 \\
\hline $\mathbf{r}_{\mathrm{A}}$ & 0.0000 & 0.0549 & 0.0000 & -0.0095 & 0.0000 & -0.0084 \\
\hline $\mathbf{r}_{M}$ & 0.0000 & 0.0549 & 0.0000 & -0.0095 & 0.0000 & -0.0084 \\
\hline $\boldsymbol{\pi \mathbf { f } _ { \mathrm { A } }}$ & 0.0000 & 0.4754 & 0.0000 & -0.0821 & 0.0000 & -0.0726 \\
\hline$\pi \mathbf{f}_{M}$ & 0.0000 & 0.1779 & 0.0000 & -0.0307 & 0.0000 & -0.0272 \\
\hline $\mathbf{P}$ & 0.0000 & 0.4929 & 0.0000 & -0.0851 & 0.0000 & -0.0753 \\
\hline $\operatorname{grh}_{I}$ & 0.0000 & 0.4546 & 0.0000 & -0.0785 & 2.7164 & 2.6469 \\
\hline $\operatorname{grf}_{\mathbf{A}}$ & 0.0000 & 0.0000 & 0.0000 & 0.0000 & 0.0000 & 0.0000 \\
\hline $\operatorname{grh}_{C}$ & 0.0000 & 0.0432 & 0.0000 & -0.0075 & -1.6249 & -1.6315 \\
\hline $\operatorname{grf}_{M}$ & 0.0000 & 0.0000 & 0.0000 & 0.0000 & 0.0000 & 0.0000 \\
\hline $\mathbf{g c}_{\mathrm{I}}$ & 0.0000 & 0.4208 & 1.0000 & 1.0000 & 0.0474 & -0.0169 \\
\hline $\mathbf{g c}_{\mathrm{C}}$ & 0.0000 & 0.0000 & -0.9205 & -0.9873 & 0.0000 & 0.0000 \\
\hline $\mathbf{f}_{\mathrm{A}}$ & 0.0000 & 0.0000 & 0.0000 & 0.0000 & 0.0000 & 0.0000 \\
\hline $\mathbf{f}_{M}$ & 0.0000 & 0.0000 & 0.0000 & 0.0000 & 0.0000 & 0.0000 \\
\hline $\mathbf{d}_{\mathbf{A}}$ & 0.0000 & 0.0000 & 0.0000 & 0.0000 & 0.0000 & 0.0000 \\
\hline$d_{M}$ & 0.0000 & 0.0000 & 0.0000 & 0.0000 & 0.0000 & 0.0000 \\
\hline$t_{A}$ & 0.0000 & 0.0000 & 0.0000 & 0.0000 & 0.0000 & 0.0000 \\
\hline$t_{M}$ & 0.0000 & 0.0000 & 0.0000 & 0.0000 & 0.0000 & 0.0000 \\
\hline$\theta *{ }_{I}$ & 0.0000 & 0.0000 & 0.0000 & 0.0000 & -1.0000 & -1.0000 \\
\hline$\theta^{*} \mathrm{C}$ & 0.0000 & 0.0000 & 0.0000 & 0.0000 & 0.8013 & 0.8013 \\
\hline $\mathbf{t}_{\mathrm{v}}$ & 0.0000 & 0.0000 & 0.0000 & 0.0000 & 0.0000 & 0.0000 \\
\hline $\mathrm{n}$ & 0.0000 & 0.0000 & 0.0000 & 0.0000 & 0.0000 & 0.0000 \\
\hline$\mu^{*}$ & -1.0000 & -1.0000 & 0.0000 & 0.0000 & 0.0000 & 0.0000 \\
\hline $\mathbf{k}$ & 0.0000 & 0.0000 & 0.0000 & 0.0000 & 0.0000 & 0.0000 \\
\hline
\end{tabular}




\begin{tabular}{|c|c|c|c|c|c|c|c|c|}
\hline \multirow[t]{2}{*}{ Variables } & \multicolumn{2}{|c|}{$\begin{array}{c}\text { Policy 1: } \\
\operatorname{grh}_{\mathrm{I}}=1\end{array}$} & \multicolumn{2}{|c|}{$\begin{array}{c}\text { Policy 2: } \\
\operatorname{grf}_{\mathbf{A}}=1\end{array}$} & \multicolumn{2}{|c|}{$\begin{array}{c}\text { Policy 3: } \\
t_{A}=-1\end{array}$} & \multicolumn{2}{|c|}{$\begin{array}{c}\text { Policy 4: } \\
d_{A}=1\end{array}$} \\
\hline & SR & LR & SR & LR & SR & LR & SR & LR \\
\hline$v_{I}$ & -0.0606 & -0.0675 & 0.0519 & 0.0574 & -0.0391 & -0.0260 & 0.3848 & 0.3586 \\
\hline $\mathbf{v}_{\mathrm{C}}$ & -0.0884 & -0.0826 & 0.0757 & 0.0702 & 0.0171 & 0.0040 & 0.2719 & 0.2982 \\
\hline $\mathbf{c a}_{\text {I }}$ & -0.3523 & -0.3574 & 0.3017 & 0.3037 & 0.0683 & 0.0731 & 1.0833 & 1.0735 \\
\hline $\mathbf{c m}_{\mathrm{I}}$ & 0.0431 & 0.0330 & -0.0369 & -0.0281 & -0.0084 & 0.0125 & -0.1327 & -0.1746 \\
\hline $\mathbf{c a}_{\mathbf{C}}$ & -0.3523 & -0.3424 & 0.3017 & 0.2910 & 0.0683 & 0.0431 & 1.0833 & 1.1339 \\
\hline $\mathbf{c m}_{\mathrm{C}}$ & 0.0431 & 0.0480 & -0.0369 & -0.0408 & -0.0084 & -0.0175 & -0.1327 & -0.1142 \\
\hline $\mathbf{g h}_{\mathbf{I}}$ & 0.3168 & 0.3132 & -0.2713 & -0.2662 & -0.3407 & -0.3287 & 0.1170 & 0.0929 \\
\hline $\mathbf{g h}_{\mathbf{C}}$ & 0.0369 & 0.0379 & -0.0316 & -0.0322 & -0.0072 & -0.0086 & -0.1134 & -0.1105 \\
\hline $\mathbf{j}_{\mathbf{I}}$ & 0.0431 & 0.0330 & -0.0369 & -0.0281 & -0.0084 & 0.0125 & -0.1327 & -0.1746 \\
\hline $\mathbf{j}_{\mathbf{C}}$ & 0.0431 & 0.0480 & -0.0369 & -0.0408 & -0.0084 & -0.0175 & -0.1327 & -0.1142 \\
\hline$\pi \mathbf{h}_{\mathrm{I}}$ & -0.3523 & -0.3703 & 0.3017 & 0.3147 & 0.0683 & 0.0991 & 1.0833 & 1.0214 \\
\hline$\pi \mathbf{h}_{\mathbf{C}}$ & 0.0431 & 0.0499 & -0.0369 & -0.0424 & -0.0084 & -0.0213 & -0.1327 & -0.1066 \\
\hline $\mathbf{w}_{\mathbf{I}}$ & -0.3523 & -0.3467 & 0.3017 & 0.2947 & 0.0683 & 0.0518 & 1.0833 & 1.1164 \\
\hline $\mathbf{w}_{\mathbf{C}}$ & 0.0431 & 0.0499 & -0.0369 & -0.0424 & -0.0084 & -0.0213 & -0.1327 & -0.1066 \\
\hline $\mathbf{y}_{\mathbf{A}}$ & -0.3523 & -0.3531 & 0.3017 & 0.3001 & 0.0053 & 0.0015 & 1.0833 & 1.0908 \\
\hline $\mathbf{y}_{\mathbf{M}}$ & 0.0431 & 0.0413 & -0.0369 & -0.0351 & -0.0084 & -0.0040 & -0.1327 & -0.1414 \\
\hline $\mathbf{I}_{\mathbf{A}}$ & 0.0000 & 0.0064 & 0.0000 & -0.0054 & 0.0000 & -0.0128 & 0.0000 & 0.0256 \\
\hline $\mathbf{l}_{M}$ & 0.0000 & -0.0086 & 0.0000 & 0.0073 & 0.0000 & 0.0173 & 0.0000 & -0.0348 \\
\hline $\mathbf{k}_{\mathbf{A}}$ & -0.2229 & -0.2223 & 0.1908 & 0.1889 & 0.0432 & 0.0386 & 0.6853 & 0.6945 \\
\hline $\mathbf{k}_{\mathbf{M}}$ & 0.1726 & 0.1721 & -0.1478 & -0.1463 & -0.0334 & -0.0299 & -0.5306 & -0.5377 \\
\hline $\mathbf{r}_{\mathrm{A}}$ & -0.1294 & -0.1308 & 0.1108 & 0.1112 & 0.0251 & 0.0259 & 0.3980 & 0.3963 \\
\hline $\mathbf{r}_{\mathbf{M}}$ & -0.1294 & -0.1308 & 0.1108 & 0.1112 & 0.0251 & 0.0259 & 0.3980 & 0.3963 \\
\hline$\pi \mathbf{f}_{\mathrm{A}}$ & -0.3523 & -0.3640 & 0.3017 & 0.3093 & 0.0683 & 0.0863 & 1.0833 & 1.0470 \\
\hline$\pi \mathbf{f}_{M}$ & 0.0431 & 0.0413 & -0.0369 & -0.0351 & -0.0084 & -0.0040 & -0.1327 & -0.1414 \\
\hline $\mathbf{P}$ & 0.3954 & 0.3904 & -0.3386 & -0.3318 & -0.0766 & -0.0606 & -1.2159 & -1.2481 \\
\hline $\operatorname{grh}_{I}$ & 1.0000 & 1.0000 & -0.8563 & -0.8499 & -1.3144 & -1.2991 & 1.3030 & 1.2724 \\
\hline $\operatorname{grf}_{\mathbf{A}}$ & -1.1678 & -1.1767 & 1.0000 & 1.0000 & 0.0000 & 0.0000 & 0.0000 & 0.0000 \\
\hline $\operatorname{grh}_{\mathrm{C}}$ & 0.1055 & 0.1083 & -0.0903 & -0.0921 & -0.0204 & -0.0246 & -0.3243 & -0.3160 \\
\hline $\operatorname{grf}_{M}$ & 0.0000 & 0.0000 & 0.0000 & 0.0000 & 0.0000 & 0.0000 & 0.0000 & 0.0000 \\
\hline $\mathbf{g c}_{\mathrm{I}}$ & 0.0900 & 0.0852 & -0.0771 & -0.0724 & -0.0174 & -0.0065 & -0.2768 & -0.2987 \\
\hline $\mathbf{g c}_{\mathbf{C}}$ & 0.0000 & 0.0000 & 0.0000 & 0.0000 & 0.0000 & 0.0000 & 0.0000 & 0.0000 \\
\hline$f_{A}$ & 0.0000 & 0.0000 & 0.0000 & 0.0000 & 0.0000 & 0.0000 & 0.0000 & 0.0000 \\
\hline $\mathbf{f}_{M}$ & 0.0000 & 0.0000 & 0.0000 & 0.0000 & 0.0000 & 0.0000 & 0.0000 & 0.0000 \\
\hline $\mathbf{d}_{\mathrm{A}}$ & 0.0000 & 0.0000 & 0.0000 & 0.0000 & 0.0000 & 0.0000 & 1.0000 & 1.0000 \\
\hline $\mathbf{d}_{\mathbf{M}}$ & 0.0000 & 0.0000 & 0.0000 & 0.0000 & 0.0000 & 0.0000 & 0.0000 & 0.0000 \\
\hline $\mathbf{t}_{\mathrm{A}}$ & 0.0000 & 0.0000 & 0.0000 & 0.0000 & -1.0000 & -1.0000 & 0.0000 & 0.0000 \\
\hline $\mathbf{t}_{M}$ & 0.0000 & 0.0000 & 0.0000 & 0.0000 & 0.0000 & 0.0000 & 0.0000 & 0.0000 \\
\hline$\theta *{ }_{I}$ & 0.0000 & 0.0000 & 0.0000 & 0.0000 & 0.0000 & 0.0000 & 0.0000 & 0.0000 \\
\hline$\theta^{*}{ }_{C}$ & 0.0000 & 0.0000 & 0.0000 & 0.0000 & 0.0000 & 0.0000 & 0.0000 & 0.0000 \\
\hline $\mathbf{t}_{\mathrm{V}}$ & 0.0000 & 0.0000 & 0.0000 & 0.0000 & 0.0000 & 0.0000 & 0.0000 & 0.0000 \\
\hline n & 0.0000 & 0.0000 & 0.0000 & 0.0000 & 0.0000 & 0.0000 & 0.0000 & 0.0000 \\
\hline$\mu^{*}$ & 0.0000 & 0.0000 & 0.0000 & 0.0000 & 0.0000 & 0.0000 & 0.0000 & 0.0000 \\
\hline $\mathbf{k}$ & 0.0000 & 0.0000 & 0.0000 & 0.0000 & 0.0000 & 0.0000 & 0.0000 & 0.0000 \\
\hline
\end{tabular}




\begin{tabular}{|c|c|c|c|c|c|c|}
\hline \multirow[t]{2}{*}{ Variables } & \multicolumn{2}{|c|}{$\begin{array}{c}\text { Policy 5: } \\
\mu^{*}=-1\end{array}$} & \multicolumn{2}{|c|}{$\begin{array}{c}\text { Policy 6: } \\
\mathrm{gc}_{\mathrm{I}}=1\end{array}$} & \multicolumn{2}{|c|}{$\begin{array}{c}\text { Policy 7: } \\
\theta *{ }_{\mathrm{I}}=-1, \theta *{ }_{C}=0.8013\end{array}$} \\
\hline & SR & LR & SR & $\mathbf{L R}$ & SR & LR \\
\hline $\mathbf{V}_{\mathbf{I}}$ & 0.0000 & 0.3482 & 0.1366 & 0.0845 & 0.1297 & 0.0765 \\
\hline $\mathbf{v}_{\mathbf{C}}$ & 0.0000 & -0.3497 & -0.1049 & -0.0510 & -0.0995 & -0.0461 \\
\hline $\mathbf{c a}_{\mathbf{I}}$ & 0.0000 & 0.1298 & 0.0000 & -0.0219 & 0.0000 & -0.0198 \\
\hline $\mathbf{c m}_{\mathrm{I}}$ & 0.0000 & 0.5574 & 0.0000 & -0.0942 & 0.0000 & -0.0852 \\
\hline$c a_{C}$ & 0.0000 & -0.6723 & 0.0000 & 0.1136 & 0.0000 & 0.1027 \\
\hline $\mathbf{c m}_{\mathrm{C}}$ & 0.0000 & -0.2447 & 0.0000 & 0.0413 & 0.0000 & 0.0374 \\
\hline $\mathbf{g h}_{\mathbf{I}}$ & 0.0000 & 0.3201 & 0.7508 & 0.7337 & 0.7127 & 0.6637 \\
\hline $\mathbf{g h}_{\mathrm{C}}$ & 0.0000 & -0.0385 & -0.5986 & -0.6216 & -0.5682 & -0.5623 \\
\hline $\mathbf{j}_{\mathbf{I}}$ & 0.0000 & 0.5574 & 0.0000 & -0.0942 & 0.0000 & -0.0852 \\
\hline $\mathbf{j}_{\mathbf{C}}$ & 0.0000 & -0.2447 & 0.0000 & 0.0413 & 0.0000 & 0.0374 \\
\hline$\pi \mathbf{h}_{\mathbf{I}}$ & 0.0000 & 0.8223 & 0.0000 & -0.1389 & 0.0000 & -0.1257 \\
\hline $\boldsymbol{\pi} \mathbf{h}_{\mathbf{C}}$ & 0.0000 & -0.3459 & 0.0000 & 0.0584 & 0.0000 & 0.0529 \\
\hline $\mathbf{w}_{\mathbf{I}}$ & 0.0000 & -0.4402 & 0.0000 & 0.0744 & 0.0000 & 0.0673 \\
\hline $\mathbf{w}_{\mathbf{C}}$ & 0.0000 & -0.3459 & 0.0000 & 0.0584 & 0.0000 & 0.0529 \\
\hline $\mathbf{y}_{\mathbf{A}}$ & 0.0000 & -0.0999 & 0.0000 & 0.0169 & 0.0000 & 0.0153 \\
\hline $\mathbf{y}_{\mathbf{M}}$ & 0.0000 & 0.1159 & 0.0000 & -0.0196 & 0.0000 & -0.0177 \\
\hline $\mathbf{l}_{\mathbf{A}}$ & 0.0000 & -0.3403 & 0.0000 & 0.0575 & 0.0000 & 0.0520 \\
\hline $\mathbf{l}_{M}$ & 0.0000 & 0.4618 & 0.0000 & -0.0780 & 0.0000 & -0.0706 \\
\hline $\mathbf{k}_{\mathbf{A}}$ & 0.0000 & -0.1216 & 0.0000 & 0.0205 & 0.0000 & 0.0186 \\
\hline $\mathbf{k}_{\mathbf{M}}$ & 0.0000 & 0.0942 & 0.0000 & -0.0159 & 0.0000 & -0.0144 \\
\hline $\mathbf{r}_{\mathrm{A}}$ & 0.0000 & 0.0218 & 0.0000 & -0.0037 & 0.0000 & -0.0033 \\
\hline $\mathbf{r}_{M}$ & 0.0000 & 0.0218 & 0.0000 & -0.0037 & 0.0000 & -0.0033 \\
\hline $\boldsymbol{\pi \mathbf { f } _ { \mathrm { A } }}$ & 0.0000 & 0.4820 & 0.0000 & -0.0814 & 0.0000 & -0.0737 \\
\hline$\pi \mathbf{f}_{M}$ & 0.0000 & 0.1159 & 0.0000 & -0.0196 & 0.0000 & -0.0177 \\
\hline $\mathbf{P}$ & 0.0000 & 0.4277 & 0.0000 & -0.0722 & 0.0000 & -0.0654 \\
\hline $\operatorname{grh}_{\text {I }}$ & 0.0000 & 0.4057 & 0.0000 & -0.0685 & 2.7164 & 2.6544 \\
\hline $\operatorname{grf}_{\mathbf{A}}$ & 0.0000 & 0.0000 & 0.0000 & 0.0000 & 0.0000 & 0.0000 \\
\hline $\operatorname{grh}_{\mathrm{C}}$ & 0.0000 & -0.1100 & 0.0000 & 0.0186 & -1.6249 & -1.6081 \\
\hline $\operatorname{grf}_{M}$ & 0.0000 & 0.0000 & 0.0000 & 0.0000 & 0.0000 & 0.0000 \\
\hline $\mathbf{g c}_{\mathrm{I}}$ & 0.0000 & 0.2916 & 1.0000 & 1.0000 & 0.0474 & 0.0029 \\
\hline $\mathbf{g c}_{\mathrm{C}}$ & 0.0000 & 0.0000 & -0.9205 & -0.9658 & 0.0000 & 0.0000 \\
\hline $\mathbf{f}_{\mathrm{A}}$ & 0.0000 & 0.0000 & 0.0000 & 0.0000 & 0.0000 & 0.0000 \\
\hline $\mathbf{f}_{M}$ & 0.0000 & 0.0000 & 0.0000 & 0.0000 & 0.0000 & 0.0000 \\
\hline $\mathbf{d}_{\mathbf{A}}$ & 0.0000 & 0.0000 & 0.0000 & 0.0000 & 0.0000 & 0.0000 \\
\hline $\mathbf{d}_{\mathbf{M}}$ & 0.0000 & 0.0000 & 0.0000 & 0.0000 & 0.0000 & 0.0000 \\
\hline $\mathbf{t}_{\mathrm{A}}$ & 0.0000 & 0.0000 & 0.0000 & 0.0000 & 0.0000 & 0.0000 \\
\hline $\mathbf{t}_{M}$ & 0.0000 & 0.0000 & 0.0000 & 0.0000 & 0.0000 & 0.0000 \\
\hline$\theta *{ }_{I}$ & 0.0000 & 0.0000 & 0.0000 & 0.0000 & -1.0000 & -1.0000 \\
\hline$\theta *_{C}$ & 0.0000 & 0.0000 & 0.0000 & 0.0000 & 0.8013 & 0.8013 \\
\hline $\mathbf{t}_{\mathrm{V}}$ & 0.0000 & 0.0000 & 0.0000 & 0.0000 & 0.0000 & 0.0000 \\
\hline n & 0.0000 & 0.0000 & 0.0000 & 0.0000 & 0.0000 & 0.0000 \\
\hline$\mu^{*}$ & -1.0000 & -1.0000 & 0.0000 & 0.0000 & 0.0000 & 0.0000 \\
\hline $\mathbf{k}$ & 0.0000 & 0.0000 & 0.0000 & 0.0000 & 0.0000 & 0.0000 \\
\hline
\end{tabular}




\begin{tabular}{|c|c|c|c|c|c|c|c|c|}
\hline \multirow[t]{2}{*}{ Variables } & \multicolumn{2}{|c|}{$\begin{array}{c}\text { Policy 1: } \\
\operatorname{grh}_{\mathrm{I}}=1\end{array}$} & \multicolumn{2}{|c|}{$\begin{array}{c}\text { Policy 2: } \\
\operatorname{grf}_{A}=1\end{array}$} & \multicolumn{2}{|c|}{$\begin{array}{c}\text { Policy 3: } \\
t_{A}=-1\end{array}$} & \multicolumn{2}{|c|}{$\begin{array}{c}\text { Policy 4: } \\
d_{A}=1\end{array}$} \\
\hline & SR & LR & SR & LR & SR & LR & SR & LR \\
\hline $\mathbf{v}_{\mathbf{I}}$ & -0.0812 & -0.0879 & 0.0680 & 0.0731 & -0.0356 & -0.0223 & 0.4403 & 0.4115 \\
\hline $\mathbf{v}_{\mathbf{C}}$ & -0.1069 & -0.1017 & 0.0895 & 0.0846 & 0.0201 & 0.0075 & 0.3196 & 0.3469 \\
\hline$c a_{I}$ & -0.3601 & -0.3636 & 0.3014 & 0.3025 & 0.0678 & 0.0705 & 1.0766 & 1.0708 \\
\hline $\mathbf{c m}_{\mathrm{I}}$ & 0.0185 & 0.0082 & -0.0155 & -0.0068 & -0.0035 & 0.0190 & -0.0552 & -0.1039 \\
\hline $\mathbf{c a}_{\mathbf{C}}$ & -0.3601 & -0.3498 & 0.3014 & 0.2910 & 0.0678 & 0.0407 & 1.0766 & 1.1354 \\
\hline $\mathbf{c m}_{\mathrm{C}}$ & 0.0185 & 0.0220 & -0.0155 & -0.0183 & -0.0035 & -0.0109 & -0.0552 & -0.0392 \\
\hline $\mathbf{g h}_{\mathbf{I}}$ & 0.2782 & 0.2734 & -0.2329 & -0.2274 & -0.3321 & -0.3178 & 0.2535 & 0.2226 \\
\hline $\mathbf{g h}_{\mathbf{C}}$ & 0.0158 & 0.0159 & -0.0132 & -0.0132 & -0.0030 & -0.0030 & -0.0472 & -0.0473 \\
\hline $\mathbf{j}_{\mathbf{I}}$ & 0.0185 & 0.0082 & -0.0155 & -0.0068 & -0.0035 & 0.0190 & -0.0552 & -0.1039 \\
\hline $\mathbf{j}_{\mathbf{C}}$ & 0.0185 & 0.0220 & -0.0155 & -0.0183 & -0.0035 & -0.0109 & -0.0552 & -0.0392 \\
\hline$\pi \mathbf{h}_{\mathrm{I}}$ & -0.3601 & -0.3756 & 0.3014 & 0.3124 & 0.0678 & 0.0963 & 1.0766 & 1.0150 \\
\hline$\pi \mathbf{h}_{\mathbf{C}}$ & 0.0185 & 0.0238 & -0.0155 & -0.0198 & -0.0035 & -0.0146 & -0.0552 & -0.0311 \\
\hline $\mathbf{w}_{\text {I }}$ & -0.3601 & -0.3538 & 0.3014 & 0.2943 & 0.0678 & 0.0493 & 1.0766 & 1.1167 \\
\hline $\mathbf{w}_{\mathbf{C}}$ & 0.0185 & 0.0238 & -0.0155 & -0.0198 & -0.0035 & -0.0146 & -0.0552 & -0.0311 \\
\hline $\mathbf{y}_{\mathbf{A}}$ & -0.3601 & -0.3597 & 0.3014 & 0.2992 & 0.0048 & -0.0010 & 1.0766 & 1.0893 \\
\hline $\mathbf{y}_{\mathbf{M}}$ & 0.0185 & 0.0158 & -0.0155 & -0.0132 & -0.0035 & 0.0025 & -0.0552 & -0.0683 \\
\hline $\mathbf{l}_{\mathrm{A}}$ & 0.0000 & 0.0059 & 0.0000 & -0.0049 & 0.0000 & -0.0127 & 0.0000 & 0.0274 \\
\hline $\mathbf{l}_{M}$ & 0.0000 & -0.0080 & 0.0000 & 0.0066 & 0.0000 & 0.0172 & 0.0000 & -0.0372 \\
\hline $\mathbf{k}_{\mathbf{A}}$ & -0.2134 & -0.2116 & 0.1786 & 0.1760 & 0.0402 & 0.0335 & 0.6379 & 0.6524 \\
\hline $\mathbf{k}_{\mathbf{M}}$ & 0.1652 & 0.1638 & -0.1383 & -0.1363 & -0.0311 & -0.0259 & -0.4939 & -0.5051 \\
\hline $\mathbf{r}_{\mathrm{A}}$ & -0.1467 & -0.1480 & 0.1228 & 0.1231 & 0.0276 & 0.0285 & 0.4387 & 0.4369 \\
\hline $\mathbf{r}_{M}$ & -0.1467 & -0.1480 & 0.1228 & 0.1231 & 0.0276 & 0.0285 & 0.4387 & 0.4369 \\
\hline $\boldsymbol{\pi} \mathbf{f}_{\mathrm{A}}$ & -0.3601 & -0.3697 & 0.3014 & 0.3075 & 0.0678 & 0.0836 & 1.0766 & 1.0424 \\
\hline$\pi \mathbf{f}_{\mathbf{M}}$ & 0.0185 & 0.0158 & -0.0155 & -0.0132 & -0.0035 & 0.0025 & -0.0552 & -0.0683 \\
\hline $\mathbf{P}$ & 0.3786 & 0.3718 & -0.3169 & -0.3093 & -0.0713 & -0.0516 & -1.1318 & -1.1746 \\
\hline $\operatorname{grh}_{I}$ & 1.0000 & 1.0000 & -0.8372 & -0.8318 & -1.3105 & -1.2967 & 1.3642 & 1.3343 \\
\hline $\operatorname{grf}_{A}$ & -1.1945 & -1.2022 & 1.0000 & 1.0000 & 0.0000 & 0.0000 & 0.0000 & 0.0000 \\
\hline $\operatorname{grh}_{\mathbf{C}}$ & 0.0452 & 0.0454 & -0.0378 & -0.0378 & -0.0085 & -0.0084 & -0.1351 & -0.1352 \\
\hline $\operatorname{grf}_{M}$ & 0.0000 & 0.0000 & 0.0000 & 0.0000 & 0.0000 & 0.0000 & 0.0000 & 0.0000 \\
\hline $\mathbf{g c}_{\mathrm{I}}$ & 0.0386 & 0.0321 & -0.0323 & -0.0267 & -0.0073 & 0.0071 & -0.1153 & -0.1465 \\
\hline $\mathbf{g c}_{\mathbf{C}}$ & 0.0000 & 0.0000 & 0.0000 & 0.0000 & 0.0000 & 0.0000 & 0.0000 & 0.0000 \\
\hline $\mathbf{f}_{\mathrm{A}}$ & 0.0000 & 0.0000 & 0.0000 & 0.0000 & 0.0000 & 0.0000 & 0.0000 & 0.0000 \\
\hline $\mathbf{f}_{M}$ & 0.0000 & 0.0000 & 0.0000 & 0.0000 & 0.0000 & 0.0000 & 0.0000 & 0.0000 \\
\hline $\mathbf{d}_{\mathrm{A}}$ & 0.0000 & 0.0000 & 0.0000 & 0.0000 & 0.0000 & 0.0000 & 1.0000 & 1.0000 \\
\hline $\mathbf{d}_{\mathbf{M}}$ & 0.0000 & 0.0000 & 0.0000 & 0.0000 & 0.0000 & 0.0000 & 0.0000 & 0.0000 \\
\hline $\mathbf{t}_{\mathrm{A}}$ & 0.0000 & 0.0000 & 0.0000 & 0.0000 & -1.0000 & -1.0000 & 0.0000 & 0.0000 \\
\hline $\mathbf{t}_{M}$ & 0.0000 & 0.0000 & 0.0000 & 0.0000 & 0.0000 & 0.0000 & 0.0000 & 0.0000 \\
\hline$\theta *{ }_{I}$ & 0.0000 & 0.0000 & 0.0000 & 0.0000 & 0.0000 & 0.0000 & 0.0000 & 0.0000 \\
\hline$\theta^{*} \mathrm{C}$ & 0.0000 & 0.0000 & 0.0000 & 0.0000 & 0.0000 & 0.0000 & 0.0000 & 0.0000 \\
\hline$t_{V}$ & 0.0000 & 0.0000 & 0.0000 & 0.0000 & 0.0000 & 0.0000 & 0.0000 & 0.0000 \\
\hline $\mathbf{N}$ & 0.0000 & 0.0000 & 0.0000 & 0.0000 & 0.0000 & 0.0000 & 0.0000 & 0.0000 \\
\hline$\mu^{*}$ & 0.0000 & 0.0000 & 0.0000 & 0.0000 & 0.0000 & 0.0000 & 0.0000 & 0.0000 \\
\hline $\mathbf{k}$ & 0.0000 & 0.0000 & 0.0000 & 0.0000 & 0.0000 & 0.0000 & 0.0000 & 0.0000 \\
\hline
\end{tabular}




\begin{tabular}{|c|c|c|c|c|c|c|}
\hline \multirow[t]{2}{*}{ Variables } & \multicolumn{2}{|c|}{$\begin{array}{c}\text { Policy 5: } \\
\mu^{*}=-1\end{array}$} & \multicolumn{2}{|c|}{$\begin{array}{c}\text { Policy 6: } \\
\operatorname{gc}_{\mathrm{I}}=1\end{array}$} & \multicolumn{2}{|c|}{$\begin{array}{c}\text { Policy 7: } \\
\theta *_{\mathrm{I}}=-1, \theta^{*}{ }_{\mathrm{C}}=\mathbf{0 . 8 0 1 3}\end{array}$} \\
\hline & SR & LR & SR & LR & SR & LR \\
\hline $\mathbf{V}_{\mathbf{I}}$ & 0.0000 & 0.3573 & 0.1366 & 0.0844 & 0.1297 & 0.0751 \\
\hline $\mathbf{v}_{\mathbf{C}}$ & 0.0000 & -0.3396 & -0.1049 & -0.0535 & -0.0995 & -0.0476 \\
\hline $\mathbf{c a}_{I}$ & 0.0000 & 0.0720 & 0.0000 & -0.0124 & 0.0000 & -0.0110 \\
\hline $\mathbf{c m}_{I}$ & 0.0000 & 0.6039 & 0.0000 & -0.1037 & 0.0000 & -0.0923 \\
\hline $\mathbf{c a} \mathbf{a}_{\mathrm{C}}$ & 0.0000 & -0.7311 & 0.0000 & 0.1255 & 0.0000 & 0.1117 \\
\hline $\mathbf{c m}_{\mathrm{C}}$ & 0.0000 & -0.1991 & 0.0000 & 0.0342 & 0.0000 & 0.0304 \\
\hline $\mathbf{g h}_{\mathbf{I}}$ & 0.0000 & 0.3836 & 0.7508 & 0.7349 & 0.7127 & 0.6540 \\
\hline $\mathbf{g h}_{\mathbf{C}}$ & 0.0000 & 0.0007 & -0.5986 & -0.6385 & -0.5682 & -0.5683 \\
\hline $\mathbf{j}_{\mathbf{I}}$ & 0.0000 & 0.6039 & 0.0000 & -0.1037 & 0.0000 & -0.0923 \\
\hline $\mathbf{j}_{\mathbf{C}}$ & 0.0000 & -0.1991 & 0.0000 & 0.0342 & 0.0000 & 0.0304 \\
\hline$\pi \mathbf{h}_{\mathbf{I}}$ & 0.0000 & 0.7654 & 0.0000 & -0.1314 & 0.0000 & -0.1170 \\
\hline $\boldsymbol{\pi} \mathbf{h}_{\mathrm{C}}$ & 0.0000 & -0.3005 & 0.0000 & 0.0516 & 0.0000 & 0.0459 \\
\hline $\mathbf{w}_{\mathbf{I}}$ & 0.0000 & -0.4986 & 0.0000 & 0.0856 & 0.0000 & 0.0762 \\
\hline $\mathbf{w}_{\mathbf{C}}$ & 0.0000 & -0.3005 & 0.0000 & 0.0516 & 0.0000 & 0.0459 \\
\hline $\mathbf{y}_{\mathbf{A}}$ & 0.0000 & -0.1579 & 0.0000 & 0.0271 & 0.0000 & 0.0241 \\
\hline $\mathbf{y}_{\mathbf{M}}$ & 0.0000 & 0.1619 & 0.0000 & -0.0278 & 0.0000 & -0.0247 \\
\hline $\mathbf{l}_{\mathbf{A}}$ & 0.0000 & -0.3407 & 0.0000 & 0.0585 & 0.0000 & 0.0521 \\
\hline $\mathbf{l}_{\mathbf{M}}$ & 0.0000 & 0.4624 & 0.0000 & -0.0794 & 0.0000 & -0.0707 \\
\hline $\mathbf{k}_{\mathbf{A}}$ & 0.0000 & -0.1802 & 0.0000 & 0.0310 & 0.0000 & 0.0275 \\
\hline $\mathbf{k}_{\mathbf{M}}$ & 0.0000 & 0.1396 & 0.0000 & -0.0240 & 0.0000 & -0.0213 \\
\hline $\mathbf{r}_{\mathrm{A}}$ & 0.0000 & 0.0223 & 0.0000 & -0.0038 & 0.0000 & -0.0034 \\
\hline $\mathbf{r}_{\mathbf{M}}$ & 0.0000 & 0.0223 & 0.0000 & -0.0038 & 0.0000 & -0.0034 \\
\hline $\boldsymbol{\pi} \mathbf{f}_{\mathrm{A}}$ & 0.0000 & 0.4247 & 0.0000 & -0.0729 & 0.0000 & -0.0649 \\
\hline$\pi \mathbf{f}_{M}$ & 0.0000 & 0.1619 & 0.0000 & -0.0278 & 0.0000 & -0.0247 \\
\hline $\mathbf{P}$ & 0.0000 & 0.5319 & 0.0000 & -0.0913 & 0.0000 & -0.0813 \\
\hline $\operatorname{grh}_{\text {I }}$ & 0.0000 & 0.3716 & 0.0000 & -0.0638 & 2.7164 & 2.6596 \\
\hline $\operatorname{grf}_{\mathbf{A}}$ & 0.0000 & 0.0000 & 0.0000 & 0.0000 & 0.0000 & 0.0000 \\
\hline $\operatorname{grh}_{\mathrm{C}}$ & 0.0000 & 0.0019 & 0.0000 & -0.0003 & -1.6249 & -1.6252 \\
\hline $\operatorname{grf}_{M}$ & 0.0000 & 0.0000 & 0.0000 & 0.0000 & 0.0000 & 0.0000 \\
\hline $\mathbf{g c}_{\mathrm{I}}$ & 0.0000 & 0.3876 & 1.0000 & 1.0000 & 0.0474 & -0.0118 \\
\hline $\mathbf{g c}_{\mathrm{C}}$ & 0.0000 & 0.0000 & -0.9205 & -0.9817 & 0.0000 & 0.0000 \\
\hline $\mathbf{f}_{\mathrm{A}}$ & 0.0000 & 0.0000 & 0.0000 & 0.0000 & 0.0000 & 0.0000 \\
\hline $\mathbf{f}_{\mathbf{M}}$ & 0.0000 & 0.0000 & 0.0000 & 0.0000 & 0.0000 & 0.0000 \\
\hline $\mathbf{d}_{\mathbf{A}}$ & 0.0000 & 0.0000 & 0.0000 & 0.0000 & 0.0000 & 0.0000 \\
\hline $\mathbf{d}_{M}$ & 0.0000 & 0.0000 & 0.0000 & 0.0000 & 0.0000 & 0.0000 \\
\hline $\mathbf{t}_{\mathrm{A}}$ & 0.0000 & 0.0000 & 0.0000 & 0.0000 & 0.0000 & 0.0000 \\
\hline $\mathbf{t}_{M}$ & 0.0000 & 0.0000 & 0.0000 & 0.0000 & 0.0000 & 0.0000 \\
\hline$\theta *{ }_{I}$ & 0.0000 & 0.0000 & 0.0000 & 0.0000 & -1.0000 & -1.0000 \\
\hline$\theta^{*}{ }_{C}$ & 0.0000 & 0.0000 & 0.0000 & 0.0000 & 0.8013 & 0.8013 \\
\hline $\mathbf{t}_{\mathrm{V}}$ & 0.0000 & 0.0000 & 0.0000 & 0.0000 & 0.0000 & 0.0000 \\
\hline $\mathbf{n}$ & 0.0000 & 0.0000 & 0.0000 & 0.0000 & 0.0000 & 0.0000 \\
\hline$\mu^{*}$ & -1.0000 & -1.0000 & 0.0000 & 0.0000 & 0.0000 & 0.0000 \\
\hline $\mathbf{k}$ & 0.0000 & 0.0000 & 0.0000 & 0.0000 & 0.0000 & 0.0000 \\
\hline
\end{tabular}




\begin{tabular}{|c|c|c|c|c|c|c|c|c|}
\hline \multirow[t]{2}{*}{ Variables } & \multicolumn{2}{|c|}{$\begin{array}{c}\text { Policy 1: } \\
\operatorname{grh}_{\mathrm{I}}=1\end{array}$} & \multicolumn{2}{|c|}{$\begin{array}{c}\text { Policy 2: } \\
\operatorname{grf}_{A}=1\end{array}$} & \multicolumn{2}{|c|}{$\begin{array}{c}\text { Policy 3: } \\
t_{A}=-1\end{array}$} & \multicolumn{2}{|c|}{$\begin{array}{c}\text { Policy 4: } \\
d_{A}=1\end{array}$} \\
\hline & SR & LR & SR & LR & SR & LR & SR & LR \\
\hline $\mathbf{v}_{\mathbf{I}}$ & -0.0914 & -0.0980 & 0.0746 & 0.0795 & -0.0341 & -0.0203 & 0.4640 & 0.4323 \\
\hline $\mathbf{v}_{\mathbf{C}}$ & -0.1155 & -0.1110 & 0.0943 & 0.0900 & 0.0212 & 0.0092 & 0.3368 & 0.3644 \\
\hline $\mathrm{ca}_{I}$ & -0.3890 & -0.3935 & 0.3176 & 0.3191 & 0.0715 & 0.0757 & 1.1344 & 1.1248 \\
\hline $\mathbf{c m}_{\mathrm{I}}$ & 0.0200 & 0.0104 & -0.0163 & -0.0084 & -0.0037 & 0.0185 & -0.0582 & -0.1091 \\
\hline $\mathrm{ca}_{\mathrm{C}}$ & -0.3890 & -0.3805 & 0.3176 & 0.3086 & 0.0715 & 0.0461 & 1.1344 & 1.1927 \\
\hline $\mathbf{c m}_{\mathrm{C}}$ & 0.0200 & 0.0233 & -0.0163 & -0.0189 & -0.0037 & -0.0111 & -0.0582 & -0.0412 \\
\hline $\mathbf{g h}_{\mathrm{I}}$ & 0.2805 & 0.2761 & -0.2291 & -0.2239 & -0.3312 & $\begin{array}{l}-0.3168 \\
\end{array}$ & 0.2671 & 0.2339 \\
\hline $\mathbf{g h}_{\mathrm{C}}$ & 0.0171 & 0.0172 & -0.0139 & -0.0140 & -0.0031 & -0.0032 & -0.0498 & -0.0497 \\
\hline $\mathbf{j}_{\mathbf{I}}$ & 0.0200 & 0.0104 & -0.0163 & -0.0084 & -0.0037 & 0.0185 & -0.0582 & -0.1091 \\
\hline $\mathbf{j}_{\mathrm{C}}$ & 0.0200 & 0.0233 & -0.0163 & -0.0189 & -0.0037 & -0.0111 & -0.0582 & -0.0412 \\
\hline$\pi \mathbf{h}_{\mathbf{I}}$ & -0.3890 & -0.4046 & 0.3176 & 0.3282 & 0.0715 & 0.1011 & 1.1344 & 1.0662 \\
\hline$\pi \mathbf{h}_{\mathbf{C}}$ & 0.0200 & 0.0250 & -0.0163 & -0.0203 & -0.0037 & -0.0148 & -0.0582 & -0.0326 \\
\hline$w_{I}$ & -0.3890 & -0.3843 & 0.3176 & 0.3117 & 0.0715 & 0.0547 & 1.1344 & 1.1731 \\
\hline $\mathbf{w}_{\mathbf{C}}$ & 0.0200 & 0.0250 & -0.0163 & -0.0203 & -0.0037 & $\begin{array}{l}-0.0148 \\
\end{array}$ & -0.0582 & -0.0326 \\
\hline $\mathbf{y}_{\mathrm{A}}$ & -0.3890 & -0.3898 & 0.3176 & 0.3161 & 0.0085 & 0.0042 & 1.1344 & 1.1443 \\
\hline $\mathbf{y}_{\mathbf{M}}$ & 0.0200 & 0.0175 & -0.0163 & -0.0142 & -0.0037 & 0.0022 & -0.0582 & -0.0717 \\
\hline$l_{A}$ & 0.0000 & 0.0055 & 0.0000 & -0.0045 & 0.0000 & -0.0125 & 0.0000 & 0.0288 \\
\hline$l_{M}$ & 0.0000 & -0.0075 & 0.0000 & 0.0060 & 0.0000 & 0.0170 & 0.0000 & -0.0391 \\
\hline $\mathbf{k}_{\mathbf{A}}$ & -0.2305 & -0.2296 & 0.1882 & 0.1862 & 0.0424 & 0.0366 & 0.6722 & 0.6854 \\
\hline $\mathbf{k}_{\mathbf{M}}$ & 0.1785 & 0.1777 & -0.1457 & -0.1442 & -0.0328 & -0.0284 & -0.5205 & -0.5306 \\
\hline $\mathbf{r}_{\mathrm{A}}$ & -0.1585 & -0.1602 & 0.1294 & 0.1299 & 0.0291 & 0.0306 & 0.4622 & 0.4589 \\
\hline $\mathbf{r}_{M}$ & -0.1585 & -0.1602 & 0.1294 & 0.1299 & 0.0291 & 0.0306 & 0.4622 & 0.4589 \\
\hline $\boldsymbol{\pi} \mathbf{f}_{\mathrm{A}}$ & -0.3890 & -0.3992 & 0.3176 & 0.3237 & 0.0715 & 0.0886 & 1.1344 & 1.0950 \\
\hline$\pi \mathbf{f}_{\mathbf{M}}$ & 0.0200 & 0.0175 & -0.0163 & -0.0142 & -0.0037 & 0.0022 & -0.0582 & -0.0717 \\
\hline $\mathbf{P}$ & 0.4089 & 0.4039 & -0.3339 & -0.3276 & -0.0751 & -0.0572 & -1.1927 & -1.2339 \\
\hline $\operatorname{grh}_{I}$ & 1.0000 & 1.0000 & -0.8166 & -0.8111 & -1.3059 & -1.2903 & 1.4376 & 1.4017 \\
\hline $\operatorname{grf}_{\mathrm{A}}$ & -1.2246 & -1.2330 & 1.0000 & 1.0000 & 0.0000 & 0.0000 & 0.0000 & 0.0000 \\
\hline $\operatorname{grh}_{\mathrm{C}}$ & 0.0488 & 0.0492 & -0.0399 & -0.0399 & -0.0090 & -0.0091 & -0.1423 & -0.1420 \\
\hline $\operatorname{grf}_{M}$ & 0.0000 & 0.0000 & 0.0000 & 0.0000 & 0.0000 & 0.0000 & 0.0000 & 0.0000 \\
\hline $\mathbf{g c}_{\mathrm{I}}$ & 0.0416 & 0.0358 & -0.0340 & -0.0290 & -0.0077 & 0.0064 & -0.1215 & -0.1539 \\
\hline $\mathbf{g c}_{\mathrm{C}}$ & 0.0000 & 0.0000 & 0.0000 & 0.0000 & 0.0000 & 0.0000 & 0.0000 & 0.0000 \\
\hline$f_{A}$ & 0.0000 & 0.0000 & 0.0000 & 0.0000 & 0.0000 & 0.0000 & 0.0000 & 0.0000 \\
\hline $\mathbf{f}_{M}$ & 0.0000 & 0.0000 & 0.0000 & 0.0000 & 0.0000 & 0.0000 & 0.0000 & 0.0000 \\
\hline$d_{A}$ & 0.0000 & 0.0000 & 0.0000 & 0.0000 & 0.0000 & 0.0000 & 1.0000 & 1.0000 \\
\hline$d_{M}$ & 0.0000 & 0.0000 & 0.0000 & 0.0000 & 0.0000 & 0.0000 & 0.0000 & 0.0000 \\
\hline$t_{A}$ & 0.0000 & 0.0000 & 0.0000 & 0.0000 & -1.0000 & -1.0000 & 0.0000 & 0.0000 \\
\hline$t_{M}$ & 0.0000 & 0.0000 & 0.0000 & 0.0000 & 0.0000 & 0.0000 & 0.0000 & 0.0000 \\
\hline$\theta *{ }_{I}$ & 0.0000 & 0.0000 & 0.0000 & 0.0000 & 0.0000 & 0.0000 & 0.0000 & 0.0000 \\
\hline$\theta *_{C}$ & 0.0000 & 0.0000 & 0.0000 & 0.0000 & 0.0000 & 0.0000 & 0.0000 & 0.0000 \\
\hline $\mathbf{t}_{\mathrm{V}}$ & 0.0000 & 0.0000 & 0.0000 & 0.0000 & 0.0000 & 0.0000 & 0.0000 & 0.0000 \\
\hline $\mathrm{n}$ & 0.0000 & 0.0000 & 0.0000 & 0.0000 & 0.0000 & 0.0000 & 0.0000 & 0.0000 \\
\hline$\mu^{*}$ & 0.0000 & 0.0000 & 0.0000 & 0.0000 & 0.0000 & 0.0000 & 0.0000 & 0.0000 \\
\hline $\mathbf{k}$ & 0.0000 & 0.0000 & 0.0000 & 0.0000 & 0.0000 & 0.0000 & 0.0000 & 0.0000 \\
\hline
\end{tabular}




\begin{tabular}{|c|c|c|c|c|c|c|}
\hline \multirow[t]{2}{*}{ Variables } & \multicolumn{2}{|c|}{$\begin{array}{c}\text { Policy 5: } \\
\mu^{*}=-1\end{array}$} & \multicolumn{2}{|c|}{$\begin{array}{c}\text { Policy 6: } \\
\mathrm{gc}_{\mathrm{I}}=1\end{array}$} & \multicolumn{2}{|c|}{$\begin{array}{c}\text { Policy 7: } \\
\theta *{ }_{1}=-1, \theta *_{C}=0.8013\end{array}$} \\
\hline & SR & LR & SR & LR & SR & LR \\
\hline $\mathbf{V}_{\text {I }}$ & 0.0000 & 0.3732 & 0.1366 & 0.0816 & 0.1297 & 0.0727 \\
\hline $\mathbf{v}_{\mathrm{C}}$ & 0.0000 & -0.3263 & -0.1049 & -0.0558 & -0.0995 & -0.0497 \\
\hline $\mathbf{c a}_{\mathbf{I}}$ & 0.0000 & 0.1133 & 0.0000 & -0.0194 & 0.0000 & -0.0173 \\
\hline $\mathrm{cm}_{\mathrm{I}}$ & 0.0000 & 0.5999 & 0.0000 & -0.1029 & 0.0000 & -0.0917 \\
\hline $\mathbf{c a}_{\mathrm{C}}$ & 0.0000 & -0.6873 & 0.0000 & 0.1179 & 0.0000 & 0.1050 \\
\hline $\mathbf{c m}_{\mathrm{C}}$ & 0.0000 & -0.2006 & 0.0000 & 0.0344 & 0.0000 & 0.0307 \\
\hline $\mathbf{g h}_{\mathbf{I}}$ & 0.0000 & 0.3922 & 0.7508 & 0.7327 & 0.7127 & 0.6527 \\
\hline $\mathbf{g h}_{\mathrm{C}}$ & 0.0000 & -0.0012 & -0.5986 & -0.6376 & -0.5682 & -0.5680 \\
\hline $\mathbf{j}_{\mathbf{I}}$ & 0.0000 & 0.5999 & 0.0000 & -0.1029 & 0.0000 & -0.0917 \\
\hline $\mathbf{j}_{\mathbf{C}}$ & 0.0000 & -0.2006 & 0.0000 & 0.0344 & 0.0000 & 0.0307 \\
\hline$\pi \mathbf{h}_{\mathbf{I}}$ & 0.0000 & 0.8045 & 0.0000 & -0.1380 & 0.0000 & -0.1229 \\
\hline $\boldsymbol{\pi} \mathbf{h}_{\mathbf{C}}$ & 0.0000 & -0.3017 & 0.0000 & 0.0517 & 0.0000 & 0.0461 \\
\hline $\mathbf{w}_{\text {I }}$ & 0.0000 & -0.4556 & 0.0000 & 0.0781 & 0.0000 & 0.0696 \\
\hline $\mathbf{w}_{\mathbf{C}}$ & 0.0000 & -0.3017 & 0.0000 & 0.0517 & 0.0000 & 0.0461 \\
\hline $\mathbf{y}_{\mathbf{A}}$ & 0.0000 & -0.1159 & 0.0000 & 0.0199 & 0.0000 & 0.0177 \\
\hline $\mathbf{y}_{\mathbf{M}}$ & 0.0000 & 0.1593 & 0.0000 & -0.0273 & 0.0000 & -0.0243 \\
\hline $\mathbf{I}_{\mathbf{A}}$ & 0.0000 & -0.3396 & 0.0000 & 0.0583 & 0.0000 & 0.0519 \\
\hline $\mathbf{l}_{M}$ & 0.0000 & 0.4609 & 0.0000 & -0.0791 & 0.0000 & -0.0704 \\
\hline $\mathbf{k}_{\mathbf{A}}$ & 0.0000 & -0.1551 & 0.0000 & 0.0266 & 0.0000 & 0.0237 \\
\hline $\mathbf{k}_{\mathbf{M}}$ & 0.0000 & 0.1201 & 0.0000 & -0.0206 & 0.0000 & -0.0184 \\
\hline $\mathbf{r}_{\mathrm{A}}$ & 0.0000 & 0.0392 & 0.0000 & -0.0067 & 0.0000 & -0.0060 \\
\hline $\mathbf{r}_{\mathbf{M}}$ & 0.0000 & 0.0392 & 0.0000 & -0.0067 & 0.0000 & -0.0060 \\
\hline $\boldsymbol{\pi} \mathbf{f}_{\mathrm{A}}$ & 0.0000 & 0.4648 & 0.0000 & -0.0797 & 0.0000 & -0.0710 \\
\hline$\pi \mathbf{f}_{M}$ & 0.0000 & 0.1593 & 0.0000 & -0.0273 & 0.0000 & -0.0243 \\
\hline $\mathbf{P}$ & 0.0000 & 0.4867 & 0.0000 & -0.0835 & 0.0000 & -0.0744 \\
\hline $\operatorname{grh}_{I}$ & 0.0000 & 0.4230 & 0.0000 & -0.0726 & 2.7164 & 2.6517 \\
\hline $\operatorname{grf}_{A}$ & 0.0000 & 0.0000 & 0.0000 & 0.0000 & 0.0000 & 0.0000 \\
\hline $\operatorname{grh}_{\mathrm{C}}$ & 0.0000 & -0.0033 & 0.0000 & 0.0006 & -1.6249 & -1.6244 \\
\hline $\operatorname{grf}_{M}$ & 0.0000 & 0.0000 & 0.0000 & 0.0000 & 0.0000 & 0.0000 \\
\hline $\mathrm{gc}_{\mathrm{I}}$ & 0.0000 & 0.3820 & 1.0000 & 1.0000 & 0.0474 & -0.0109 \\
\hline $\mathbf{g c}_{\mathrm{C}}$ & 0.0000 & 0.0000 & -0.9205 & -0.9808 & 0.0000 & 0.0000 \\
\hline $\mathbf{f}_{\mathrm{A}}$ & 0.0000 & 0.0000 & 0.0000 & 0.0000 & 0.0000 & 0.0000 \\
\hline $\mathbf{f}_{\mathbf{M}}$ & 0.0000 & 0.0000 & 0.0000 & 0.0000 & 0.0000 & 0.0000 \\
\hline $\mathbf{d}_{\mathrm{A}}$ & 0.0000 & 0.0000 & 0.0000 & 0.0000 & 0.0000 & 0.0000 \\
\hline $\mathbf{d}_{M}$ & 0.0000 & 0.0000 & 0.0000 & 0.0000 & 0.0000 & 0.0000 \\
\hline $\mathbf{t}_{\mathrm{A}}$ & 0.0000 & 0.0000 & 0.0000 & 0.0000 & 0.0000 & 0.0000 \\
\hline $\mathbf{t}_{M}$ & 0.0000 & 0.0000 & 0.0000 & 0.0000 & 0.0000 & 0.0000 \\
\hline$\theta *{ }_{I}$ & 0.0000 & 0.0000 & 0.0000 & 0.0000 & -1.0000 & -1.0000 \\
\hline$\theta *_{C}$ & 0.0000 & 0.0000 & 0.0000 & 0.0000 & 0.8013 & 0.8013 \\
\hline $\mathbf{t}_{\mathrm{v}}$ & 0.0000 & 0.0000 & 0.0000 & 0.0000 & 0.0000 & 0.0000 \\
\hline n & 0.0000 & 0.0000 & 0.0000 & 0.0000 & 0.0000 & 0.0000 \\
\hline$\mu^{*}$ & -1.0000 & -1.0000 & 0.0000 & 0.0000 & 0.0000 & 0.0000 \\
\hline $\mathbf{k}$ & 0.0000 & 0.0000 & 0.0000 & 0.0000 & 0.0000 & 0.0000 \\
\hline
\end{tabular}


Appendix 4 Table 7: Sensitivity to hukou Parameter $(\mu=1.2)$

\begin{tabular}{|c|c|c|c|c|c|c|c|c|}
\hline \multirow[t]{2}{*}{ Variables } & \multicolumn{2}{|c|}{$\begin{array}{c}\text { Policy 1: } \\
\operatorname{grh}_{1}=1\end{array}$} & \multicolumn{2}{|c|}{$\begin{array}{c}\text { Policy 2: } \\
\operatorname{grf}_{\mathbf{A}}=1\end{array}$} & \multicolumn{2}{|c|}{$\begin{array}{c}\text { Policy 3: } \\
t_{\mathrm{A}}=-1\end{array}$} & \multicolumn{2}{|c|}{$\begin{array}{c}\text { Policy 4: } \\
d_{A}=1\end{array}$} \\
\hline & SR & LR & SR & LR & SR & LR & SR & LR \\
\hline$v_{I}$ & -0.0804 & -0.0869 & 0.0674 & 0.0724 & -0.0356 & -0.0229 & 0.4407 & 0.4132 \\
\hline $\mathbf{v}_{\mathbf{C}}$ & -0.1062 & -0.1019 & 0.0891 & 0.0849 & 0.0202 & 0.0094 & 0.3199 & 0.3433 \\
\hline ca I & -0.3577 & -0.3622 & 0.3001 & 0.3017 & 0.0679 & 0.0721 & 1.0776 & 1.0684 \\
\hline $\mathbf{c m}_{\mathrm{I}}$ & 0.0184 & 0.0091 & -0.0154 & -0.0076 & -0.0035 & 0.0166 & -0.0553 & -0.0989 \\
\hline $\mathbf{c a _ { C }}$ & -0.3577 & -0.3496 & 0.3001 & 0.2913 & 0.0679 & 0.0453 & 1.0776 & 1.1266 \\
\hline $\mathbf{c m}_{\mathrm{C}}$ & 0.0184 & 0.0216 & -0.0154 & -0.0180 & -0.0035 & -0.0102 & -0.0553 & -0.0407 \\
\hline $\mathbf{g h}_{\mathbf{I}}$ & 0.2780 & 0.2737 & -0.2332 & -0.2281 & -0.3321 & -0.3188 & 0.2537 & 0.2250 \\
\hline $\mathbf{g h}_{\mathbf{C}}$ & 0.0157 & 0.0158 & -0.0132 & -0.0132 & -0.0030 & -0.0030 & -0.0473 & -0.0472 \\
\hline $\mathbf{j}_{\mathbf{I}}$ & 0.0184 & 0.0091 & -0.0154 & -0.0076 & -0.0035 & 0.0166 & -0.0553 & -0.0989 \\
\hline $\mathbf{j}_{\mathbf{C}}$ & 0.0184 & 0.0216 & -0.0154 & -0.0180 & -0.0035 & -0.0102 & -0.0553 & -0.0407 \\
\hline$\pi \mathbf{h}_{\mathbf{I}}$ & -0.3577 & -0.3730 & 0.3001 & 0.3107 & 0.0679 & 0.0953 & 1.0776 & 1.0181 \\
\hline$\pi \mathbf{h}_{\mathbf{C}}$ & 0.0184 & 0.0232 & -0.0154 & -0.0193 & -0.0035 & -0.0136 & -0.0553 & -0.0333 \\
\hline $\mathbf{w}_{\text {I }}$ & -0.3577 & -0.3533 & 0.3001 & 0.2943 & 0.0679 & 0.0531 & 1.0776 & 1.1098 \\
\hline $\mathbf{w}_{\mathbf{C}}$ & 0.0184 & 0.0232 & -0.0154 & -0.0193 & -0.0035 & -0.0136 & -0.0553 & -0.0333 \\
\hline $\mathbf{y}_{\mathbf{A}}$ & -0.3577 & -0.3586 & 0.3001 & 0.2987 & 0.0049 & 0.0014 & 1.0776 & 1.0851 \\
\hline $\mathbf{y}_{\mathbf{M}}$ & 0.0184 & 0.0160 & -0.0154 & -0.0133 & -0.0035 & 0.0018 & -0.0553 & -0.0668 \\
\hline $\mathbf{l}_{\mathbf{A}}$ & 0.0000 & 0.0053 & 0.0000 & -0.0044 & 0.0000 & -0.0114 & 0.0000 & 0.0247 \\
\hline $\mathbf{l}_{M}$ & 0.0000 & -0.0072 & 0.0000 & 0.0060 & 0.0000 & 0.0155 & 0.0000 & -0.0335 \\
\hline $\mathbf{k}_{\mathbf{A}}$ & -0.2120 & -0.2111 & 0.1778 & 0.1759 & 0.0402 & 0.0353 & 0.6385 & 0.6492 \\
\hline $\mathbf{k}_{\mathbf{M}}$ & 0.1641 & 0.1635 & -0.1377 & -0.1362 & -0.0312 & -0.0273 & -0.4944 & -0.5027 \\
\hline $\mathbf{r}_{\mathrm{A}}$ & -0.1458 & -0.1475 & 0.1223 & 0.1229 & 0.0277 & 0.0292 & 0.4391 & 0.4358 \\
\hline $\mathbf{r}_{\mathbf{M}}$ & -0.1458 & -0.1475 & 0.1223 & 0.1229 & 0.0277 & 0.0292 & 0.4391 & 0.4358 \\
\hline $\boldsymbol{\pi f _ { A }}$ & -0.3577 & -0.3676 & 0.3001 & 0.3063 & 0.0679 & 0.0839 & 1.0776 & 1.0428 \\
\hline$\pi \mathbf{f}_{M}$ & 0.0184 & 0.0160 & -0.0154 & -0.0133 & -0.0035 & 0.0018 & -0.0553 & -0.0668 \\
\hline $\mathbf{P}$ & 0.3761 & 0.3713 & -0.3155 & -0.3093 & -0.0714 & -0.0555 & -1.1329 & -1.1673 \\
\hline $\operatorname{grh}_{I}$ & 1.0000 & 1.0000 & -0.8389 & -0.8332 & -1.3104 & -1.2957 & 1.3656 & 1.3336 \\
\hline $\operatorname{grf}_{A}$ & -1.1921 & -1.2003 & 1.0000 & 1.0000 & 0.0000 & 0.0000 & 0.0000 & 0.0000 \\
\hline $\operatorname{grh}_{C}$ & 0.0449 & 0.0453 & -0.0376 & -0.0377 & -0.0085 & -0.0087 & -0.1352 & -0.1348 \\
\hline $\operatorname{grf}_{M}$ & 0.0000 & 0.0000 & 0.0000 & 0.0000 & 0.0000 & 0.0000 & 0.0000 & 0.0000 \\
\hline $\mathbf{g c}_{\mathrm{I}}$ & 0.0383 & 0.0326 & -0.0321 & -0.0272 & -0.0073 & 0.0055 & -0.1154 & -0.1431 \\
\hline $\mathbf{g c}_{\mathrm{C}}$ & 0.0000 & 0.0000 & 0.0000 & 0.0000 & 0.0000 & 0.0000 & 0.0000 & 0.0000 \\
\hline $\mathbf{f}_{\mathrm{A}}$ & 0.0000 & 0.0000 & 0.0000 & 0.0000 & 0.0000 & 0.0000 & 0.0000 & 0.0000 \\
\hline $\mathbf{f}_{\mathbf{M}}$ & 0.0000 & 0.0000 & 0.0000 & 0.0000 & 0.0000 & 0.0000 & 0.0000 & 0.0000 \\
\hline $\mathbf{d}_{\mathbf{A}}$ & 0.0000 & 0.0000 & 0.0000 & 0.0000 & 0.0000 & 0.0000 & 1.0000 & 1.0000 \\
\hline $\mathbf{d}_{\mathrm{M}}$ & 0.0000 & 0.0000 & 0.0000 & 0.0000 & 0.0000 & 0.0000 & 0.0000 & 0.0000 \\
\hline $\mathbf{t}_{\mathrm{A}}$ & 0.0000 & 0.0000 & 0.0000 & 0.0000 & -1.0000 & -1.0000 & 0.0000 & 0.0000 \\
\hline $\mathbf{t}_{M}$ & 0.0000 & 0.0000 & 0.0000 & 0.0000 & 0.0000 & 0.0000 & 0.0000 & 0.0000 \\
\hline$\theta *{ }_{I}$ & 0.0000 & 0.0000 & 0.0000 & 0.0000 & 0.0000 & 0.0000 & 0.0000 & 0.0000 \\
\hline$\theta^{*} \mathrm{C}$ & 0.0000 & 0.0000 & 0.0000 & 0.0000 & 0.0000 & 0.0000 & 0.0000 & 0.0000 \\
\hline $\mathbf{t}_{\mathrm{v}}$ & 0.0000 & 0.0000 & 0.0000 & 0.0000 & 0.0000 & 0.0000 & 0.0000 & 0.0000 \\
\hline n & 0.0000 & 0.0000 & 0.0000 & 0.0000 & 0.0000 & 0.0000 & 0.0000 & 0.0000 \\
\hline$\mu^{*}$ & 0.0000 & 0.0000 & 0.0000 & 0.0000 & 0.0000 & 0.0000 & 0.0000 & 0.0000 \\
\hline $\mathbf{k}$ & 0.0000 & 0.0000 & 0.0000 & 0.0000 & 0.0000 & 0.0000 & 0.0000 & 0.0000 \\
\hline
\end{tabular}


Appendix 4 Table 7(cont'd): Sensitivity to hukou Parameter $(\mu=1.2)$

\begin{tabular}{|c|c|c|c|c|c|c|}
\hline \multirow[t]{2}{*}{ Variables } & \multicolumn{2}{|c|}{$\begin{array}{c}\text { Policy 5: } \\
\mu^{*=-1}\end{array}$} & \multicolumn{2}{|c|}{$\begin{array}{c}\text { Policy 6: } \\
\mathrm{gc}_{\mathrm{I}}=1\end{array}$} & \multicolumn{2}{|c|}{$\begin{array}{c}\text { Policy 7: } \\
\theta *_{\mathrm{I}}=-1, \theta^{*}{ }_{\mathrm{C}}=0.8013\end{array}$} \\
\hline & SR & LR & SR & LR & SR & LR \\
\hline $\mathbf{V}_{\text {I }}$ & 0.0000 & 0.4101 & 0.1366 & 0.0864 & 0.1297 & 0.0775 \\
\hline $\mathbf{v}_{\mathbf{C}}$ & 0.0000 & -0.3492 & -0.1049 & -0.0614 & -0.0995 & -0.0551 \\
\hline $\mathbf{c a}_{\mathbf{I}}$ & 0.0000 & 0.1369 & 0.0000 & -0.0194 & 0.0000 & -0.0174 \\
\hline $\mathbf{c m}_{I}$ & 0.0000 & 0.6492 & 0.0000 & -0.0922 & 0.0000 & -0.0827 \\
\hline $\mathbf{c a}_{\mathrm{C}}$ & 0.0000 & -0.7303 & 0.0000 & 0.1037 & 0.0000 & 0.0930 \\
\hline $\mathbf{c m}_{\mathrm{C}}$ & 0.0000 & -0.2181 & 0.0000 & 0.0310 & 0.0000 & 0.0278 \\
\hline $\mathbf{g h}_{\mathbf{I}}$ & 0.0000 & 0.4282 & 0.7508 & 0.7339 & 0.7127 & 0.6581 \\
\hline $\mathbf{g h}_{\mathbf{C}}$ & 0.0000 & -0.0019 & -0.5986 & -0.6334 & -0.5682 & -0.5680 \\
\hline $\mathbf{j}_{\mathbf{I}}$ & 0.0000 & 0.6492 & 0.0000 & -0.0922 & 0.0000 & -0.0827 \\
\hline $\mathbf{j}_{\mathbf{C}}$ & 0.0000 & -0.2181 & 0.0000 & 0.0310 & 0.0000 & 0.0278 \\
\hline$\pi \mathbf{h}_{\mathbf{I}}$ & 0.0000 & 0.8857 & 0.0000 & -0.1258 & 0.0000 & -0.1128 \\
\hline $\boldsymbol{\pi} \mathbf{h}_{\mathrm{C}}$ & 0.0000 & -0.3275 & 0.0000 & 0.0465 & 0.0000 & 0.0417 \\
\hline $\mathbf{w}_{\text {I }}$ & 0.0000 & -0.4793 & 0.0000 & 0.0681 & 0.0000 & 0.0610 \\
\hline $\mathbf{w}_{\mathbf{C}}$ & 0.0000 & -0.3275 & 0.0000 & 0.0465 & 0.0000 & 0.0417 \\
\hline $\mathbf{y}_{\mathbf{A}}$ & 0.0000 & -0.1114 & 0.0000 & 0.0158 & 0.0000 & 0.0142 \\
\hline $\mathbf{y}_{\mathbf{M}}$ & 0.0000 & 0.1718 & 0.0000 & -0.0244 & 0.0000 & -0.0219 \\
\hline $\mathbf{l}_{\mathbf{A}}$ & 0.0000 & -0.3679 & 0.0000 & 0.0523 & 0.0000 & 0.0469 \\
\hline $\mathbf{I}_{M}$ & 0.0000 & 0.4993 & 0.0000 & -0.0709 & 0.0000 & -0.0636 \\
\hline $\mathbf{k}_{\mathbf{A}}$ & 0.0000 & -0.1596 & 0.0000 & 0.0227 & 0.0000 & 0.0203 \\
\hline $\mathbf{k}_{\mathbf{M}}$ & 0.0000 & 0.1236 & 0.0000 & -0.0176 & 0.0000 & -0.0157 \\
\hline $\mathbf{r}_{\mathrm{A}}$ & 0.0000 & 0.0482 & 0.0000 & -0.0069 & 0.0000 & -0.0061 \\
\hline $\mathbf{r}_{\mathbf{M}}$ & 0.0000 & 0.0482 & 0.0000 & -0.0069 & 0.0000 & -0.0061 \\
\hline$\pi \mathbf{f}_{\mathrm{A}}$ & 0.0000 & 0.5178 & 0.0000 & -0.0735 & 0.0000 & -0.0659 \\
\hline $\boldsymbol{\pi} \mathbf{f}_{M}$ & 0.0000 & 0.1718 & 0.0000 & -0.0244 & 0.0000 & -0.0219 \\
\hline $\mathbf{P}$ & 0.0000 & 0.5123 & 0.0000 & -0.0727 & 0.0000 & -0.0652 \\
\hline $\operatorname{grh}_{I}$ & 0.0000 & 0.4763 & 0.0000 & -0.0676 & 2.7164 & 2.6557 \\
\hline $\operatorname{grf}_{\mathbf{A}}$ & 0.0000 & 0.0000 & 0.0000 & 0.0000 & 0.0000 & 0.0000 \\
\hline $\operatorname{grh}_{C}$ & 0.0000 & -0.0053 & 0.0000 & 0.0008 & -1.6249 & -1.6242 \\
\hline $\operatorname{grf}_{M}$ & 0.0000 & 0.0000 & 0.0000 & 0.0000 & 0.0000 & 0.0000 \\
\hline $\mathbf{g c}_{\mathrm{I}}$ & 0.0000 & 0.4123 & 1.0000 & 1.0000 & 0.0474 & -0.0051 \\
\hline $\mathbf{g c}_{\mathrm{C}}$ & 0.0000 & 0.0000 & -0.9205 & -0.9743 & 0.0000 & 0.0000 \\
\hline $\mathbf{f}_{\mathrm{A}}$ & 0.0000 & 0.0000 & 0.0000 & 0.0000 & 0.0000 & 0.0000 \\
\hline $\mathbf{f}_{\mathbf{M}}$ & 0.0000 & 0.0000 & 0.0000 & 0.0000 & 0.0000 & 0.0000 \\
\hline $\mathbf{d}_{\mathbf{A}}$ & 0.0000 & 0.0000 & 0.0000 & 0.0000 & 0.0000 & 0.0000 \\
\hline $\mathbf{d}_{\mathbf{M}}$ & 0.0000 & 0.0000 & 0.0000 & 0.0000 & 0.0000 & 0.0000 \\
\hline $\mathbf{t}_{\mathbf{A}}$ & 0.0000 & 0.0000 & 0.0000 & 0.0000 & 0.0000 & 0.0000 \\
\hline $\mathbf{t}_{M}$ & 0.0000 & 0.0000 & 0.0000 & 0.0000 & 0.0000 & 0.0000 \\
\hline$\theta *{ }_{I}$ & 0.0000 & 0.0000 & 0.0000 & 0.0000 & -1.0000 & -1.0000 \\
\hline$\theta *{ }_{C}$ & 0.0000 & 0.0000 & 0.0000 & 0.0000 & 0.8013 & 0.8013 \\
\hline$t_{V}$ & 0.0000 & 0.0000 & 0.0000 & 0.0000 & 0.0000 & 0.0000 \\
\hline n & 0.0000 & 0.0000 & 0.0000 & 0.0000 & 0.0000 & 0.0000 \\
\hline$\mu^{*}$ & -1.0000 & -1.0000 & 0.0000 & 0.0000 & 0.0000 & 0.0000 \\
\hline $\mathbf{k}$ & 0.0000 & 0.0000 & 0.0000 & 0.0000 & 0.0000 & 0.0000 \\
\hline
\end{tabular}




\begin{tabular}{|c|c|c|c|c|c|c|c|c|}
\hline \multirow[t]{2}{*}{ Variables } & \multicolumn{2}{|c|}{$\begin{array}{c}\text { Policy 1: } \\
\operatorname{grh}_{\mathrm{I}}=1\end{array}$} & \multicolumn{2}{|c|}{$\begin{array}{c}\text { Policy 2: } \\
\operatorname{grf}_{\mathbf{A}}=1\end{array}$} & \multicolumn{2}{|c|}{$\begin{array}{c}\text { Policy 3: } \\
t_{\mathrm{A}}=-1\end{array}$} & \multicolumn{2}{|c|}{$\begin{array}{c}\text { Policy 4: } \\
d_{A}=1\end{array}$} \\
\hline & SR & LR & SR & LR & SR & LR & SR & LR \\
\hline $\mathbf{v}_{\mathbf{I}}$ & -0.0804 & -0.0860 & 0.0674 & 0.0718 & -0.0356 & -0.0245 & 0.4407 & 0.4167 \\
\hline $\mathbf{v}_{\mathbf{C}}$ & -0.1062 & -0.1024 & 0.0891 & 0.0854 & 0.0202 & 0.0107 & 0.3199 & 0.3404 \\
\hline$c a_{I}$ & -0.3577 & -0.3616 & 0.3001 & 0.3015 & 0.0679 & 0.0716 & 1.0776 & 1.0696 \\
\hline $\mathrm{cm}_{\mathrm{I}}$ & 0.0184 & 0.0103 & -0.0154 & -0.0086 & -0.0035 & 0.0141 & -0.0553 & -0.0934 \\
\hline $\mathbf{c a}_{\mathbf{C}}$ & -0.3577 & -0.3507 & 0.3001 & 0.2924 & 0.0679 & 0.0481 & 1.0776 & 1.1204 \\
\hline $\mathbf{c m}_{\mathrm{C}}$ & 0.0184 & 0.0212 & -0.0154 & -0.0177 & -0.0035 & -0.0094 & -0.0553 & -0.0425 \\
\hline $\mathbf{g h}_{\mathbf{I}}$ & 0.2780 & 0.2743 & -0.2332 & -0.2287 & -0.3321 & -0.3205 & 0.2537 & 0.2286 \\
\hline $\mathbf{g h}_{\mathbf{C}}$ & 0.0157 & 0.0158 & -0.0132 & -0.0132 & -0.0030 & -0.0030 & -0.0473 & -0.0472 \\
\hline $\mathbf{j}_{\mathbf{I}}$ & 0.0184 & 0.0103 & -0.0154 & -0.0086 & -0.0035 & 0.0141 & -0.0553 & -0.0934 \\
\hline $\mathbf{j}_{\mathbf{C}}$ & 0.0184 & 0.0212 & -0.0154 & -0.0177 & -0.0035 & -0.0094 & -0.0553 & -0.0425 \\
\hline $\boldsymbol{\pi} \mathbf{h}_{\mathbf{I}}$ & -0.3577 & -0.3710 & 0.3001 & 0.3094 & 0.0679 & 0.0919 & 1.0776 & 1.0257 \\
\hline $\boldsymbol{\pi} \mathbf{h}_{\mathbf{C}}$ & 0.0184 & 0.0226 & -0.0154 & -0.0188 & -0.0035 & -0.0123 & -0.0553 & -0.0361 \\
\hline $\mathbf{w}_{\text {I }}$ & -0.3577 & -0.3538 & 0.3001 & 0.2950 & 0.0679 & 0.0549 & 1.0776 & 1.1057 \\
\hline $\mathbf{w}_{\mathbf{C}}$ & 0.0184 & 0.0226 & -0.0154 & -0.0188 & -0.0035 & -0.0123 & -0.0553 & -0.0361 \\
\hline $\mathbf{y}_{\mathbf{A}}$ & -0.3577 & -0.3585 & 0.3001 & 0.2989 & 0.0049 & 0.0019 & 1.0776 & 1.0841 \\
\hline $\mathbf{y}_{\mathbf{M}}$ & 0.0184 & 0.0163 & -0.0154 & -0.0136 & -0.0035 & 0.0012 & -0.0553 & -0.0654 \\
\hline$\underline{\mathbf{I}_{\mathbf{A}}}$ & 0.0000 & 0.0046 & 0.0000 & -0.0039 & 0.0000 & -0.0100 & 0.0000 & 0.0216 \\
\hline $\mathbf{l}_{M}$ & 0.0000 & -0.0063 & 0.0000 & 0.0052 & 0.0000 & 0.0135 & 0.0000 & -0.0293 \\
\hline $\mathbf{k}_{\mathbf{A}}$ & -0.2120 & -0.2112 & 0.1778 & 0.1761 & 0.0402 & 0.0359 & 0.6385 & 0.6479 \\
\hline $\mathbf{k}_{\mathbf{M}}$ & 0.1641 & 0.1635 & -0.1377 & -0.1364 & -0.0312 & -0.0278 & -0.4944 & -0.5016 \\
\hline $\mathbf{r}_{\mathbf{A}}$ & -0.1458 & -0.1472 & 0.1223 & 0.1228 & 0.0277 & 0.0290 & 0.4391 & 0.4363 \\
\hline $\mathbf{r}_{M}$ & -0.1458 & -0.1472 & 0.1223 & 0.1228 & 0.0277 & 0.0290 & 0.4391 & 0.4363 \\
\hline$\pi \mathbf{f}_{\mathrm{A}}$ & -0.3577 & -0.3664 & 0.3001 & 0.3055 & 0.0679 & 0.0819 & 1.0776 & 1.0472 \\
\hline$\pi \mathbf{f}_{\mathbf{M}}$ & 0.0184 & 0.0163 & -0.0154 & -0.0136 & -0.0035 & 0.0012 & -0.0553 & -0.0654 \\
\hline $\mathbf{P}$ & 0.3761 & 0.3719 & -0.3155 & -0.3101 & -0.0714 & -0.0575 & -1.1329 & -1.1630 \\
\hline $\operatorname{grh}_{I}$ & 1.0000 & 1.0000 & -0.8389 & -0.8339 & -1.3104 & -1.2975 & 1.3656 & 1.3376 \\
\hline $\operatorname{grf}_{A}$ & -1.1921 & -1.1992 & 1.0000 & 1.0000 & 0.0000 & 0.0000 & 0.0000 & 0.0000 \\
\hline $\operatorname{grh}_{\mathrm{C}}$ & 0.0449 & 0.0452 & -0.0376 & -0.0377 & -0.0085 & -0.0087 & -0.1352 & -0.1349 \\
\hline $\operatorname{grf}_{M}$ & 0.0000 & 0.0000 & 0.0000 & 0.0000 & 0.0000 & 0.0000 & 0.0000 & 0.0000 \\
\hline$g_{c_{I}}$ & 0.0383 & 0.0333 & -0.0321 & -0.0278 & -0.0073 & 0.0039 & -0.1154 & -0.1396 \\
\hline $\mathbf{g c}_{\mathrm{C}}$ & 0.0000 & 0.0000 & 0.0000 & 0.0000 & 0.0000 & 0.0000 & 0.0000 & 0.0000 \\
\hline $\mathbf{f}_{\mathrm{A}}$ & 0.0000 & 0.0000 & 0.0000 & 0.0000 & 0.0000 & 0.0000 & 0.0000 & 0.0000 \\
\hline $\mathbf{f}_{\mathbf{M}}$ & 0.0000 & 0.0000 & 0.0000 & 0.0000 & 0.0000 & 0.0000 & 0.0000 & 0.0000 \\
\hline $\mathbf{d}_{\mathbf{A}}$ & 0.0000 & 0.0000 & 0.0000 & 0.0000 & 0.0000 & 0.0000 & 1.0000 & 1.0000 \\
\hline $\mathbf{d}_{\mathbf{M}}$ & 0.0000 & 0.0000 & 0.0000 & 0.0000 & 0.0000 & 0.0000 & 0.0000 & 0.0000 \\
\hline $\mathbf{t}_{\mathrm{A}}$ & 0.0000 & 0.0000 & 0.0000 & 0.0000 & -1.0000 & -1.0000 & 0.0000 & 0.0000 \\
\hline$t_{M}$ & 0.0000 & 0.0000 & 0.0000 & 0.0000 & 0.0000 & 0.0000 & 0.0000 & 0.0000 \\
\hline$\theta *{ }_{I}$ & 0.0000 & 0.0000 & 0.0000 & 0.0000 & 0.0000 & 0.0000 & 0.0000 & 0.0000 \\
\hline$\theta^{*} \mathrm{C}$ & 0.0000 & 0.0000 & 0.0000 & 0.0000 & 0.0000 & 0.0000 & 0.0000 & 0.0000 \\
\hline$t_{V}$ & 0.0000 & 0.0000 & 0.0000 & 0.0000 & 0.0000 & 0.0000 & 0.0000 & 0.0000 \\
\hline $\mathrm{n}$ & 0.0000 & 0.0000 & 0.0000 & 0.0000 & 0.0000 & 0.0000 & 0.0000 & 0.0000 \\
\hline$\mu^{*}$ & 0.0000 & 0.0000 & 0.0000 & 0.0000 & 0.0000 & 0.0000 & 0.0000 & 0.0000 \\
\hline $\mathbf{k}$ & 0.0000 & 0.0000 & 0.0000 & 0.0000 & 0.0000 & 0.0000 & 0.0000 & 0.0000 \\
\hline
\end{tabular}




\begin{tabular}{|c|c|c|c|c|c|c|}
\hline \multirow[t]{2}{*}{ Variables } & \multicolumn{2}{|c|}{$\begin{array}{c}\text { Policy 5: } \\
\mu^{*}=-1\end{array}$} & \multicolumn{2}{|c|}{$\begin{array}{c}\text { Policy 6: } \\
\mathrm{gc}_{\mathrm{I}}=1\end{array}$} & \multicolumn{2}{|c|}{$\begin{array}{c}\text { Policy 7: } \\
\theta *{ }_{1}=-1, \theta *{ }_{C}=0.8013\end{array}$} \\
\hline & SR & LR & SR & LR & SR & LR \\
\hline $\mathbf{V}_{\text {I }}$ & 0.0000 & 0.4479 & 0.1366 & 0.0930 & 0.1297 & 0.0841 \\
\hline $\mathbf{v}_{\mathbf{C}}$ & 0.0000 & -0.3814 & -0.1049 & -0.0672 & -0.0995 & -0.0607 \\
\hline $\mathbf{c a}_{\mathbf{I}}$ & 0.0000 & 0.1495 & 0.0000 & -0.0169 & 0.0000 & -0.0152 \\
\hline $\mathbf{c m}_{\mathrm{I}}$ & 0.0000 & 0.7090 & 0.0000 & -0.0800 & 0.0000 & -0.0722 \\
\hline $\mathbf{c a}_{\mathrm{C}}$ & 0.0000 & -0.7976 & 0.0000 & 0.0900 & 0.0000 & 0.0813 \\
\hline $\mathbf{c m}_{\mathrm{C}}$ & 0.0000 & -0.2382 & 0.0000 & 0.0269 & 0.0000 & 0.0243 \\
\hline $\mathbf{g h}_{\mathbf{I}}$ & 0.0000 & 0.4677 & 0.7508 & 0.7361 & 0.7127 & 0.6650 \\
\hline $\mathbf{g h}_{\mathrm{C}}$ & 0.0000 & -0.0020 & -0.5986 & -0.6288 & -0.5682 & -0.5680 \\
\hline $\mathbf{j}_{\mathbf{I}}$ & 0.0000 & 0.7090 & 0.0000 & -0.0800 & 0.0000 & -0.0722 \\
\hline $\mathbf{j}_{\mathbf{C}}$ & 0.0000 & -0.2382 & 0.0000 & 0.0269 & 0.0000 & 0.0243 \\
\hline $\boldsymbol{\pi} \mathbf{h}_{\mathbf{I}}$ & 0.0000 & 0.9673 & 0.0000 & -0.1091 & 0.0000 & -0.0985 \\
\hline $\boldsymbol{\pi} \mathbf{h}_{\mathrm{C}}$ & 0.0000 & -0.3577 & 0.0000 & 0.0403 & 0.0000 & 0.0364 \\
\hline $\mathbf{w}_{\text {I }}$ & 0.0000 & -0.5235 & 0.0000 & 0.0590 & 0.0000 & 0.0533 \\
\hline $\mathbf{w}_{\mathbf{C}}$ & 0.0000 & -0.3577 & 0.0000 & 0.0403 & 0.0000 & 0.0364 \\
\hline $\mathbf{y}_{\mathbf{A}}$ & 0.0000 & -0.1216 & 0.0000 & 0.0137 & 0.0000 & 0.0124 \\
\hline $\mathbf{y}_{\mathbf{M}}$ & 0.0000 & 0.1876 & 0.0000 & -0.0212 & 0.0000 & -0.0191 \\
\hline $\mathbf{l}_{\mathrm{A}}$ & 0.0000 & -0.4018 & 0.0000 & 0.0453 & 0.0000 & 0.0409 \\
\hline $\mathbf{l}_{\mathbf{M}}$ & 0.0000 & 0.5453 & 0.0000 & -0.0615 & 0.0000 & -0.0556 \\
\hline $\mathbf{k}_{\mathbf{A}}$ & 0.0000 & -0.1743 & 0.0000 & 0.0197 & 0.0000 & 0.0178 \\
\hline $\mathbf{k}_{\mathbf{M}}$ & 0.0000 & 0.1350 & 0.0000 & -0.0152 & 0.0000 & -0.0138 \\
\hline $\mathbf{r}_{\mathbf{A}}$ & 0.0000 & 0.0527 & 0.0000 & -0.0059 & 0.0000 & -0.0054 \\
\hline $\mathbf{r}_{\mathbf{M}}$ & 0.0000 & 0.0527 & 0.0000 & -0.0059 & 0.0000 & -0.0054 \\
\hline$\pi \mathbf{f}_{A}$ & 0.0000 & 0.5655 & 0.0000 & -0.0638 & 0.0000 & -0.0576 \\
\hline$\pi \mathbf{f}_{M}$ & 0.0000 & 0.1876 & 0.0000 & -0.0212 & 0.0000 & -0.0191 \\
\hline $\mathbf{P}$ & 0.0000 & 0.5595 & 0.0000 & -0.0631 & 0.0000 & -0.0570 \\
\hline $\operatorname{grh}_{I}$ & 0.0000 & 0.5202 & 0.0000 & -0.0587 & 2.7164 & 2.6634 \\
\hline $\operatorname{grf}_{\mathbf{A}}$ & 0.0000 & 0.0000 & 0.0000 & 0.0000 & 0.0000 & 0.0000 \\
\hline $\operatorname{grh}_{C}$ & 0.0000 & -0.0058 & 0.0000 & 0.0007 & -1.6249 & -1.6243 \\
\hline $\operatorname{grf}_{M}$ & 0.0000 & 0.0000 & 0.0000 & 0.0000 & 0.0000 & 0.0000 \\
\hline $\mathbf{g c}_{\mathrm{I}}$ & 0.0000 & 0.4503 & 1.0000 & 1.0000 & 0.0474 & 0.0016 \\
\hline $\mathbf{g c}_{\mathrm{C}}$ & 0.0000 & 0.0000 & -0.9205 & -0.9672 & 0.0000 & 0.0000 \\
\hline $\mathbf{f}_{\mathrm{A}}$ & 0.0000 & 0.0000 & 0.0000 & 0.0000 & 0.0000 & 0.0000 \\
\hline $\mathbf{f}_{M}$ & 0.0000 & 0.0000 & 0.0000 & 0.0000 & 0.0000 & 0.0000 \\
\hline $\mathbf{d}_{\mathbf{A}}$ & 0.0000 & 0.0000 & 0.0000 & 0.0000 & 0.0000 & 0.0000 \\
\hline $\mathbf{d}_{\mathbf{M}}$ & 0.0000 & 0.0000 & 0.0000 & 0.0000 & 0.0000 & 0.0000 \\
\hline $\mathbf{t}_{\mathrm{A}}$ & 0.0000 & 0.0000 & 0.0000 & 0.0000 & 0.0000 & 0.0000 \\
\hline $\mathbf{t}_{M}$ & 0.0000 & 0.0000 & 0.0000 & 0.0000 & 0.0000 & 0.0000 \\
\hline$\theta *_{I}$ & 0.0000 & 0.0000 & 0.0000 & 0.0000 & -1.0000 & -1.0000 \\
\hline$\theta *_{C}$ & 0.0000 & 0.0000 & 0.0000 & 0.0000 & 0.8013 & 0.8013 \\
\hline $\mathbf{t}_{\mathrm{V}}$ & 0.0000 & 0.0000 & 0.0000 & 0.0000 & 0.0000 & 0.0000 \\
\hline n & 0.0000 & 0.0000 & 0.0000 & 0.0000 & 0.0000 & 0.0000 \\
\hline$\mu^{*}$ & -1.0000 & -1.0000 & 0.0000 & 0.0000 & 0.0000 & 0.0000 \\
\hline $\mathbf{k}$ & 0.0000 & 0.0000 & 0.0000 & 0.0000 & 0.0000 & 0.0000 \\
\hline
\end{tabular}


Appendix 4 Table 9: Sensitivity to Closure Assumption (grf $\mathrm{A}_{\mathrm{A}}$ endogenous)

\begin{tabular}{|c|c|c|c|c|c|c|}
\hline \multirow[t]{2}{*}{ Variables } & \multicolumn{2}{|c|}{$\begin{array}{c}\text { Policy 3: } \\
t_{A}=-1\end{array}$} & \multicolumn{2}{|c|}{$\begin{array}{c}\text { Policy 4: } \\
d_{A}=1\end{array}$} & \multicolumn{2}{|c|}{$\begin{array}{c}\text { Policy 5: } \\
\mu^{*}=-1\end{array}$} \\
\hline & SR & LR & SR & LR & SR & LR \\
\hline$v_{I}$ & -0.1409 & -0.1348 & 0.5505 & 0.5267 & 0.0000 & 0.4167 \\
\hline $\mathbf{v}_{\mathbf{C}}$ & -0.1190 & -0.1231 & 0.4649 & 0.4807 & 0.0000 & -0.2775 \\
\hline $\mathbf{c a}_{1}$ & -0.4009 & -0.3967 & 1.5661 & 1.5498 & 0.0000 & 0.2855 \\
\hline $\mathbf{c m}_{I}$ & 0.0206 & 0.0293 & -0.0804 & -0.1143 & 0.0000 & 0.5951 \\
\hline $\mathbf{c a}_{\mathrm{C}}$ & -0.4009 & -0.4085 & 1.5661 & 1.5958 & 0.0000 & -0.5203 \\
\hline $\mathbf{c m}_{\mathrm{C}}$ & 0.0206 & 0.0175 & -0.0804 & -0.0683 & 0.0000 & -0.2108 \\
\hline $\mathbf{g h}_{\mathbf{I}}$ & 0.0322 & 0.0362 & -0.1259 & -0.1416 & 0.0000 & 0.2749 \\
\hline $\mathbf{g h}_{\mathbf{C}}$ & 0.0176 & 0.0175 & -0.0687 & -0.0682 & 0.0000 & -0.0087 \\
\hline $\mathbf{j}_{\mathbf{I}}$ & 0.0206 & 0.0293 & -0.0804 & -0.1143 & 0.0000 & 0.5951 \\
\hline $\mathbf{j}_{\mathbf{C}}$ & 0.0206 & 0.0175 & -0.0804 & -0.0683 & 0.0000 & -0.2108 \\
\hline$\pi \mathbf{h}_{\mathbf{I}}$ & -0.4009 & -0.3865 & 1.5661 & 1.5101 & 0.0000 & 0.9813 \\
\hline$\pi \mathbf{h}_{\mathbf{C}}$ & 0.0206 & 0.0160 & -0.0804 & -0.0625 & 0.0000 & -0.3125 \\
\hline $\mathbf{w}_{\mathrm{I}}$ & -0.4009 & -0.4051 & 1.5661 & 1.5825 & 0.0000 & -0.2871 \\
\hline $\mathbf{w}_{\mathbf{C}}$ & 0.0206 & 0.0160 & -0.0804 & -0.0625 & 0.0000 & -0.3125 \\
\hline $\mathbf{y}_{\mathbf{A}}$ & -0.4639 & -0.4631 & 1.5661 & 1.5630 & 0.0000 & 0.0548 \\
\hline $\mathbf{y}_{\mathbf{M}}$ & 0.0206 & 0.0228 & -0.0804 & -0.0890 & 0.0000 & 0.1515 \\
\hline $\mathbf{I}_{\mathbf{A}}$ & 0.0000 & -0.0050 & 0.0000 & 0.0195 & 0.0000 & -0.3419 \\
\hline $\mathbf{l}_{M}$ & 0.0000 & 0.0068 & 0.0000 & -0.0265 & 0.0000 & 0.4640 \\
\hline $\mathbf{k}_{\mathbf{A}}$ & -0.2375 & -0.2383 & 0.9280 & 0.9311 & 0.0000 & -0.0545 \\
\hline $\mathbf{k}_{\mathbf{M}}$ & 0.1839 & 0.1845 & -0.7185 & -0.7209 & 0.0000 & 0.0422 \\
\hline $\mathbf{r}_{\mathrm{A}}$ & -0.1633 & -0.1617 & 0.6381 & 0.6319 & 0.0000 & 0.1093 \\
\hline $\mathbf{r}_{M}$ & -0.1633 & -0.1617 & 0.6381 & 0.6319 & 0.0000 & 0.1093 \\
\hline $\boldsymbol{\pi \mathbf { f } _ { \mathrm { A } }}$ & -0.4009 & -0.3915 & 1.5661 & 1.5296 & 0.0000 & 0.6394 \\
\hline$\pi \mathbf{f}_{M}$ & 0.0206 & 0.0228 & -0.0804 & -0.0890 & 0.0000 & 0.1515 \\
\hline $\mathbf{P}$ & 0.4214 & 0.4260 & -1.6464 & -1.6641 & 0.0000 & 0.3096 \\
\hline $\operatorname{grh}_{I}$ & 0.0000 & 0.0000 & 0.0000 & 0.0000 & 0.0000 & 0.0000 \\
\hline $\operatorname{grf}_{\mathbf{A}}$ & -1.5621 & -1.5544 & 1.6278 & 1.5977 & 0.0000 & 0.5276 \\
\hline $\operatorname{grh}_{C}$ & 0.0503 & 0.0499 & -0.1965 & -0.1951 & 0.0000 & -0.0248 \\
\hline $\operatorname{grf}_{M}$ & 0.0000 & 0.0000 & 0.0000 & 0.0000 & 0.0000 & 0.0000 \\
\hline $\mathbf{g c}_{\mathbf{I}}$ & 0.0429 & 0.0483 & -0.1677 & -0.1886 & 0.0000 & 0.3661 \\
\hline $\mathbf{g c}_{\mathbf{C}}$ & 0.0000 & 0.0000 & 0.0000 & 0.0000 & 0.0000 & 0.0000 \\
\hline $\mathbf{f}_{\mathrm{A}}$ & 0.0000 & 0.0000 & 0.0000 & 0.0000 & 0.0000 & 0.0000 \\
\hline $\mathbf{f}_{\mathbf{M}}$ & 0.0000 & 0.0000 & 0.0000 & 0.0000 & 0.0000 & 0.0000 \\
\hline $\mathbf{d}_{\mathbf{A}}$ & 0.0000 & 0.0000 & 1.0000 & 1.0000 & 0.0000 & 0.0000 \\
\hline $\mathbf{d}_{\mathbf{M}}$ & 0.0000 & 0.0000 & 0.0000 & 0.0000 & 0.0000 & 0.0000 \\
\hline $\mathbf{t}_{\mathrm{A}}$ & -1.0000 & -1.0000 & 0.0000 & 0.0000 & 0.0000 & 0.0000 \\
\hline $\mathbf{t}_{M}$ & 0.0000 & 0.0000 & 0.0000 & 0.0000 & 0.0000 & 0.0000 \\
\hline$\theta *{ }_{I}$ & 0.0000 & 0.0000 & 0.0000 & 0.0000 & 0.0000 & 0.0000 \\
\hline$\theta^{*}{ }_{C}$ & 0.0000 & 0.0000 & 0.0000 & 0.0000 & 0.0000 & 0.0000 \\
\hline $\mathbf{t}_{\mathrm{V}}$ & 0.0000 & 0.0000 & 0.0000 & 0.0000 & 0.0000 & 0.0000 \\
\hline n & 0.0000 & 0.0000 & 0.0000 & 0.0000 & 0.0000 & 0.0000 \\
\hline$\mu^{*}$ & 0.0000 & 0.0000 & 0.0000 & 0.0000 & -1.0000 & -1.0000 \\
\hline $\mathbf{k}$ & 0.0000 & 0.0000 & 0.0000 & 0.0000 & 0.0000 & 0.0000 \\
\hline
\end{tabular}


Appendix 4 Table 9(cont'd): Sensitivity to Closure Assumption (grf ${ }_{\mathrm{A}}$ endogenous)

\begin{tabular}{|c|c|c|c|c|}
\hline \multirow[t]{2}{*}{ Variables } & \multicolumn{2}{|c|}{$\begin{array}{c}\text { Policy 6: } \\
\mathrm{gc}_{\mathrm{I}}=1\end{array}$} & \multicolumn{2}{|c|}{$\begin{array}{c}\text { Policy 7: } \\
\theta^{*}=-1, \theta^{*}{ }_{C}=0.8013\end{array}$} \\
\hline & SR & LR & SR & LR \\
\hline $\mathbf{v}_{I}$ & 0.1366 & 0.0739 & 0.3481 & 0.3039 \\
\hline $\mathbf{v}_{\mathbf{C}}$ & -0.1049 & -0.0640 & 0.1889 & 0.2184 \\
\hline $\mathrm{ca}_{\mathrm{I}}$ & 0.0000 & -0.0488 & 0.9717 & 0.9414 \\
\hline $\mathbf{c m}_{\mathrm{I}}$ & 0.0000 & -0.1018 & -0.0499 & -0.1130 \\
\hline $\mathbf{c a}_{\mathrm{C}}$ & 0.0000 & 0.0890 & 0.9717 & 1.0269 \\
\hline $\mathbf{c m}_{\mathrm{C}}$ & 0.0000 & 0.0361 & -0.0499 & -0.0275 \\
\hline $\mathbf{g h}_{\mathbf{I}}$ & 0.7508 & 0.7508 & -0.0425 & -0.0717 \\
\hline $\mathbf{g h}_{\mathbf{C}}$ & -0.5986 & -0.6346 & -0.6108 & -0.6099 \\
\hline $\mathbf{j}_{\mathbf{I}}$ & 0.0000 & -0.1018 & -0.0499 & -0.1130 \\
\hline $\mathbf{j}_{\mathbf{C}}$ & 0.0000 & 0.0361 & -0.0499 & -0.0275 \\
\hline$\pi \mathbf{h}_{\mathbf{I}}$ & 0.0000 & -0.1679 & 0.9717 & 0.8676 \\
\hline $\boldsymbol{\pi} \mathbf{h}_{\mathrm{C}}$ & 0.0000 & 0.0535 & -0.0499 & -0.0167 \\
\hline $\mathbf{w}_{\mathbf{I}}$ & 0.0000 & 0.0491 & 0.9717 & 1.0021 \\
\hline $\mathbf{w}_{\mathbf{C}}$ & 0.0000 & 0.0535 & -0.0499 & -0.0167 \\
\hline $\mathbf{y}_{\mathbf{A}}$ & 0.0000 & -0.0094 & 0.9717 & 0.9659 \\
\hline $\mathbf{y}_{\mathbf{M}}$ & 0.0000 & -0.0259 & -0.0499 & -0.0659 \\
\hline $\mathbf{I}_{\mathrm{A}}$ & 0.0000 & 0.0585 & 0.0000 & 0.0363 \\
\hline $\mathbf{l}_{M}$ & 0.0000 & -0.0794 & 0.0000 & -0.0492 \\
\hline $\mathbf{k}_{\mathbf{A}}$ & 0.0000 & 0.0093 & 0.5758 & 0.5815 \\
\hline $\mathbf{k}_{\mathbf{M}}$ & 0.0000 & -0.0072 & -0.4458 & -0.4503 \\
\hline $\mathbf{r}_{\mathrm{A}}$ & 0.0000 & -0.0187 & 0.3959 & 0.3843 \\
\hline $\mathbf{r}_{\mathbf{M}}$ & 0.0000 & -0.0187 & 0.3959 & 0.3843 \\
\hline$\pi \mathbf{f}_{A}$ & 0.0000 & -0.1094 & 0.9717 & 0.9039 \\
\hline$\pi \mathbf{f}_{M}$ & 0.0000 & -0.0259 & -0.0499 & -0.0659 \\
\hline $\mathbf{P}$ & 0.0000 & -0.0530 & -1.0215 & -1.0544 \\
\hline $\operatorname{grh}_{I}$ & 0.0000 & 0.0000 & 0.0000 & 0.0000 \\
\hline $\operatorname{grf}_{\mathbf{A}}$ & 0.0000 & -0.0902 & 3.2381 & 3.1822 \\
\hline $\operatorname{grh}_{C}$ & 0.0000 & 0.0042 & -1.7468 & -1.7442 \\
\hline $\operatorname{grf}_{M}$ & 0.0000 & 0.0000 & 0.0000 & 0.0000 \\
\hline $\mathbf{g c}_{\mathrm{I}}$ & 1.0000 & 1.0000 & -0.0566 & -0.0954 \\
\hline $\mathbf{g c}_{\mathbf{C}}$ & -0.9205 & -0.9781 & 0.0000 & 0.0000 \\
\hline $\mathbf{f}_{\mathrm{A}}$ & 0.0000 & 0.0000 & 0.0000 & 0.0000 \\
\hline $\mathbf{f}_{M}$ & 0.0000 & 0.0000 & 0.0000 & 0.0000 \\
\hline $\mathbf{d}_{\mathrm{A}}$ & 0.0000 & 0.0000 & 0.0000 & 0.0000 \\
\hline$d_{M}$ & 0.0000 & 0.0000 & 0.0000 & 0.0000 \\
\hline $\mathbf{t}_{\mathrm{A}}$ & 0.0000 & 0.0000 & 0.0000 & 0.0000 \\
\hline $\mathbf{t}_{M}$ & 0.0000 & 0.0000 & 0.0000 & 0.0000 \\
\hline$\theta *{ }_{I}$ & 0.0000 & 0.0000 & -1.0000 & -1.0000 \\
\hline$\theta^{*}{ }_{C}$ & 0.0000 & 0.0000 & 0.8013 & 0.8013 \\
\hline $\mathbf{t}_{\mathrm{v}}$ & 0.0000 & 0.0000 & 0.0000 & 0.0000 \\
\hline n & 0.0000 & 0.0000 & 0.0000 & 0.0000 \\
\hline$\mu^{*}$ & 0.0000 & 0.0000 & 0.0000 & 0.0000 \\
\hline $\mathbf{k}$ & 0.0000 & 0.0000 & 0.0000 & 0.0000 \\
\hline
\end{tabular}


Appendix 4 Table 10: Regional Governments as Empire-Builders

\begin{tabular}{|c|c|c|c|c|c|c|}
\hline \multirow[t]{2}{*}{ Variables } & \multicolumn{2}{|c|}{$\begin{array}{c}\text { Policy 3: } \\
t_{A}=-1\end{array}$} & \multicolumn{2}{|c|}{$\begin{array}{c}\text { Policy 4: } \\
d_{A}=1\end{array}$} & \multicolumn{2}{|c|}{$\begin{array}{c}\text { Policy 5: } \\
\mu^{*}=-1\end{array}$} \\
\hline & SR & LR & SR & LR & SR & LR \\
\hline $\mathbf{V}_{\text {I }}$ & -0.1379 & -0.1331 & 0.5389 & 0.5200 & 0.0000 & 0.4040 \\
\hline $\mathbf{v}_{\mathbf{C}}$ & -0.1200 & -0.1237 & 0.4687 & 0.4834 & 0.0000 & -0.3133 \\
\hline $\mathbf{c a}_{\mathbf{I}}$ & -0.4000 & -0.3981 & 1.5629 & 1.5552 & 0.0000 & 0.1657 \\
\hline $\mathbf{c m}_{I}$ & 0.0243 & 0.0317 & -0.0949 & -0.1237 & 0.0000 & 0.6166 \\
\hline $\mathbf{c a}_{\mathrm{C}}$ & -0.4000 & -0.4074 & 1.5629 & 1.5918 & 0.0000 & -0.6170 \\
\hline $\mathbf{c m}_{\mathrm{C}}$ & 0.0243 & 0.0223 & -0.0949 & -0.0871 & 0.0000 & -0.1660 \\
\hline $\mathbf{g h}_{\mathbf{I}}$ & 0.0380 & 0.0430 & -0.1486 & -0.1678 & 0.0000 & 0.4103 \\
\hline $\mathrm{gh}_{\mathrm{C}}$ & 0.0000 & -0.0019 & 0.0000 & 0.0074 & 0.0000 & -0.1576 \\
\hline $\mathbf{j}_{\mathbf{I}}$ & 0.0243 & 0.0317 & -0.0949 & -0.1237 & 0.0000 & 0.6166 \\
\hline $\mathbf{j}_{\mathbf{C}}$ & 0.0243 & 0.0223 & -0.0949 & -0.0871 & 0.0000 & -0.1660 \\
\hline$\pi \mathbf{h}_{\mathbf{I}}$ & -0.4000 & -0.3900 & 1.5629 & 1.5235 & 0.0000 & 0.8414 \\
\hline$\pi \mathbf{h}_{\mathrm{C}}$ & 0.0243 & 0.0211 & -0.0949 & -0.0825 & 0.0000 & -0.2648 \\
\hline $\mathbf{w}_{\mathbf{I}}$ & -0.4000 & -0.4047 & 1.5629 & 1.5812 & 0.0000 & -0.3905 \\
\hline $\mathbf{w}_{\mathbf{C}}$ & 0.0243 & 0.0211 & -0.0949 & -0.0825 & 0.0000 & -0.2648 \\
\hline $\mathbf{y}_{\mathbf{A}}$ & -0.4631 & -0.4638 & 1.5629 & 1.5656 & 0.0000 & -0.0584 \\
\hline $\mathbf{y}_{\mathbf{M}}$ & 0.0243 & 0.0265 & -0.0949 & -0.1036 & 0.0000 & 0.1858 \\
\hline $\mathbf{l}_{\mathbf{A}}$ & 0.0000 & -0.0040 & 0.0000 & 0.0155 & 0.0000 & -0.3320 \\
\hline$I_{M}$ & 0.0000 & 0.0054 & 0.0000 & -0.0211 & 0.0000 & 0.4506 \\
\hline $\mathbf{k}_{\mathbf{A}}$ & -0.2392 & -0.2408 & 0.9343 & 0.9408 & 0.0000 & -0.1377 \\
\hline $\mathbf{k}_{\mathbf{M}}$ & 0.1852 & 0.1864 & -0.7234 & -0.7284 & 0.0000 & 0.1066 \\
\hline $\mathbf{r}_{\mathbf{A}}$ & -0.1609 & -0.1599 & 0.6286 & 0.6249 & 0.0000 & 0.0792 \\
\hline $\mathbf{r}_{\mathbf{M}}$ & -0.1609 & -0.1599 & 0.6286 & 0.6249 & 0.0000 & 0.0792 \\
\hline$\pi \mathbf{f}_{\mathrm{A}}$ & -0.4000 & -0.3939 & 1.5629 & 1.5391 & 0.0000 & 0.5094 \\
\hline $\boldsymbol{\pi} \mathbf{f}_{M}$ & 0.0243 & 0.0265 & -0.0949 & -0.1036 & 0.0000 & 0.1858 \\
\hline $\mathbf{P}$ & 0.4243 & 0.4297 & -1.6578 & -1.6789 & 0.0000 & 0.4510 \\
\hline $\operatorname{grh}_{I}$ & 0.0000 & 0.0040 & 0.0000 & -0.0155 & 0.0000 & 0.3320 \\
\hline $\operatorname{grf}_{\mathbf{A}}$ & -1.5585 & -1.5567 & 1.6137 & 1.6067 & 0.0000 & 0.1484 \\
\hline $\operatorname{grh}_{\mathrm{C}}$ & 0.0000 & -0.0054 & 0.0000 & 0.0211 & 0.0000 & -0.4506 \\
\hline $\operatorname{grf}_{M}$ & 0.0411 & 0.0454 & -0.1605 & -0.1774 & 0.0000 & 0.3607 \\
\hline $\mathbf{g c}_{\mathbf{I}}$ & 0.0507 & 0.0559 & -0.1979 & -0.2183 & 0.0000 & 0.4363 \\
\hline $\mathbf{g c}_{\mathrm{C}}$ & 0.0000 & 0.0000 & 0.0000 & 0.0000 & 0.0000 & 0.0000 \\
\hline $\mathbf{f}_{\mathrm{A}}$ & 0.0000 & 0.0000 & 0.0000 & 0.0000 & 0.0000 & 0.0000 \\
\hline $\mathbf{f}_{M}$ & 0.0000 & 0.0000 & 0.0000 & 0.0000 & 0.0000 & 0.0000 \\
\hline $\mathbf{d}_{\mathbf{A}}$ & 0.0000 & 0.0000 & 1.0000 & 1.0000 & 0.0000 & 0.0000 \\
\hline $\mathbf{d}_{M}$ & 0.0000 & 0.0000 & 0.0000 & 0.0000 & 0.0000 & 0.0000 \\
\hline $\mathbf{t}_{\mathrm{A}}$ & -1.0000 & -1.0000 & 0.0000 & 0.0000 & 0.0000 & 0.0000 \\
\hline $\mathbf{t}_{M}$ & 0.0000 & 0.0000 & 0.0000 & 0.0000 & 0.0000 & 0.0000 \\
\hline$\theta *{ }_{I}$ & 0.0000 & 0.0000 & 0.0000 & 0.0000 & 0.0000 & 0.0000 \\
\hline$\theta{ }^{*}{ }_{C}$ & 0.0000 & 0.0000 & 0.0000 & 0.0000 & 0.0000 & 0.0000 \\
\hline $\mathbf{t}_{\mathrm{V}}$ & 0.0000 & 0.0000 & 0.0000 & 0.0000 & 0.0000 & 0.0000 \\
\hline n & 0.0000 & 0.0000 & 0.0000 & 0.0000 & 0.0000 & 0.0000 \\
\hline$\mu^{*}$ & 0.0000 & 0.0000 & 0.0000 & 0.0000 & -1.0000 & -1.0000 \\
\hline $\mathbf{k}$ & 0.0000 & 0.0000 & 0.0000 & 0.0000 & 0.0000 & 0.0000 \\
\hline
\end{tabular}


Appendix 4 Table 10(cont'd): Regional Governments as Empire-Builders

\begin{tabular}{|c|c|c|c|c|}
\hline \multirow[t]{2}{*}{ Variables } & \multicolumn{2}{|c|}{$\begin{array}{c}\text { Policy 6: } \\
\mathrm{gc}_{\mathrm{I}}=1\end{array}$} & \multicolumn{2}{|c|}{$\begin{array}{c}\text { Policy 7: } \\
\theta^{*}=-1, \theta^{*}{ }_{C}=0.8013\end{array}$} \\
\hline & SR & LR & SR & LR \\
\hline $\mathbf{v}_{\mathbf{I}}$ & 0.1366 & 0.0770 & 0.2894 & 0.2645 \\
\hline $\mathbf{v}_{\mathbf{C}}$ & -0.1049 & -0.0585 & 0.1887 & 0.2080 \\
\hline$c a_{I}$ & 0.0000 & -0.0287 & 0.9434 & 0.9315 \\
\hline $\mathrm{cm}_{\mathrm{I}}$ & 0.0000 & -0.1068 & -0.1788 & -0.2233 \\
\hline $\mathbf{c a} \mathbf{a}_{\mathbf{C}}$ & 0.0000 & 0.1068 & 0.9434 & 0.9880 \\
\hline $\mathbf{c m}_{\mathrm{C}}$ & 0.0000 & 0.0287 & -0.1788 & -0.1668 \\
\hline $\mathbf{g h}_{\mathbf{I}}$ & 0.7508 & 0.7364 & 0.0000 & -0.0060 \\
\hline $\mathbf{g h}_{\mathbf{C}}$ & -0.5986 & -0.6165 & -0.1949 & -0.2024 \\
\hline $\mathbf{j}_{\mathbf{I}}$ & 0.0000 & -0.1068 & -0.1788 & -0.2233 \\
\hline $\mathbf{j}_{\mathbf{C}}$ & 0.0000 & 0.0287 & -0.1788 & -0.1668 \\
\hline$\pi \mathbf{h}_{\mathbf{I}}$ & 0.0000 & -0.1457 & 0.9434 & 0.8827 \\
\hline$\pi \mathbf{h}_{\mathrm{C}}$ & 0.0000 & 0.0458 & -0.1788 & -0.1596 \\
\hline $\mathbf{w}_{\mathbf{I}}$ & 0.0000 & 0.0676 & 0.9434 & 0.9717 \\
\hline $\mathbf{w}_{\mathbf{C}}$ & 0.0000 & 0.0458 & -0.1788 & -0.1596 \\
\hline $\mathbf{y}_{\mathbf{A}}$ & 0.0000 & 0.0101 & 0.9434 & 0.9477 \\
\hline $\mathbf{y}_{\mathbf{M}}$ & 0.0000 & -0.0322 & -0.1788 & -0.1922 \\
\hline $\mathbf{l}_{\mathbf{A}}$ & 0.0000 & 0.0575 & 0.0000 & 0.0240 \\
\hline $\mathbf{l}_{M}$ & 0.0000 & -0.0780 & 0.0000 & -0.0326 \\
\hline $\mathbf{k}_{\mathbf{A}}$ & 0.0000 & 0.0238 & 0.6325 & 0.6424 \\
\hline $\mathbf{k}_{\mathbf{M}}$ & 0.0000 & -0.0185 & -0.4897 & -0.4974 \\
\hline $\mathbf{r}_{\mathrm{A}}$ & 0.0000 & -0.0137 & 0.3109 & 0.3052 \\
\hline $\mathbf{r}_{M}$ & 0.0000 & -0.0137 & 0.3109 & 0.3052 \\
\hline$\pi \mathbf{f}_{\mathrm{A}}$ & 0.0000 & -0.0882 & 0.9434 & 0.9067 \\
\hline$\pi \mathbf{f}_{M}$ & 0.0000 & -0.0322 & -0.1788 & -0.1922 \\
\hline $\mathbf{P}$ & 0.0000 & -0.0781 & -1.1222 & -1.1548 \\
\hline $\operatorname{grh}_{I}$ & 0.0000 & -0.0575 & 0.0000 & -0.0240 \\
\hline $\operatorname{grf}_{\mathbf{A}}$ & 0.0000 & -0.0257 & 3.1120 & 3.1012 \\
\hline $\operatorname{grh}_{\mathrm{C}}$ & 0.0000 & 0.0780 & 0.0000 & 0.0326 \\
\hline $\operatorname{grf}_{M}$ & 0.0000 & -0.0624 & -1.4272 & -1.4532 \\
\hline $\mathbf{g c}_{\mathrm{I}}$ & 1.0000 & 1.0000 & 0.0000 & 0.0000 \\
\hline $\mathbf{g c}_{\mathbf{C}}$ & -0.9205 & -0.9900 & -0.2997 & -0.3287 \\
\hline $\mathbf{f}_{\mathrm{A}}$ & 0.0000 & 0.0000 & 0.0000 & 0.0000 \\
\hline $\mathbf{f}_{M}$ & 0.0000 & 0.0000 & 0.0000 & 0.0000 \\
\hline$d_{A}$ & 0.0000 & 0.0000 & 0.0000 & 0.0000 \\
\hline$d_{M}$ & 0.0000 & 0.0000 & 0.0000 & 0.0000 \\
\hline$t_{A}$ & 0.0000 & 0.0000 & 0.0000 & 0.0000 \\
\hline$t_{M}$ & 0.0000 & 0.0000 & 0.0000 & 0.0000 \\
\hline$\theta *{ }_{I}$ & 0.0000 & 0.0000 & -1.0000 & -1.0000 \\
\hline$\theta{ }^{*}{ }_{C}$ & 0.0000 & 0.0000 & 0.8013 & 0.8013 \\
\hline $\mathbf{t}_{\mathrm{v}}$ & 0.0000 & 0.0000 & 0.0000 & 0.0000 \\
\hline $\mathbf{N}$ & 0.0000 & 0.0000 & 0.0000 & 0.0000 \\
\hline$\mu^{*}$ & 0.0000 & 0.0000 & 0.0000 & 0.0000 \\
\hline $\mathbf{k}$ & 0.0000 & 0.0000 & 0.0000 & 0.0000 \\
\hline
\end{tabular}


Appendix 4 Table 11: Sensitivity to Migration Assumption

\begin{tabular}{|c|c|c|c|c|c|c|c|c|}
\hline \multirow[t]{2}{*}{ Variables } & \multicolumn{2}{|c|}{$\begin{array}{c}\text { Policy 1: } \\
\operatorname{grh}_{1}=1\end{array}$} & \multicolumn{2}{|c|}{$\begin{array}{c}\text { Policy 2: } \\
\operatorname{grf}_{A}=1\end{array}$} & \multicolumn{2}{|c|}{$\begin{array}{c}\text { Policy 3: } \\
t_{A}=-1\end{array}$} & \multicolumn{2}{|c|}{$\begin{array}{c}\text { Policy 4: } \\
d_{A}=1\end{array}$} \\
\hline & SR & LR & SR & LR & SR & LR & SR & LR \\
\hline $\mathbf{v}_{\mathbf{I}}$ & -0.0804 & 0.1081 & 0.0674 & -0.1134 & -0.0356 & -0.0765 & 0.4407 & -0.2087 \\
\hline $\mathbf{v}_{\mathbf{C}}$ & -0.1062 & -0.2317 & 0.0891 & 0.2431 & 0.0202 & 0.0550 & 0.3199 & 0.8729 \\
\hline $\mathbf{c a}_{1}$ & -0.3577 & -0.2285 & 0.3001 & 0.2397 & 0.0679 & 0.0542 & 1.0776 & 0.8608 \\
\hline $\mathbf{c m}_{\mathrm{I}}$ & 0.0184 & 0.2876 & -0.0154 & -0.3017 & -0.0035 & -0.0683 & -0.0553 & -1.0833 \\
\hline $\mathbf{c a _ { C }}$ & -0.3577 & -0.5931 & 0.3001 & 0.6221 & 0.0679 & 0.1408 & 1.0776 & 2.2341 \\
\hline $\mathbf{c m}_{\mathrm{C}}$ & 0.0184 & -0.0770 & -0.0154 & 0.0808 & -0.0035 & 0.0183 & -0.0553 & 0.2900 \\
\hline $\mathbf{g h}_{\mathbf{I}}$ & 0.2780 & 0.4024 & -0.2332 & -0.4220 & -0.3321 & -0.3748 & 0.2537 & -0.4243 \\
\hline $\mathbf{g h}_{\mathrm{C}}$ & 0.0157 & 0.0118 & -0.0132 & -0.0123 & -0.0030 & -0.0028 & -0.0473 & -0.0443 \\
\hline $\mathbf{j}_{\mathbf{I}}$ & 0.0184 & 0.2876 & -0.0154 & -0.3017 & -0.0035 & -0.0683 & -0.0553 & -1.0833 \\
\hline $\mathbf{j}_{\mathbf{C}}$ & 0.0184 & -0.0770 & -0.0154 & 0.0808 & -0.0035 & 0.0183 & -0.0553 & 0.2900 \\
\hline$\pi \mathbf{h}_{\mathbf{I}}$ & -0.3577 & 0.0863 & 0.3001 & -0.0905 & 0.0679 & -0.0205 & 1.0776 & -0.3249 \\
\hline$\pi \mathbf{h}_{\mathbf{C}}$ & 0.0184 & -0.1230 & -0.0154 & 0.1290 & -0.0035 & 0.0292 & -0.0553 & 0.4633 \\
\hline $\mathbf{w}_{\mathbf{I}}$ & -0.3577 & -0.4876 & 0.3001 & 0.5114 & 0.0679 & 0.1157 & 1.0776 & 1.8366 \\
\hline $\mathbf{w}_{\mathbf{C}}$ & 0.0184 & -0.1230 & -0.0154 & 0.1290 & -0.0035 & 0.0292 & -0.0553 & 0.4633 \\
\hline $\mathbf{y}_{\mathbf{A}}$ & -0.3577 & -0.3329 & 0.3001 & 0.3492 & 0.0049 & 0.0160 & 1.0776 & 1.2540 \\
\hline $\mathbf{y}_{\mathbf{M}}$ & 0.0184 & 0.0869 & -0.0154 & -0.0912 & -0.0035 & -0.0206 & -0.0553 & -0.3273 \\
\hline $\mathbf{l}_{\mathbf{A}}$ & 0.0000 & -0.1547 & 0.0000 & 0.1622 & 0.0000 & 0.0367 & 0.0000 & 0.5826 \\
\hline $\mathbf{l}_{M}$ & 0.0000 & 0.2099 & 0.0000 & -0.2202 & 0.0000 & -0.0498 & 0.0000 & -0.7907 \\
\hline $\mathbf{k}_{\mathbf{A}}$ & -0.2120 & -0.2366 & 0.1778 & 0.2482 & 0.0402 & 0.0562 & 0.6385 & 0.8913 \\
\hline $\mathbf{k}_{\mathbf{M}}$ & 0.1641 & 0.1832 & -0.1377 & -0.1922 & -0.0312 & -0.0435 & -0.4944 & -0.6901 \\
\hline $\mathbf{r}_{\mathrm{A}}$ & -0.1458 & -0.0963 & 0.1223 & 0.1010 & 0.0277 & 0.0229 & 0.4391 & 0.3627 \\
\hline $\mathbf{r}_{M}$ & -0.1458 & -0.0963 & 0.1223 & 0.1010 & 0.0277 & 0.0229 & 0.4391 & 0.3627 \\
\hline$\pi \mathbf{f}_{\mathrm{A}}$ & -0.3577 & -0.0684 & 0.3001 & 0.0718 & 0.0679 & 0.0162 & 1.0776 & 0.2578 \\
\hline$\pi \mathbf{f}_{\mathrm{M}}$ & 0.0184 & 0.0869 & -0.0154 & -0.0912 & -0.0035 & -0.0206 & -0.0553 & -0.3273 \\
\hline $\mathbf{P}$ & 0.3761 & 0.5161 & -0.3155 & -0.5414 & -0.0714 & -0.1225 & -1.1329 & -1.9441 \\
\hline $\operatorname{grh}_{I}$ & 1.0000 & 1.0000 & -0.8389 & -1.0489 & -1.3104 & -1.3579 & 1.3656 & 0.6114 \\
\hline $\operatorname{grf}_{\mathbf{A}}$ & -1.1921 & -0.9534 & 1.0000 & 1.0000 & 0.0000 & 0.0000 & 0.0000 & 0.0000 \\
\hline $\operatorname{grh}_{C}$ & 0.0449 & 0.0337 & -0.0376 & -0.0353 & -0.0085 & -0.0080 & -0.1352 & -0.1267 \\
\hline $\operatorname{grf}_{M}$ & 0.0000 & 0.0000 & 0.0000 & 0.0000 & 0.0000 & 0.0000 & 0.0000 & 0.0000 \\
\hline $\mathrm{gc}_{\mathrm{I}}$ & 0.0383 & 0.2039 & -0.0321 & -0.2139 & -0.0073 & -0.0484 & -0.1154 & -0.7682 \\
\hline $\mathbf{g c}_{\mathrm{C}}$ & 0.0000 & 0.0000 & 0.0000 & 0.0000 & 0.0000 & 0.0000 & 0.0000 & 0.0000 \\
\hline$f_{A}$ & 0.0000 & 0.0000 & 0.0000 & 0.0000 & 0.0000 & 0.0000 & 0.0000 & 0.0000 \\
\hline $\mathbf{f}_{M}$ & 0.0000 & 0.0000 & 0.0000 & 0.0000 & 0.0000 & 0.0000 & 0.0000 & 0.0000 \\
\hline $\mathbf{d}_{\mathrm{A}}$ & 0.0000 & 0.0000 & 0.0000 & 0.0000 & 0.0000 & 0.0000 & 1.0000 & 1.0000 \\
\hline $\mathbf{d}_{\mathbf{M}}$ & 0.0000 & 0.0000 & 0.0000 & 0.0000 & 0.0000 & 0.0000 & 0.0000 & 0.0000 \\
\hline $\mathbf{t}_{\mathrm{A}}$ & 0.0000 & 0.0000 & 0.0000 & 0.0000 & -1.0000 & -1.0000 & 0.0000 & 0.0000 \\
\hline $\mathbf{t}_{M}$ & 0.0000 & 0.0000 & 0.0000 & 0.0000 & 0.0000 & 0.0000 & 0.0000 & 0.0000 \\
\hline$\theta *{ }_{I}$ & 0.0000 & 0.0000 & 0.0000 & 0.0000 & 0.0000 & 0.0000 & 0.0000 & 0.0000 \\
\hline$\theta^{*}{ }_{C}$ & 0.0000 & 0.0000 & 0.0000 & 0.0000 & 0.0000 & 0.0000 & 0.0000 & 0.0000 \\
\hline $\mathbf{t}_{\mathrm{V}}$ & 0.0000 & 0.0000 & 0.0000 & 0.0000 & 0.0000 & 0.0000 & 0.0000 & 0.0000 \\
\hline n & 0.0000 & 0.0000 & 0.0000 & 0.0000 & 0.0000 & 0.0000 & 0.0000 & 0.0000 \\
\hline$\mu^{*}$ & 0.0000 & 0.0000 & 0.0000 & 0.0000 & -1.0000 & -1.0000 & 0.0000 & 0.0000 \\
\hline k & 0.0000 & 0.0000 & 0.0000 & 0.0000 & 0.0000 & 0.0000 & 0.0000 & 0.0000 \\
\hline
\end{tabular}


Appendix 4 Table 11(cont'd): Sensitivity to the Migration Assumption

\begin{tabular}{|c|c|c|c|c|c|c|}
\hline \multirow[t]{2}{*}{ Variables } & \multicolumn{2}{|c|}{$\begin{array}{c}\text { Policy 5: } \\
\mu^{*=-1}\end{array}$} & \multicolumn{2}{|c|}{$\begin{array}{c}\text { Policy 6: } \\
\mathrm{gc}_{\mathrm{I}}=1\end{array}$} & \multicolumn{2}{|c|}{$\begin{array}{c}\text { Policy 7: } \\
\theta^{*}=-1, \theta^{*}{ }_{C}=0.8013\end{array}$} \\
\hline & SR & LR & SR & LR & SR & LR \\
\hline$v_{I}$ & 0.0000 & 0.8598 & 0.1366 & 0.1366 & 0.1297 & 0.1297 \\
\hline $\mathbf{v}_{\mathbf{C}}$ & 0.0000 & -0.7322 & -0.1049 & -0.1049 & -0.0995 & -0.0995 \\
\hline$c a_{I}$ & 0.0000 & 0.2870 & 0.0000 & 0.0000 & 0.0000 & 0.0000 \\
\hline $\mathbf{c m}_{I}$ & 0.0000 & 1.3611 & 0.0000 & 0.0000 & 0.0000 & 0.0000 \\
\hline $\mathbf{c a} \mathbf{a}_{\mathbf{C}}$ & 0.0000 & -1.5312 & 0.0000 & 0.0000 & 0.0000 & 0.0000 \\
\hline $\mathrm{cm}_{\mathrm{C}}$ & 0.0000 & -0.4572 & 0.0000 & 0.0000 & 0.0000 & 0.0000 \\
\hline $\mathbf{g h}_{\mathbf{I}}$ & 0.0000 & 0.8978 & 0.7508 & 0.7508 & 0.7127 & 0.7127 \\
\hline $\mathbf{g h}_{\mathbf{C}}$ & 0.0000 & -0.0039 & -0.5986 & -0.5986 & -0.5682 & -0.5682 \\
\hline $\mathbf{j}_{\mathbf{I}}$ & 0.0000 & 1.3611 & 0.0000 & 0.0000 & 0.0000 & 0.0000 \\
\hline $\mathbf{j}_{\mathbf{C}}$ & 0.0000 & -0.4572 & 0.0000 & 0.0000 & 0.0000 & 0.0000 \\
\hline$\pi \mathbf{h}_{\mathbf{I}}$ & 0.0000 & 1.8569 & 0.0000 & 0.0000 & 0.0000 & 0.0000 \\
\hline$\pi \mathbf{h}_{\mathbf{C}}$ & 0.0000 & -0.6867 & 0.0000 & 0.0000 & 0.0000 & 0.0000 \\
\hline $\mathbf{w}_{\text {I }}$ & 0.0000 & -1.0049 & 0.0000 & 0.0000 & 0.0000 & 0.0000 \\
\hline $\mathbf{w}_{\mathbf{C}}$ & 0.0000 & -0.6867 & 0.0000 & 0.0000 & 0.0000 & 0.0000 \\
\hline $\mathbf{y}_{\mathbf{A}}$ & 0.0000 & -0.2335 & 0.0000 & 0.0000 & 0.0000 & 0.0000 \\
\hline $\mathbf{y}_{\mathbf{M}}$ & 0.0000 & 0.3602 & 0.0000 & 0.0000 & 0.0000 & 0.0000 \\
\hline$\underline{I_{A}}$ & 0.0000 & -0.7714 & 0.0000 & 0.0000 & 0.0000 & 0.0000 \\
\hline $\mathbf{l}_{M}$ & 0.0000 & 1.0469 & 0.0000 & 0.0000 & 0.0000 & 0.0000 \\
\hline $\mathbf{k}_{\mathbf{A}}$ & 0.0000 & -0.3346 & 0.0000 & 0.0000 & 0.0000 & 0.0000 \\
\hline $\mathbf{k}_{\mathbf{M}}$ & 0.0000 & 0.2591 & 0.0000 & 0.0000 & 0.0000 & 0.0000 \\
\hline $\mathbf{r}_{\mathrm{A}}$ & 0.0000 & 0.1011 & 0.0000 & 0.0000 & 0.0000 & 0.0000 \\
\hline $\mathbf{r}_{M}$ & 0.0000 & 0.1011 & 0.0000 & 0.0000 & 0.0000 & 0.0000 \\
\hline$\pi f_{A}$ & 0.0000 & 1.0855 & 0.0000 & 0.0000 & 0.0000 & 0.0000 \\
\hline$\pi \mathbf{f}_{M}$ & 0.0000 & 0.3602 & 0.0000 & 0.0000 & 0.0000 & 0.0000 \\
\hline $\mathbf{P}$ & 0.0000 & 1.0740 & 0.0000 & 0.0000 & 0.0000 & 0.0000 \\
\hline $\operatorname{grh}_{I}$ & 0.0000 & 0.9985 & 0.0000 & 0.0000 & 2.7164 & 2.7164 \\
\hline $\operatorname{grf}_{\mathbf{A}}$ & 0.0000 & 0.0000 & 0.0000 & 0.0000 & 0.0000 & 0.0000 \\
\hline $\operatorname{grh}_{C}$ & 0.0000 & -0.0112 & 0.0000 & 0.0000 & -1.6249 & -1.6249 \\
\hline $\operatorname{grf}_{M}$ & 0.0000 & 0.0000 & 0.0000 & 0.0000 & 0.0000 & 0.0000 \\
\hline $\mathbf{g c}_{\mathbf{I}}$ & 0.0000 & 0.8643 & 1.0000 & 1.0000 & 0.0474 & 0.0474 \\
\hline $\mathbf{g c}_{\mathrm{C}}$ & 0.0000 & 0.0000 & -0.9205 & -0.9205 & 0.0000 & 0.0000 \\
\hline $\mathrm{f}_{\mathrm{A}}$ & 0.0000 & 0.0000 & 0.0000 & 0.0000 & 0.0000 & 0.0000 \\
\hline $\mathbf{f}_{M}$ & 0.0000 & 0.0000 & 0.0000 & 0.0000 & 0.0000 & 0.0000 \\
\hline $\mathbf{d}_{\mathbf{A}}$ & 0.0000 & 0.0000 & 0.0000 & 0.0000 & 0.0000 & 0.0000 \\
\hline $\mathbf{d}_{M}$ & 0.0000 & 0.0000 & 0.0000 & 0.0000 & 0.0000 & 0.0000 \\
\hline$t_{A}$ & 0.0000 & 0.0000 & 0.0000 & 0.0000 & 0.0000 & 0.0000 \\
\hline $\mathbf{t}_{M}$ & 0.0000 & 0.0000 & 0.0000 & 0.0000 & 0.0000 & 0.0000 \\
\hline$\theta *_{I}$ & 0.0000 & 0.0000 & 0.0000 & 0.0000 & -1.0000 & -1.0000 \\
\hline$\theta^{*}{ }_{C}$ & 0.0000 & 0.0000 & 0.0000 & 0.0000 & 0.8013 & 0.8013 \\
\hline $\mathbf{t}_{\mathrm{v}}$ & 0.0000 & 0.0000 & 0.0000 & 0.0000 & 0.0000 & 0.0000 \\
\hline n & 0.0000 & 0.0000 & 0.0000 & 0.0000 & 0.0000 & 0.0000 \\
\hline$\mu^{*}$ & 0.0000 & 0.0000 & 0.0000 & 0.0000 & 0.0000 & 0.0000 \\
\hline k & 0.0000 & 0.0000 & 0.0000 & 0.0000 & 0.0000 & 0.0000 \\
\hline
\end{tabular}

